\title{
An assessment of the use of sediment traps for estimating upper ocean particle fluxes
}

\author{
by Ken O. Buesseler ${ }^{1}$, Avan N. Antia ${ }^{2}$, Min Chen $^{3}$, Scott W. Fowler ${ }^{4,5}$, \\ Wilford D. Gardner ${ }^{6}$, Orjan Gustafsson ${ }^{7}, K_{\text {Koh Harada }}{ }^{8}$, Anthony F. Michaels $^{9}$, \\ Michiel Rutgers van der Loeff ${ }^{10}$, Manmohan Sarin ${ }^{11}$, \\ Deborah K. Steinberg, ${ }^{12}$ and Thomas Trull ${ }^{13}$
}

\begin{abstract}
This review provides an assessment of sediment trap accuracy issues by gathering data to address trap hydrodynamics, the problem of zooplankton "swimmers," and the solubilization of material after collection. For each topic, the problem is identified, its magnitude and causes reviewed using selected examples, and an update on methods to correct for the potential bias or minimize the problem using new technologies is presented. To minimize hydrodynamic biases due to flow over the trap mouth, the use of neutrally buoyant sediment traps is encouraged. The influence of swimmers is best minimized using traps that limit zooplankton access to the sample collection chamber. New data on the impact of different swimmer removal protocols at the US time-series sites HOT and BATS are compared and shown to be important. Recent data on solubilization are compiled and assessed suggesting selective losses from sinking particles to the trap supernatant after collection, which may alter both fluxes and ratios of elements in long term and typically deeper trap deployments. Different methods are needed to assess shallow and short- term trap solubilization effects, but thus far new incubation experiments suggest these impacts to be small for most elements. A discussion of trap calibration methods reviews independent assessments of flux, including elemental budgets, particle abundance and flux modeling, and emphasizes the utility of U-Th radionuclide calibration methods.
\end{abstract}

1. Woods Hole Oceanographic Institution, Department of Marine Chemistry and Geochemistry, Woods Hole, Massachusetts 02543, U.S.A. email: kbuesseler@whoi.edu

2. Leibniz-Institute for Marine Sciences, Research Division Marine Biogeochemistry, Düsternbrooker Weg 20, 24105 Kiel, Germany.

3. State Key Laboratory of Marine Environmental Science, Department of Oceanography, Xiamen University, Xiamen 361005, China.

4. IAEA Marine Environment Laboratory, 4 Quai Antoine 1er, MC 98000 MONACO.

5. Present address: 8 Allée des Orangers, 06320 Cap d'Ail, France.

6. Texas A\&M University, Department of Oceanography, College Station, Texas, 77843-3146, U.S.A.

7. Stockholm University, Department of Applied Environmental Science (ITM), 10691 Stockholm, Sweden.

8. Marine Environment Division, National Institute for Resources and Environment, 16-3 Onogawa, Tsukuba, Ibaraki, 305-8569, Japan.

9. Wrigley Institute for Environmental Studies, University of Southern California, Los Angeles, California, 90089-0371, U.S.A.

10. Alfred-Wegener Institute for Polar and Marine Research, D 27570 Bremerhaven, Germany.

11. Physical Research Laboratory, Ahmedabad, 380009 India.

12. Virginia Institute of Marine Science, Rt. 1208/Greate Rd., Gloucester Point, Virginia, 23062, U.S.A.

13. ACE CRC, University of Tasmania, and CSIRO Marine Research, Hobart, Tasmania, 7001 Australia. 
In a synthesis of four annual time-series ${ }^{234} \mathrm{Th}$ trap comparison studies in the upper ocean, a factor of two trap under-collection of ${ }^{234}$ Th-carrying particles was found. At present it is unclear whether this under-collection reflects missed episodic flux events, issues with the comparison between radionuclide models and trap flux, or a more general pattern that should be applied to other elemental fluxes. A summary of recommendations for best practices, ways to compensate for biases, and documentation of methods used is also provided.

“. . deep-sea organisms are nourished by a "rain" of organic detritus from overlying surface waters.” Alexander Agassiz (1888)

\section{Introduction}

The endless "rain" of marine particles has long been considered one of the critical processes linking the surface and deep ocean. The uptake of carbon by marine phytoplankton and the consumption of this organic material by zooplankton and marine bacteria form the basis of the "biological pump" (Volk and Hoffert, 1985). These surface-dominated processes form and regulate the flux of sinking particles to depth (Fig. 1.1). A characteristic feature of the biological pump is the subsequent consumption and decomposition of particles as they sink, resulting in the net transfer of organic matter back into dissolved inorganic and organic forms and other nonsinking phases. Thus, the pump results in both a transformation in the character of suspended and sinking matter and an overall decrease in the particle flux with depth in the oceans.

The magnitude of the sinking particle flux and its variability is fundamental to understanding the distribution of many chemical elements in the ocean. Elements that form the building blocks of marine biota, such as carbon and associated bioactive elements, have vertical distributions that are controlled by sinking particles. The size of the stock of total carbon and its distribution within the sea has a major influence on the partitioning of carbon between ocean and atmosphere, the net uptake of anthropogenic $\mathrm{CO}_{2}$ by the sea, and thus global climate (Siegenthaler and Sarmiento, 1993). The sinking material also includes inorganic minerals derived from airborne dust added to the surface ocean and, in coastal regions, a mix of terrestrial particles. These sinking materials also participate in this great particle sweep of elements to the deep ocean. Many elements "hitch a ride" with sinking particles as they are sorbed onto particle surfaces. This scavenging process impacts a large number of naturally occurring and pollutant elements whose distributions and residence times in the ocean are ultimately determined by the strength of the biological pump and remineralization of sinking particles at depth.

Beyond the geochemical implications, these sinking particles also represent a key component of the ocean food web with clear implications for understanding the dynamics of the ecosystem and human effects on it. The surface ocean contains complex ecosystems with organisms that cover some of the widest range of scales and diversity of any ecosystem on earth. Following nutrient inputs to the ecosystem, the subsequent biological dynamics are strongly influenced by the balance between recycling and export. These co-influence the length of the food webs and the amount of fish production. Except for hydrothermal systems, all life below about 50-150 m depth relies on the supply of food 


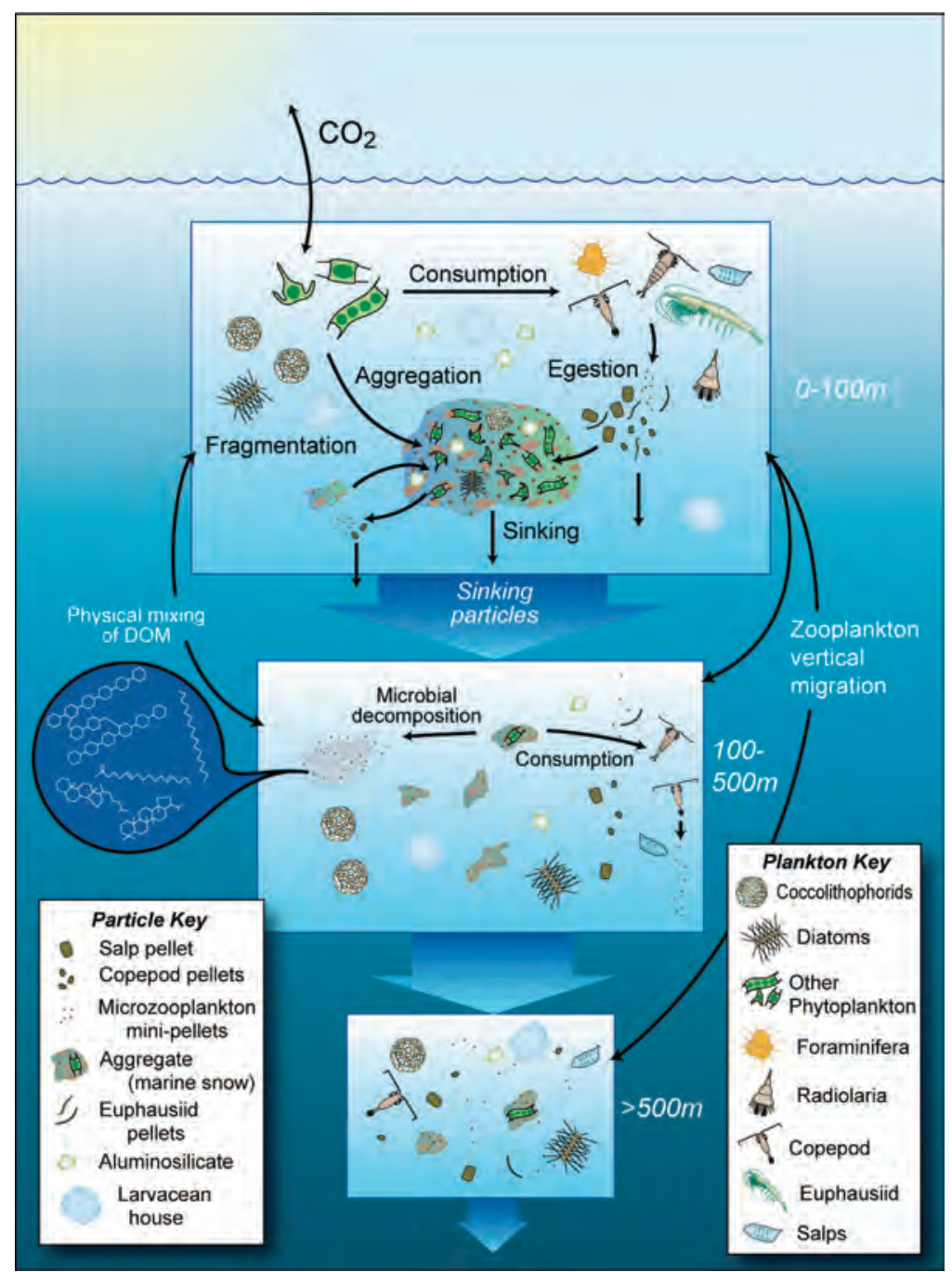

Figure 1.1. The biological pump and processes regulating the flux of particles in the ocean. Carbon dioxide fixed during photosynthesis by phytoplankton in the upper ocean can be transferred below the surface mixed layer via three major processes, (i) passive sinking of particles, (ii) physical mixing of particulate and dissolved organic matter (DOM), and (iii) active transport by zooplankton vertical migration. The sinking flux includes senescent phytoplankton, zooplankton fecal pellets, molts and mucous feeding-webs (e.g. larvacean houses) and aggregates of these materials. The sinking particle flux decreases with depth as aggregates are fragmented into smaller, nonsinking particles, decomposed by bacteria, and consumed and respired by zooplankton. This remineralization returns carbon and nutrients to dissolved forms. The structure of the planktonic community affects the composition and the sinking rates of particles. Particle size, form, density, and the content of biogenic minerals affect sinking and remineralization rates. 
from above. Thus, understanding the processes that create vertical particle fluxes is a prerequisite for understanding the overall ecosystem behavior.

The goal of this review is to present a current assessment of the state of the art in measuring particle fluxes and changes in flux with depth using sediment traps. Sediment traps come in many shapes, styles and deployment configurations. All are based upon the direct interception of sinking material caught in a tube, cone or other device of a known area and over a known length of time. We focus here on traps in the upper ocean (surface to depths of about $1000 \mathrm{~m}$ ) since this is where most sinking particles are formed and where the largest gradients are seen in particle flux vs. depth. This is also a region where sediment trap sampling is most difficult due to the complex nature of the fresh particle sources, the rapid transformations of sinking material, and complex physical oceanographic conditions which make the sinking particle field more difficult to sample than in the more quiescent deep sea. However, studies of processes that can bias shallow traps may overlap with studies of deep traps, and thus, as appropriate, deeper trap data are also discussed.

\section{a. Background}

There are multiple processes that can lead to export of carbon from the surface ocean (Fig. 1.1). Each of these processes impacts the vertical gradients of carbon in the upper ocean. Time-varying changes in these gradients and their stoichiometry with other nutrients can impact air-sea exchange of $\mathrm{CO}_{2}$. The most obvious and well-studied export process is the passive sinking of larger particles. These particles are created by a variety of processes, each of which has an impact on composition, geometry, specific gravity and sinking speed, and the likelihood of degradation (Fowler and Knauer, 1986).

However, there are at least two other major processes that transfer carbon to the deep sea. Dissolved organic matter (DOM) is produced at the surface and usually has a surface maximum in concentration. The same physical processes that affect nutrients and bring them to the surface will transport this extra DOM to depth (Carlson et al., 1994; Hansell et al., 2002). Some organisms also move vertically in the water column for feeding or reproduction but less is known about the magnitude or details of these processes. When these vertical migrators feed in surface waters and respire or excrete at depth, they will cause a net transport of materials, including carbon (Longhurst et al., 1990; Dam et al., 1995; Steinberg et al., 2000; Al-Mutairi and Landry, 2001). While significant, these processes are usually considered moderate parts of the export of carbon and associated elements and therefore the bulk of this report will explore particle fluxes.

Throughout the world's oceans, there is a depletion of inorganic carbon in the surface waters, largely due to biological activity (Falkowski et al., 1998). A vertical gradient in DIC (dissolved inorganic carbon) is created by the net incorporation of carbon into biomass at the surface and the net remineralization of organic matter below the euphotic zone. The gradient is maintained when the rate of biological transport or vertical flux exceeds the vertical components of ocean mixing that work to homogenize the gradients. The strength of this gradient has a significant impact on the partial pressure of $\mathrm{CO}_{2}$ in the 


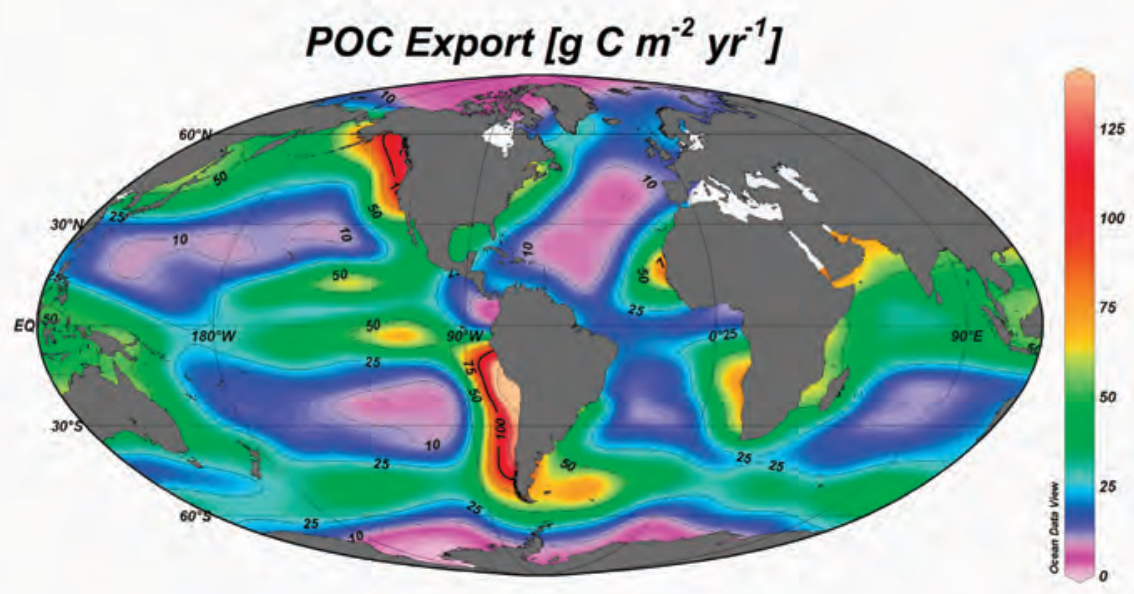

Figure 1.2. Global estimate of upper ocean $(130 \mathrm{~m})$ particulate organic carbon flux $\left(\mathrm{g} \mathrm{C} \mathrm{m}^{-2} \mathrm{yr}^{-1}\right)$ derived from inverse modeling (redrawn from Schlitzer, 2000). Global variations exceed an order of magnitude, with factor of 5 variations in the open ocean.

surface mixed layer and the net exchange of $\mathrm{CO}_{2}$ between ocean and atmosphere (Takahashi, 2004). It has been estimated that if the biological pump were somehow shut off, atmospheric $\mathrm{CO}_{2}$ levels would increase by 200 ppmv (Sarmiento and Toggweiler, 1984). To understand and predict the future dynamics of atmospheric $\mathrm{CO}_{2}$ requires a mechanistic understanding of the processes that control these gradients and the ability to accurately measure the gross and net fluxes of carbon.

Because most particles are made in the surface ocean by biological processes, nutrient availability can limit particle production. Conversely, the particulate export of nutrients affects the global availability of resources for marine ecosystems. This export is not globally uniform, but varies up to an order of magnitude (Fig. 1.2) in response to the interplay between nutrient availability, the intensity of primary production and ecosystem controls on export processes. The largest spatial gradients in upper ocean particle flux exist between the coastal and open ocean, but even within open ocean regions, factors of 5 or more variability are observed (Buesseler, 1998).

Particulate export is a dynamic balance between particle supply, production, consumption and aggregation. Each of these processes has biological and physical controls that are modified by interannual and seasonal cycles as well as short-term episodic events. These processes lead to a number of scales of variability in export flux as well as time lags between biological production and export. Since most marine particles are biologically derived, seasonal dynamics are particularly important. For example, shallow time-series flux measurements from a coastal site and from an open ocean site show a factor of 3 to 6 seasonal variability in POC (particulate organic carbon) flux during a 2 to 3 year time 

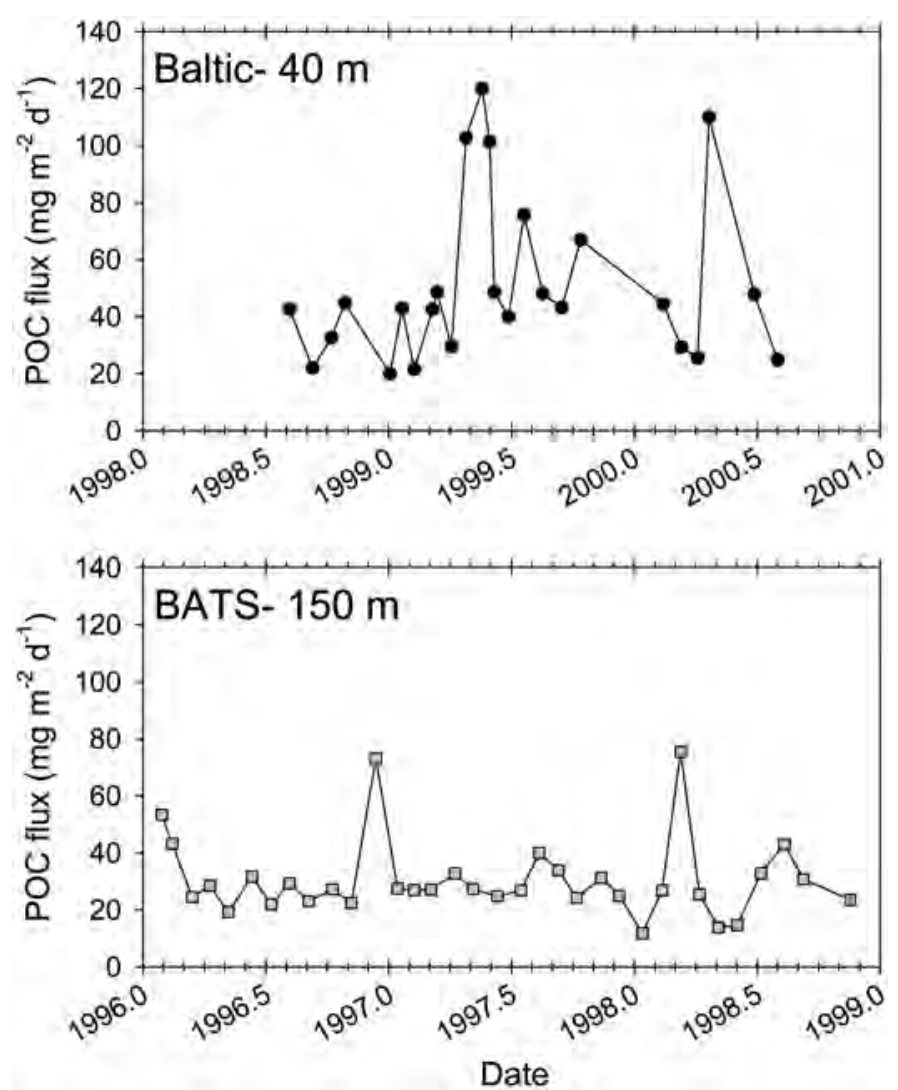

Figure 1.3. Seasonality in sediment trap POC flux for portions of two time-series records from a coastal setting (upper panel, Baltic data from Gustafsson et al., 2004) and open ocean site (lower panel; Bermuda time-series data from the BATS data web site). Temporal variations are a factor of 3 to 5 .

period (Fig. 1.3). Cases of even larger ranges in seasonal flux can be found. Documenting this temporal variability is important both in terms of understanding ecosystem controls on particle export and in closing elemental budgets in the ocean.

As particles sink through the water column, they disaggregate, decompose and disappear. Most are transformed into smaller suspended particles or into dissolved materials as part of remineralization processes (e.g., Angel, 1989; Steinberg et al., 1997; Nagata et al., 2000). Some may coalesce into other sinking particle types by processes such as grazing or aggregation (Alldredge and Silver, 1988; Jackson and Burd, 2002). The net loss of sinking particles is the key link to the remineralization of nutrients and organic $\mathrm{C}$ and their relative availability for subsequent re-introduction to the surface waters by mixing (Najjar et al., 1992; Antia et al., 2001; Toggweiler et al., 2003). This feature of particle fluxes has traditionally been parameterized with simple, nonlinear functions, most frequently the 


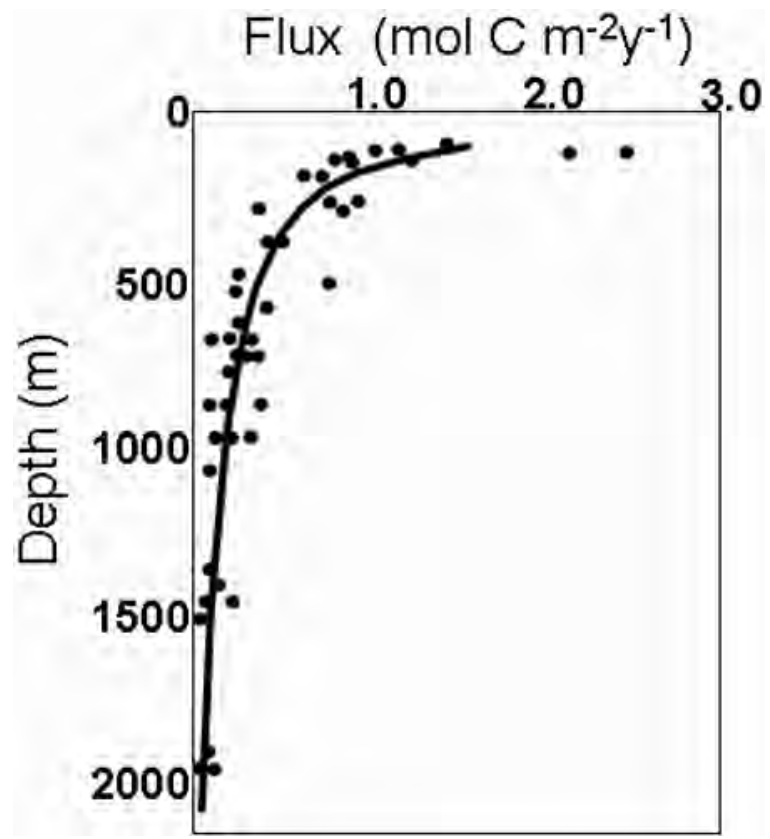

Figure 1.4. Typical pattern of flux vs. depth derived from sediment trap experiment (redrawn from Martin et al. 1987). More than an order of magnitude decrease occurs in the top $1000 \mathrm{~m}$. The curve is a power law best-fit expressing flux at depth in terms of flux leaving the mixed layer (at depth $\left.z_{o}=100 \mathrm{~m}\right), F(z)=F\left(z_{o}\right)\left(z / z_{o}\right)^{-0.86}$.

Martin curve (Martin et al., 1987), where the data are fit to the function and compared to one or more of the terms of that function (Fig. 1.4).

In reality these changes in particle flux with depth are complex and the fits to a specific function are a mathematical convenience rather than a reflection of the governing processes (Lutz et al., 2002). The changes in remineralization with depth could show a variety of profiles with only a few common features. Changes in this length-scale will influence carbon gradients and air-sea partitioning on a time-scale associated with the change in depth profile. Blooms of some species, like coccolithophores or diatoms, can cause episodic changes in remineralization length-scales, element ratios, sinking speeds and ballasting (Boyd and Newton, 1995).

Beyond the overall changes in particle flux with depth, changes in composition of the sinking material can have an impact on carbon gradients, particularly if carbon changes differently than nutrients or the bulk material (Knauer et al., 1979). Element ratios in organic matter have been considered fixed at the Redfield ratio in many past studies and in most models of the ocean carbon cycle (Doney, 1999; Anderson and Pondaven, 2003). However, the composition of each of the constituents of sinking material should vary from this canonical ratio as more labile nutrients disappear more quickly than refractory ones 
(Christian et al., 1997). This progressive increase in carbon:nutrient ratios with depth is well documented (Schneider et al., 2003), but the controls on these ratios are poorly understood.

Inorganic materials can also have an affect on fluxes and remineralization of sinking material. About $10 \%$ of the sinking carbon at depth is $\mathrm{CaCO}_{3}$, mostly in the skeletons of a few taxa of plants or animals (Honjo et al., 1982). This material is very refractory and most of it dissolves at depth (Milliman et al., 1999). Changes in the amount of $\mathrm{CaCO}_{3}$ flux have three different but inter-linked effects on export. The refractory nature of carbonate may influence the overall length-scale of the carbon remineralization (Armstrong et al., 2002; Klaas and Archer, 2002). The formation of carbonate in the surface waters also changes the alkalinity and has the opposite impact on $\mathrm{pCO}_{2}$ as carbon uptake by plankton (Feely et al., 2004). Finally, the relative density of carbonate, as with silicate and other mineral forms, may increase the export of organic carbon (Francois et al., 2002) by increasing the sinking speed of some of the particles or protecting some fraction of $\mathrm{C}$ associated with the biomineral matrix (Ittekkot and Haake, 1992; Ittekkot, 1993; Berelson, 2002). An alternative view is that organic $\mathrm{C}$ flux controls inorganic mineral fluxes through its role in aggregation (Passow, 2004; Passow and De La Roche, 2006).

\section{b. Measurement of particle fluxes using sediment traps}

With the advent of modern ocean sediment traps (Berger, 1971; Honjo, 1976; Wiebe et al., 1976; Soutar et al., 1977), the study of the nature and dynamics of sinking particles expanded rapidly. By simple analogy with a rain gauge, these tools allowed a direct sampling of sinking particles from the water column, yet the dynamics are far more complex (see Section 2). Early issues of trap design and deployment already hinted at possible quantification difficulties in collecting sinking particles (GOFS, 1989). Different designs produced different flux estimates and different compositions of sinking material. However, the relative consistency of the results and the profound implications of the patterns in the early data combined to lend confidence to the tool and its value (Moore et $a l ., 1981)$. Fluxes declined with depth and were greater in areas of greater productivity (Pace et al., 1987). Elegant interpretations of the data combined with the "new production hypothesis" (Dugdale and Goering, 1967) indicated a higher proportion of the production was exported in areas of high production (Eppley and Peterson, 1979). Seasonal patterns became obvious in quantity and even composition (Lohrenz et al., 1992) and these patterns were often coherent with depth and with the overlying biology (Asper et al., 1992). The Joint Global Ocean Flux Study (JGOFS) time-series projects in Hawaii (HOT) and Bermuda (BATS) and the many deep, sequencing conical traps showed interannual variability in interpretable patterns (selected BATS data are shown in Fig. 1.3).

Within the broad patterns revealed by traps, however, there were a variety of regular and troubling inconsistencies. Detailed examination of the particles collected in traps showed artifacts, some of which exhibited consistent patterns and could bias the observed 
distributions with depth (Michaels et al., 1990). Comparisons with radionuclide scavenging in shallow waters often showed very different patterns than the particle fluxes themselves (Buesseler, 1991). Attempts at making a carbon mass balance raised questions about the accuracy of traps, though other factors could also have caused the mass balance closure problems (Michaels et al., 1994a).

The largest challenge for the accurate estimation of particle fluxes is the absence of any standardization procedure or robust controls on accuracy. In addition, there are still fundamental concerns about what exactly a trap collects and what is measured by the other proxy tracers. A trap does not measure positively buoyant particles; however, it does capture motile animals that are considered artifacts ("swimmers"- see Section 3) but some of which participate in other export processes. There are some new technologies, such as swimmer avoidance traps (Peterson et al., 1993) and neutrally buoyant sediment traps (NBSTs; Buesseler et al., 2000) that offer opportunities to correct some of the putative biases, but the search for an independent assessment of the trapping collection efficiency continues (see Section 5).

A group of experts met in 1996 to assess the accuracy of upper ocean trapping and make recommendations for the future (as reported in Gardner, 2000). What resulted from that meeting was an assessment of trap accuracy relative to their use in constraining the flux of sinking particles in order to close carbon budgets in JGOFS. It was also evident that many experiments and data collected by each group to assess trap accuracy or reduce trap biases remained unpublished and part of the "art" of sediment trapping. Since that time, additional progress has been made in understanding both the magnitude of the potential trapping biases and how these may change for different particle types in a changing physical ocean environment.

Our assessment provides an update to Gardner (2000) by using selected references, combined with new data and/or synthesis of prior studies, to review trap performance issues. Unfortunately, there is still a lack of sufficient data and replication of experiments to fully investigate some of the facets of trap accuracy. This lack of replication for different trap designs and under changing particle and physical conditions does make extrapolation of individual studies difficult. However, there has been considerable progress in both understanding the overall magnitude of the accuracy issues and in forming best practices to reduce these uncertainties.

\section{Hydrodynamics}

\section{a. The hydrodynamic issue}

Without repeating all the detailed evaluations in the most recent JGOFS sediment trap workshop (Gardner, 2000), we provide an up-to-date overview of the state of understanding trap hydrodynamics and progress toward correction for and/or reducing possible trap biases. Sediment traps have commonly been employed to obtain an estimate of the "vertical flux" of sinking particles. This measurement is difficult in part because the 
concept is surprisingly complex. For a still fluid, the sinking flux is defined by particle concentrations $\left(C_{i}\right)$ and their settling velocities $\left(W_{i}\right)$, for all particle classes $(i)$, which contribute to the flux,

$$
\text { Flux }=\Sigma_{i} C_{i} W_{i}
$$

and this flux is also equivalent to the sum of all the particles that pass through a horizontal surface in the fluid per unit time. But if the fluid is not still, the flux through the horizontal surface will include particles that are moving up as well as down, and it is no longer the sum of all the particles that pass through the surface that is of interest but rather the net flux. In nonboundary layer flows, the settling of particles is not affected by the flow. However, sediment trap flux measurements in flows with large-scale cyclic vertical motions, such as in the upper ocean mixed layer (Langmuir cells) or near-bottom boundary layers, are particularly difficult to interpret because particles have more than one chance to move down across the same plane and enter the trap. More importantly, perturbations of the horizontal flow caused by the trap can also cause particles to be over- or under-collected relative to the undisturbed net downward flux (the in situ flux), and this is the crux of the hydrodynamic problem for moored or surface-tethered sediment traps. In the upper ocean, generally higher current velocities mean that hydrodynamic effects will be more prevalent than in most deep ocean traps, but some of our understanding about how traps collect particles has been derived from relationships in deep water.

A sediment trap itself can affect the vertical particle flux in several ways. Much attention has been focused on the disturbance of the in situ flow field produced by the presence of the sediment trap (discussed below). A trap can also affect the flux by changing the distribution of particles $\left(C_{i}\right)$ across sinking classes $\left(W_{i}\right)$, e.g. if particles agglomerate or break apart in the flow field of the trap, or properties such as density or shape are affected by the trap. These trap-particle interactions have remained virtually unstudied because of the difficulty in quantifying such changes in situ. Consequently, we cannot discuss these impacts here.

\section{b. Progress in understanding the origin and scope of hydrodynamic biases}

Butman et al. (1986) reviewed early laboratory and field studies of trap hydrodynamics for both aqueous and atmospheric systems. They noted that for most oceanic flow fields and particle types (with the exception of large dense particles), the inertia of marine particles can be ignored as can particle-particle interactions for the low particle concentrations that characterize open ocean environments. Much of the early data came from laboratory flume studies, which offer the advantages of control of particle types and flow velocities, and easier visualization and measurement of collection processes. Drawbacks of flumes are that the flow is a boundary layer. Material settled on the flume bottom can be resuspended if the threshold velocity is exceeded (thus limiting the velocities studied in some setups), and it is not possible to reproduce the complexity of particle size, composition and biological interactions encountered in the ocean. 


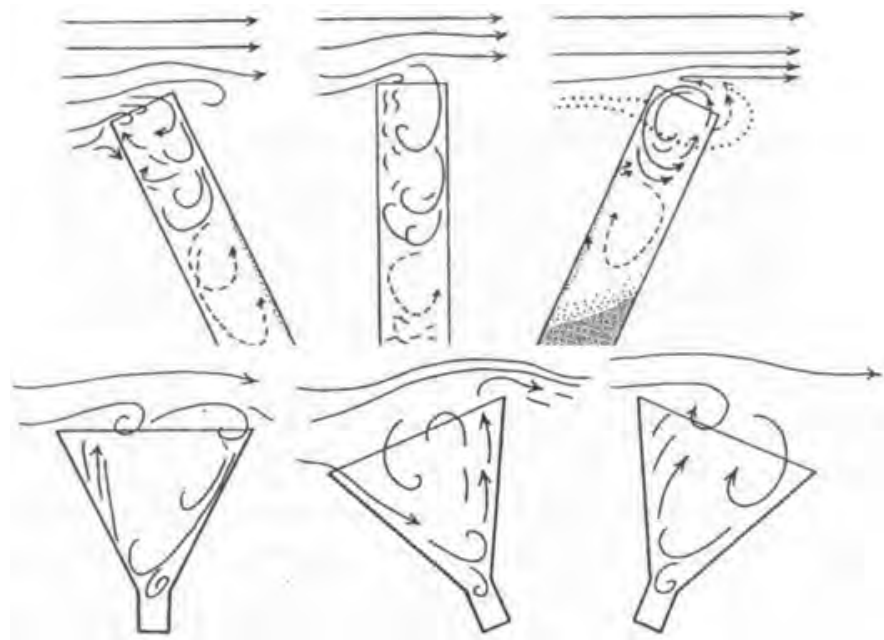

Figure 2.1. Flow fields in cylindrical and conical sediment traps as visualized in dye studies, showing both general characteristics and the effects of tilt towards and away from the flow; from Gardner (1985).

Flume studies have demonstrated that most particles do not settle into a trap the way they do through the water column, but primarily are carried into the trap as water flows into and out of the trap opening. The general structure of these flows has been visualized in dye studies for a range of trap geometries (Gardner, 1980a; Butman et al., 1986; Hawley, 1988). There are three general steps in the trap collection of particles, (i) entrainment within the unsteady vertical eddies that form over the trap top, (ii) exchange of particles within the initial eddy which enters the trap at its downstream side and re-exits at the upstream side (this pattern can be reversed for some geometries, or if the trap is tilted downstream), and then cascades down to slower eddies within the trap, and (iii) transfer of the particles by settling, or by the unsteady incorporation of water and particles into the "tranquil zone" at the trap bottom where the slow-settling particles are no longer affected by turbulence. The eddies in the flow are generally not steady and may include horizontal eddies. Figure 2.1 illustrates the general characteristics of flows into and out of sediment traps as revealed by dye studies.

An important consequence of flow over traps is that advective flux into traps is large. For example, for $60 \mathrm{~cm}$ tall, $7 \mathrm{~cm}$ internal diameter cylindrical Particle-Interceptor-Traps (PITs), similar to those used in the VERTEX (Martin et al., 1987) and Bermuda Atlantic Time-series Study (BATS) programs (Michaels et al., 1994b), flow through the trap is estimated to increase from $\sim 500$ to $\sim 3000$ liters/day as horizontal water velocities increase from 6 to $30 \mathrm{~cm} \mathrm{~s}^{-1}$ (Gust et al., 1996). These laboratory flows are well within the range of mesoscale ocean advective velocities, typically ranging from 5 to $30 \mathrm{~cm} \mathrm{~s}^{-1}$. As a consequence of flow, the majority of particles appear to enter the trap with the advective flow. Also a consequence of flow over traps 
is that particles sinking at $\sim 100 \mathrm{~m} \mathrm{~d}^{-1}$ have approach angles of less than 5 degrees from horizontal in flows faster than $2 \mathrm{~cm} \mathrm{~s}^{-1}\left(\sim 2 \mathrm{~km} \mathrm{~d}^{-1}\right.$; Siegel and Deuser, 1997). Larger, denser particles, have steeper trajectories, e.g. 20 to 60 degrees from horizontal for $3000 \mathrm{~m} \mathrm{~d}^{-1}$ sinking rates and advective flows of 10 to $2 \mathrm{~cm} \mathrm{~s}^{-1}$.

Dimensional analysis by Butman et al. (1986) identified three dimensionless parameters to be important in typical trapping conditions in the ocean: (1) trap Reynolds number, $R_{t}=$ $u_{f} D v^{-1}$ where $u_{f}$ is the horizontal current velocity, $D$ the trap diameter, and $v$ is the fluid kinematic viscosity, (2) trap aspect ratio, $A=H / D$ where $H$ is the trap height and $D$ is the inside diameter of the trap mouth, and (3) the ratio of current speed to particle fall velocity, $u / W$, where $W$ is the gravitational sinking speed of the particles. For fixed values of the other two parameters, the collection efficiency of cylinders was expected to (1) decrease over some range of increasing $R_{t},(2)$ decrease over some range of increasing $u / W$, and (3) increase over some range of increasing $A$. As will be discussed later, the field studies of Baker et al. (1988) validated the first and second expectations, and field work by Hargrave and Burns (1979), Gardner (1980b), and Blomqvist and Kofoed (1981) validated expectation 3.

By whatever path particles enter the trap, their subsequent retention depends on the flow-field within the trap, which is strongly influenced by its shape (typically cylindrical or conical), including the presence of baffles, and also by density gradients within the trap as generated by the use of brines. For example, cylindrical traps with mouth openings smaller than the cylinder diameter over-collect particles relative to the in situ flux (Gardner, 1980a; Butman, 1986) because particles swept into the trap by the flow do not easily exit again, while conical traps tend to under-collect because even those particles which gravitationally settle (rather than being swept) into the trap can be swept out again by flows which enter the traps and 'swirl' within it with velocities that can exceed those of the approach velocity (Butman, 1986; Gust et al., 1996). Tilt of the sediment trap changes the flows within the trap, producing as much as a two-fold over-collection for cylindrical traps tilted either upor downstream, and a bias toward smaller particles (Gardner, 1985). Steep funnels at the bottom of cylindrical traps quickly dampen the eddies entering the trap (Gardner et al., 1997). Cylindrical trap collection efficiencies depend on cylinder aspect ratios, with height to diameter ratios of more than 3 and preferably more than 5 required for good collection efficiency under most ocean current velocities (Hargrave and Burns, 1979; Gardner, 1980b; Blomqvist and Kofoed, 1981; Butman et al., 1986).

The details of the flow within the trap and occurrence of dynamic boundaries between flowing and still portions of the fluid are important for particle collection, and the dependence of these internal flow fields on tilt magnitude, tilt direction, trap geometry, and external flow fields is complex. Results from three major laboratory flume studies of cylindrical trap particle collection efficiency as a function of horizontal flow velocity yielded conflicting results (Gardner, 1980a; Butman, 1986; Gust et al., 1996) when collection efficiency was plotted as a function of the 'trap Reynolds number' ( $R_{t} ;$ Fig. 2.2). Laboratory measurements by Gardner (1980a) at low velocities $\left(<10 \mathrm{~cm} \mathrm{~s}^{-1}\right)$ showed no 

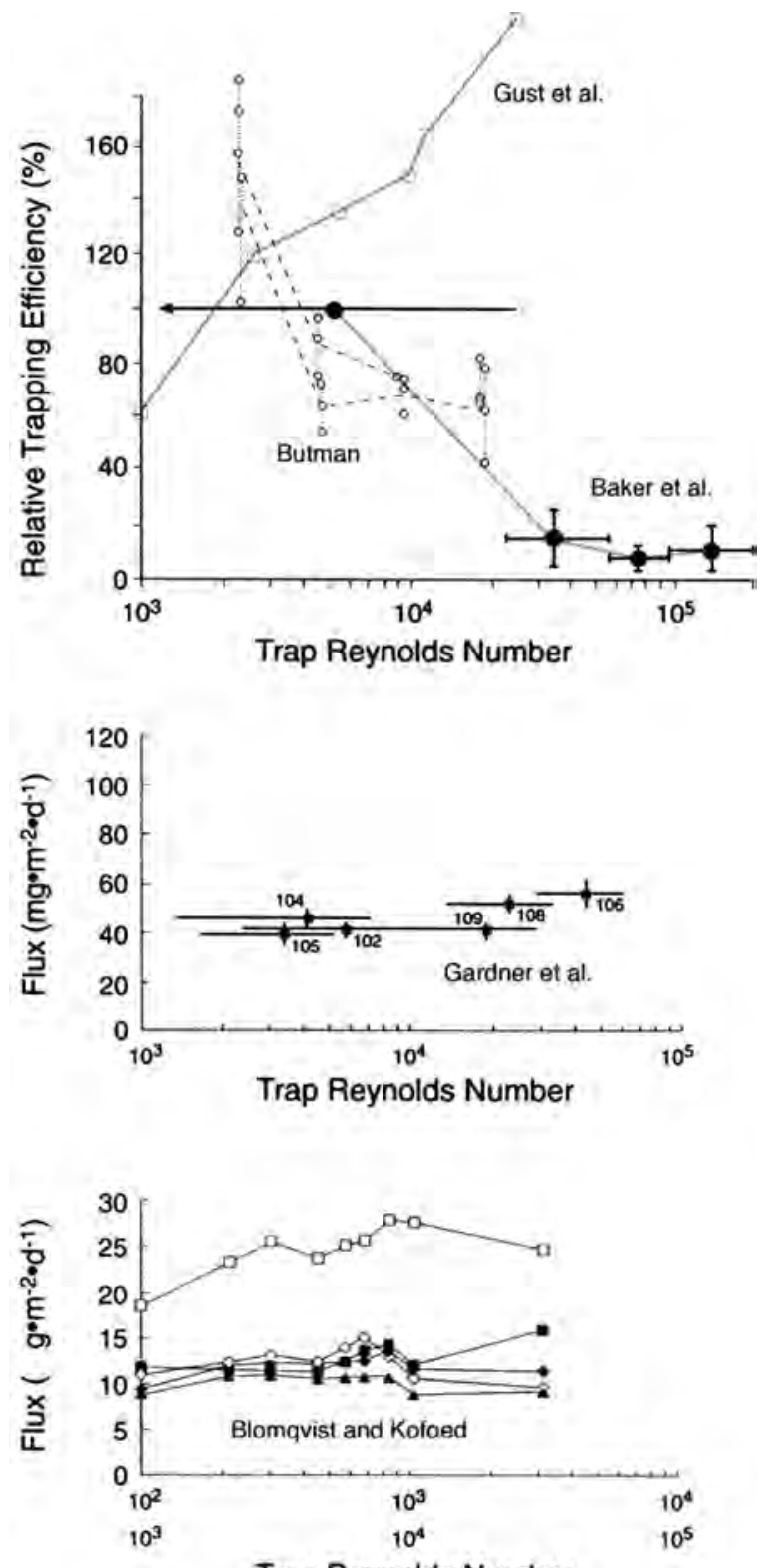

Trap Reynolds Number

Figure 2.2. Upper panel: relative collection efficiency vs. trap Reynolds number $\left(R_{t}\right)$ for the laboratory study by Butman (1986; Fig. 6b) (open symbols and dashed lines), the field study of Baker et al. (1988) (solid lines and symbols), and the flume study of Gust et al. (1996). In the Baker et al. (1988) data, horizontal lines delineate the $R_{t}$ range for each speed interval; symbols and vertical lines mark the mean and standard deviation of the relative collection efficiency during each speed interval for four deployments. Middle panel: flux vs. $R_{t}$ from Gardner et al. (1997) during a 1-yr oceanic deployment. Lower panel: particle flux vs. $R_{t}$ for five consecutive field experiments by Blomqvist and Kofoed (1981). Experiments lasted 12-30 days and used cylinders with different diameters (which create a range of $R_{t}$ for each experiment, as in Butman, 1986) but a constant aspect ratio of 8. Currents were not measured concurrently, but numerous current measurements at other times were between $1-10 \mathrm{~cm} \mathrm{~s}^{-1}$ (Blomqvist, personal communication, 1988) thus constraining $R_{t}$ to within one order of magnitude. 
significant $R_{t}$ dependence for cylinders, and a decrease in efficiency with $R_{t}$ for cones; however, the flume tests were over a low and limited range of $R_{t}$. Butman et al. (1986) found that collection efficiency of $25 \mu \mathrm{m}$ diameter glass beads decreased with $R_{t}$, whereas Gust et al. (1996) found a sharp increase over the same range of $R_{t}$.

The experimental techniques used to expose particles to traps in these three studies differed considerably. Gardner (1980a) and Butman (1986) allowed particles to encounter the trap within the flume flow, whereas Gust et al. (1996) released the particles into the trap through a tube at a velocity that matched the flow velocity of the fluid entering the trap, so that the impact of the first step of particles naturally encountering the trap in the external flow field was excluded. Gust et al. (1996) explained the differences between the flume studies conducted in their manner of manipulating $R_{t}$ (by changing trap diameter versus approach velocity) and suggested that Reynolds number similarity was not a valid criterion for predicting trap efficiency. But Gardner et al. (1997), comparing the flume data with a wider set of field data (see below), argued that the different result of Gust et al. (1996) resulted from Gust bypassing the first of the three steps of trap collection. In addition to this methodological issue, it is probable that particle collection efficiencies cannot be scaled to properties of the external flow alone (e.g. to $R_{t}$ ), since flow within the trap plays an important role as do the characteristics of the particles, especially in affecting whether particles that reach the bottom of the trap can be resuspended and exit.

Many of these laboratory studies have had the objective of determining quantitative expressions describing sediment trapping efficiencies and thus a path to obtaining accurate estimates of in situ fluxes from existing sediment trap technologies. Unfortunately, this objective remains elusive because of the difficulty in controlling hydrodynamic variables in typical field deployments (e.g. vertical and horizontal velocity, tilt, flow deflection from trap frames and cables, mooring-generated turbulence, change in trap aspect ratio as brines are washed out, etc.) and hydrodynamic interactions with the properties of marine particles (e.g., size, sinking rate, and change(s) as the particles encounter brines and are disrupted or aggregated by trap flow fields). While it is possible to dynamically scale the flow around trap models in a flume to traps used in the ocean or lakes, the behavior of complex aquatic particles and aggregates within the turbulent flow around and inside traps is not yet fully predictable and is best studied in situ because the particle motions are not easily represented by scaling. How can we predict the behavior of particles within turbulence when we cannot model the turbulence itself?

Despite the limitations of controlled laboratory and field experiments, these studies have suggested certain qualitative aspects of trap collection processes which should be kept in mind in designing, evaluating and comparing field studies. First and foremost, the higher the relative advective velocity experienced by a trap, the less likely that its flux will accurately represent the in situ flux. The relative magnitude of this flux difference is not possible to specify from the velocity (or $R_{t}$ ) alone. Higher collections can occur if the trap tilts toward or with the flow, which also biases samples toward smaller particles (Gardner, 1985). Smaller collections can occur if the high velocities wash everything out while the 
trap is deployed or recovered. Tilt is likely to be a function of the full mooring dynamics, and its evaluation requires that it also be correlated with directional velocities. Designs which reduce the possibility of wash-out, such as cylinders with high aspect ratios (rather than low-angle cones), or those which isolate the particles by closing collection cups, can minimize these problems. The influence of brines to improve retention is controversial, with laboratory experiments suggesting that complete or partial filling of cylinders with brine may reduce collections by reducing the aspect ratio of the trap (Gardner and Zhang, 1997); however, field experiments suggest negligible or inconsistent differences from brine levels (for further discussion see Nodder and Alexander, 1999; Gardner, 2000; Stanley et al., 2004).

Field experiments provide less control on hydrodynamic variables, but they are a test of natural sampling conditions and indicate relative fluxes under a variety of conditions. Several attempts to inter-compare traps of different design in moored and drifting modes exposed to a range of current speeds have been made (Dymond et al., 1981; Blomqvist and Kofoed, 1981; Baker et al., 1988; Honjo et al., 1992; Gardner et al., 1997). In the most carefully monitored and temporally/spatially constrained field experiment, Baker et al. (1988) showed that in currents $<12 \mathrm{~cm} \mathrm{~s}^{-1}$, the magnitude and characteristics of settling particles collected in moored cylindrical traps were similar to those collected simultaneously in drifting cylindrical traps. When currents ranged between $12-30 \mathrm{~cm} \mathrm{~s}^{-1}$ (Reynolds numbers from $0.1-10 \times 10^{4}$ ), the moored traps under-trapped by $75-95 \%$ compared to an identical cylindrical trap drifting near the same site during overlapping time periods. Undertrapping continued at speeds $>50 \mathrm{~cm} \mathrm{~s}^{-1}$ and, at current speeds $>12 \mathrm{~cm} \mathrm{~s}^{-1}$, the mean size and density of the trapped particulates increased.

This was the first field-derived evidence giving support to the flume-derived observations (e.g., Butman, 1986) that collection efficiency decreases with increased trap Reynolds number (increased velocity) or a decrease in particle sinking speed (Fig. 2.2). Over a narrower range of Reynolds numbers $\left(0.2\right.$ to $\left.4.4 \times 10^{4}\right)$ in an open ocean experiment, Gardner et al. (1997) found no statistically significant change in flux (Fig. 2.2), and no influence of horizontal flux of particulate matter on trap collections using cylindrical traps with an interior cone; however, the temporal conditions were not as well constrained as those of Baker et al. (1988). The data of Blomqvist and Kofoed (1981) are replotted in Figure 2.2 and show no significant variation in flux as a function of trap Reynolds number. Using a conical trap design in a field experiment, Gust et al. (1992) found that traps with higher approach velocities registered higher mass fluxes. They reported $0.5 \mathrm{~m}$ vertical excursions with a $10 \mathrm{~s}$ period during deployment, and this and tilt could have affected their results. Bonnin et al. $(2002,2006)$ deployed cylindrical traps with a concentrating cone at the bottom near the seafloor and found no increase in trapping rates as a function of Reynolds number over the same range of trap Reynolds numbers. These varying results may in part derive from the different trap designs, but also from differences in the full mooring configurations, deployment conditions, and the characteristics of ambient particles. Except for one field study with conical traps (Gust et al., 1992), all other field studies 
show either no increase or a decrease in trapping efficiency as a function of Reynolds number.

The results obtained from laboratory and field measurements favor a decrease or no change in trap efficiency with Reynolds number and suggest that the methodology of the Gust et al. (1996) flume experiments and resulting theory needs re-examination. Still, methodological differences (trap types, mooring types, etc.) and/or varying physical and particle characteristics make extrapolation from any one study to all conditions tenuous. This is an important point and emphasizes that collection efficiencies should not be considered to be representative of hydrodynamic conditions alone, but arise from the interaction of collection conditions and particle properties (density, size, sinking rates, particle integrity, etc.). Thus progress in understanding hydrodynamic biases requires progress in understanding particle properties (see Section 2d).

\section{c. Progress in avoiding the hydrodynamic problem}

Many investigators have made efforts to improve surface-tethered, drifting trap designs to reduce mooring line motions and to attempt to achieve true Lagrangian drift conditions, including the use of sub-surface drogues, small surface floats, and elastic elements (bungees) to dampen surface motions (e.g. GOFS, 1989; Nodder et al., 2001). The single most important advance in avoiding the effects of hydrodynamic biases has been the development of NBSTs (Fig. 2.3.; Asper, 1996; Buesseler et al., 2000; Valdes and Price, 2000; Lampitt et al., 2004; Stanley et al., 2004; Valdes and Buesseler, 2006). A design based on the adaptation of profiling floats to carry cylindrical tubes similar to surface tethered PITs (Valdes and Price, 2000) has now been used in comparative studies with traditional surface-tethered PITs in four separate field programs in Bermuda (in two seasons in 1997, Buesseler et al., 2000; and again in 2001, Stanley et al., 2004). Deployment conditions in Bermuda were benign, with average measured current velocities across the traditional BATS program surface-tethered PITs of $\sim 5$ or at most $8 \mathrm{~cm} \mathrm{~s}^{-1}$, and shorter periods of higher velocities reaching $\sim 10-15 \mathrm{~cm} \mathrm{~s}^{-1}$ during the multi-day deployments (Buesseler et al., 2000; Stanley et al., 2004), and short period wind waves of less than $1 \mathrm{~m}$ in amplitude (Buesseler et al., unpublished data).

Bulk fluxes of mass and POC were statistically indistinguishable in the NBST and PITs in Bermuda under these conditions, and generally within the range of variations among different individual tubes on each trap of approximately 20 to 30\% (Buesseler et al., 2000; Stanley et al., 2004). This is reassuring because it suggests that at low velocities there may not be a large hydrodynamic effect on the mass flux measured with surface-tethered, drifting traps, though this is not proof that the true in situ flux has been measured. The fluxes were also reasonable in comparison to historical studies at the site; however, there were differences in the details of component fluxes with more swimmers, fecal pellets and ${ }^{234}$ Th by factors of 2 to 3 in the PIT than the NBST traps (Buesseler et al., 2000). The higher swimmer and fecal pellet collections in surface-tethered PITS can perhaps be 

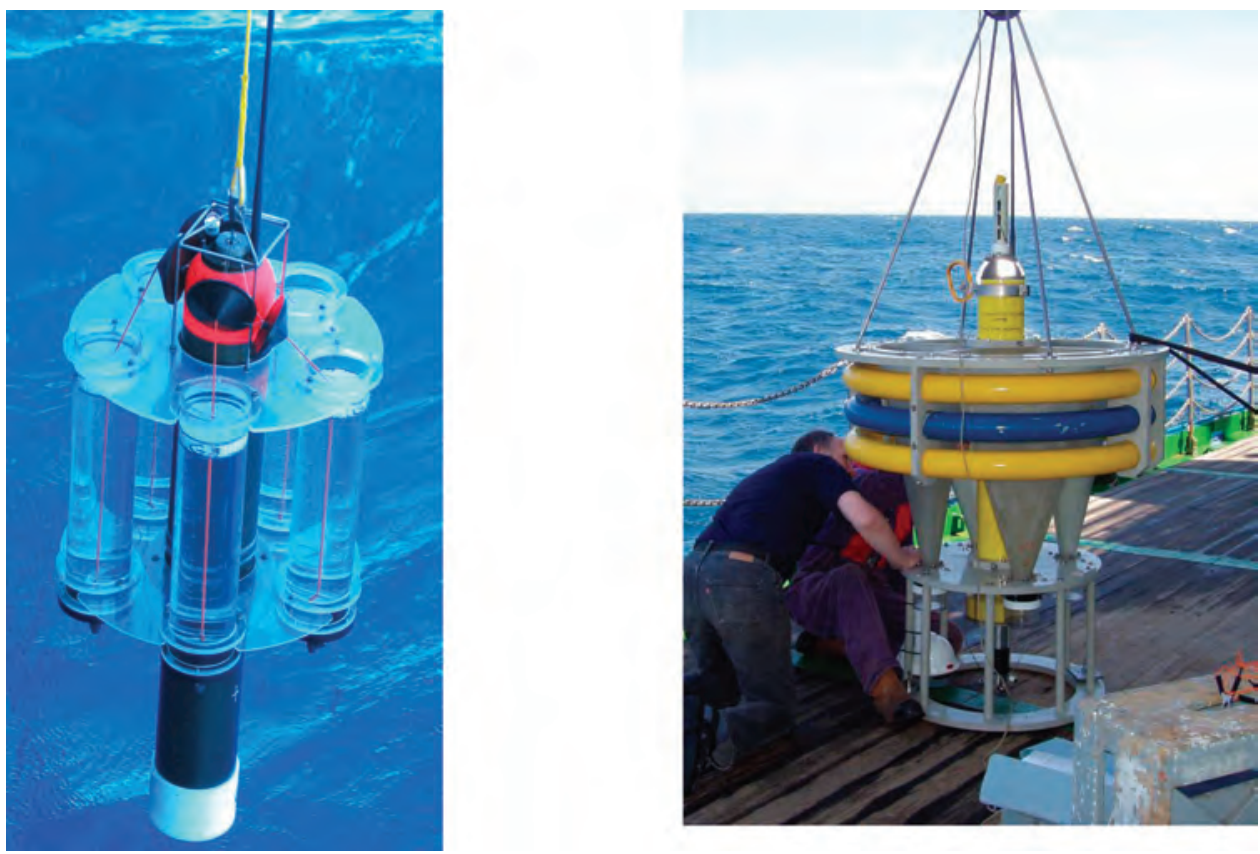

Figure 2.3. Photos of two neutrally buoyant traps used successfully to collect sinking particles in the ocean. (a) NBST (Valdes and Price, 2000; Valdes and Buesseler, 2006). (b) PELAGRA (Lampitt et al., 2004).

attributed to a greater ability of swimmers to find, or be swept into the PITs, because of their additional mooring components, associated turbulence and advective flow (see Section 3). The higher ${ }^{234} \mathrm{Th}$ collections are less easy to rationalize because ${ }^{234} \mathrm{Th}$ is not associated to any great degree with swimmers, but instead could derive from a hypothesized association of Th with small, slowly sinking particles that may have been over-collected by the PITs due to aggregation within the trap (Buesseler et al., 2000). This suggests that normalization of bulk fluxes with ${ }^{234} \mathrm{Th}$ may require consideration of variations in both collection efficiency and particle composition as functions of sinking rate (see Section 5c.i). Other differences between the NBST and PITs included variations in $\mathrm{Si}$, $\mathrm{Ca}, \mathrm{Al}$, and $\mathrm{Ba}$ fluxes and, for one deployment period, PON (but not POC), suggesting that sorting of different particle types occurred (Stanley et al., 2004).

In addition to NBSTs, which collect and return samples, there has been successful development of neutrally buoyant packages that optically characterize relative particle abundances in situ, and profile to the surface to telemeter the data. These efforts have built on earlier work that sought to estimate particle sinking rates from in situ cameras either on tethers or deployed from under-water vehicles (e.g., Asper, 1987; Lampitt et al., 1993; Pilskaln et al., 1998). Recent advances with profiling floats equipped with satellite 
data-transmission include the ability to characterize relative variations in sinking fluxes from changes in transmission measured with upward looking light beams (Bishop et al., 2004), and to measure particle sizes and estimate fluxes using upward looking cameras (Bishop et al., 2006). These approaches offer promise for much greater spatial and temporal coverage of particle fluxes than can be achieved with sample return missions with traditional traps, but await validation and calibration against other flux proxies.

\section{d. Progress in correcting for hydrodynamic biases}

As discussed above, much effort has been focused on assessing the scope of biases and their relation to field conditions. A major advance in this regard has been to apply radionuclide studies to assess collections efficiencies. This work, discussed in detail in Section 5c, suggests that traps both under- and over-collect the in situ flux in different deployment conditions. Correction of trap fluxes is, in principle, possible using the radionuclide technique, although there remains considerable work to address the degree to which the radionuclides $\left({ }^{230} \mathrm{Th},{ }^{234} \mathrm{Th},{ }^{210} \mathrm{~Pb}\right.$, etc.) are distributed across all particle types, and thus whether different radionuclides are collected with different efficiencies than are other flux components.

The only other major effort to develop a means to correct measured fluxes to obtain estimates of in situ fluxes is that of Gust and Kozerski (2000). By carefully controlling flow velocity in a river using a weir, these researchers compared collections and particle size distributions from cylinders of different diameters to calibrate a model of collection efficiency based on the extent of retention of particles that are swept into the cylinders in the eddy that forms above the cylinder (as described in Section 2a above). They concluded that the model holds for the riverine particles in quantitative agreement with results from glass beads released into traps in the laboratory (Gust et al., 1996), and suggested that the deployment of several cylinders of different diameter may offer a path to the retrieval of in situ fluxes. However, this approach depends on the Gust et al. (1996) collection efficiency model, which disagrees with all other field or flume studies using cylindrical traps (Fig. 2.2). Those studies included comparison of flux collection by traps of different diameters (Blomqvist and Kofoed, 1981) and did not reveal the variations expected by the model of Gust et al. (1996). Other aspects of the Gust and Kozerski (2000) approach are also open to debate, including the relation between collection of particles on a flat plat and within a cylinder, as discussed along with other concerns about these methods in Sukhodolov et al. (2003).

We conclude that there is not yet a clear path to the correction of hydrodynamic biases to provide an unequivocal measure of in situ sinking particle fluxes. Such a correction would have to be based on an experimental setup that gives a reproducible and realistic dependence of flux on approach velocity. Then the correction could be modeled following the procedures proposed by Gust et al. (1996), which could lead to a path of predicting mass flux for every particle class. But given the complexities of moored trap and surface-tethered trap dynamics, the development of corrections at this moment does not 
appear as promising as approaches that minimize the hydrodynamic problem in the first place, such as the use of neutrally-buoyant traps as discussed above.

Finally we note that, for so many aspects of sediment trap particle collection, the problem of potentially biased collection of particles depends not only on trap hydrodynamics, but also on particle characteristics. A general review of new techniques to characterize particle properties is beyond our scope, but we briefly mention a few techniques that measure properties of clear importance to trap function. These include,

- SPLITT - a device to separate particles by their sinking rates in a thin laminar-flow between rigid plates, (Gustafsson et al., 2000; discussed further in Section 5);

- elutriation - the fractionation of particles as they settle through a series of conical funnels with upward flowing water circulation (Peterson et al., 2005);

- separation of particles in situ by differential settling in a cylindrical settling trap using indented-rotating-sphere (IRS) sediment traps (Peterson et al., 2005; Trull et al., 2006). The IRS traps were originally designed to exclude zooplankton swimmers (see Section 3) by using a sphere within the cylindrical trap that collects particles on its upper surface and then rotates (typically every 15 minutes) to dump the particles (but not the swimmers) into a funnel that leads to a carousel of collection tubes below (Peterson et al., 1993). To separate particles by sinking velocity, the sphere rotates less frequently (e.g. every 6 hours), and after each rotation the carousel is rotated rapidly to collect particles separated by the duration of their $\sim 1$ meter fall within the internal funnel. As an example, particles can be separated into fractions sinking faster than approximately $800,400,200,100,50,25$, etc. meters per day. Up to 11 fractions can be collected, and repeating the 6-hour collection and carousel rotation cycle many times allows many particles to be obtained.

- the use of viscous polyacrylamide gels in sediment traps to gently decelerate particles and isolate them so that in situ sizes, shapes, and structures can be examined (Waite and Nodder, 2001; Trull and Ebersbach, 2007)

There are of course many other methods for the characterization of marine particle composition. Our main message is that every effort to characterize particles will benefit flux estimates and the assessment of hydrodynamic biases that may affect those estimates.

\section{e. Other hydrodynamic considerations, particle source regions for traps}

On a broader scale, an additional complexity of evaluating particle flux measurements in the field is the mesoscale variability of particle production and lateral advection, as well as the influence of advection on particle aggregation (Legendre and LeFevre, 1989; Deuser et al., 1990; Siegel et al., 1990; Siegel and Deuser, 1997). Such large-scale mesoscale dynamics may greatly influence interpretation of the area and time of origin of the collected particles (i.e. the "statistical funnel"). Siegel et al. (1990) carried out a Lagrangian analysis of a particle sinking through a random eddy field in order to evaluate effects 
of horizontal diffusion and particle sinking rate on the particle fluxes collected by an idealized sediment trap. They showed that sinking particle fluxes are spread out by the eddy field as they leave the surface, and that this spreading is greater for slow-sinking than fast-sinking particles. This means that the production of large, rapidly sinking particulates such as aggregates and zooplankton fecal pellets would be more representative of local conditions directly above the traps, whereas the smaller collected particles originating from the slowly sinking pool of finer materials will be averaged over much greater distances from the sampling site. For the same reasons, for particles with identical sinking rates, deeper traps would be collecting material that has been produced over a larger area. These effects are particularly pronounced for moored traps in the deep sea, which can have particle source areas from distant regions that are as large as hundreds of square kilometers for slowly-sinking particles. The scale of the source region and its influence on trap collections must be evaluated in each case, by examination of currents, eddies, and particle source regions. Recent studies have used remote sensing of ocean color and currents to evaluate particle source regions to deep moored traps (e.g. Waniek et al., 2005; Nodder et $a l ., 2007)$. At the same time, new high-resolution measurements of large aggregate distribution in the northeastern Atlantic suggest that some flux events could be rapid and localized in a small area (Guidi et al., 2007).

Near-surface traps are less influenced by these effects, because there is less time for differential settling to separate particles, or to supply particles from large distances, but the shorter deployments of shallow traps exacerbates another aspect of the statistical sampling of particle source regions. The short time periods that apply to most trap collections mean that only a small portion of the "statistical funnel" is sampled and that can also induce biases if particle production is variable in the local region either spatially or temporally (Siegel et al., 1990; Siegel and Deuser, 1997). Thus there is a need to estimate particle sources from small-scale production and advection variations and to make some estimate of particle sinking rates. A recent assessment of surface-tethered and neutrally-buoyant free-drifting traps at station ALOHA north of Hawaii found collection areas $<5$ to $10 \mathrm{~km}$ in radial extent that were displaced horizontally from the trap location by distances of order 10 to $40 \mathrm{~km}$ for traps at depths of 150 to $500 \mathrm{~m}$ and sinking rates of 50 to $200 \mathrm{~m} \mathrm{~d}^{-1}$ (Fields et al., 2006; Siegel et al., 2007).

These considerations emphasize that when traps are used to characterize the specific biological inputs and origins of organic particles in the export flux in relation to, for example, primary or secondary production in the water column, great care should be taken in interpreting trap-derived data, including detailed consideration of particle source regions, their spatial and temporal variability, and the mesoscale eddy advective field in the same water column over the traps. In this regard, the calibration of traps using radionuclides or mass balances for nutrient elements (see Section 5) must take into account the appropriate time and space scales of these variations. In our present context of evaluating collection efficiencies in the field, these environmental variations add uncertainty to these efforts. 


\section{Zooplankton swimmers}

\section{a. The swimmer issue}

Zooplankton affect particle flux in the sea in a number of ways; they create or aggregate particles by feeding and producing sinking fecal pellets, disaggregate sinking particles by their feeding or swimming activities, remineralize sinking particles through their feeding and metabolism, and actively transport particulate and dissolved organic matter from the surface to depth by vertical migration (e.g., Fowler and Knauer, 1986; Angel, 1989; Longhurst et al., 1990; Steinberg et al., 1997; Schnetzer and Steinberg, 2002; Goldthwait et al., 2004). An important way that zooplankton affect our ability to accurately measure particle flux in the sea, however, is their uninvited presence in sediment traps.

The term "swimmers" refers to metazoan zooplankton (and occasionally small fish) that are thought to actively enter sediment traps. The added material from these zooplankton can significantly increase the total mass of particles in traps, and can pose significant problems in measuring the flux of many chemical parameters as well (Knauer et al., 1979; Lee et al., 1988; Karl and Knauer, 1989). Thus, swimmers should be removed and not included in the calculation of flux; unfortunately in some studies this is not done or is done inappropriately. The swimmer problem generally decreases with depth, with shallow sediment traps containing more swimmers than deep traps (Lee et al., 1988), mainly because zooplankton and micronekton biomass decreases exponentially with depth (Vinogradov, 1972; Angel and Baker, 1982). Most of the swimmers are crustaceans, such as copepods, amphipods, and euphausiids (Steinberg et al., 1998), which are relatively easy to recognize and remove. However, there are a number of delicate gelatinous zooplankton such as siphonophores and larvaceans, termed "cryptic swimmers," which may break apart upon entering a trap and are difficult to see and remove (Michaels et al., 1990). Swimmer products, such as the mucous feeding webs or "houses" of larvaceans that may have entered the trap with the animal, are difficult to distinguish from the rest of the detritus (Michaels et al., 1990; Silver et al., 1991). One example of a trap sample before and after swimmer removal is shown in Figure 3.1. It should be recognized that swimmer abundances and types are highly variable; therefore, simple extrapolation from one site to a different set of conditions is not possible. Likewise there is no single swimmer correction algorithm, and methods developed to remove swimmers in one setting may not be appropriate at another site (see Section 3d).

\section{b. Progress in understanding the scope of swimmer biases}

A comparison of the quantity of detrital and swimmer carbon caught in sediment traps illustrates how important the removal of swimmers is to the accurate measurement of particle fluxes. Over a range of flux environments, swimmer contributions are highly variable and make up $14-90 \%$ of the total POC caught in traps (Table 1). In low flux 


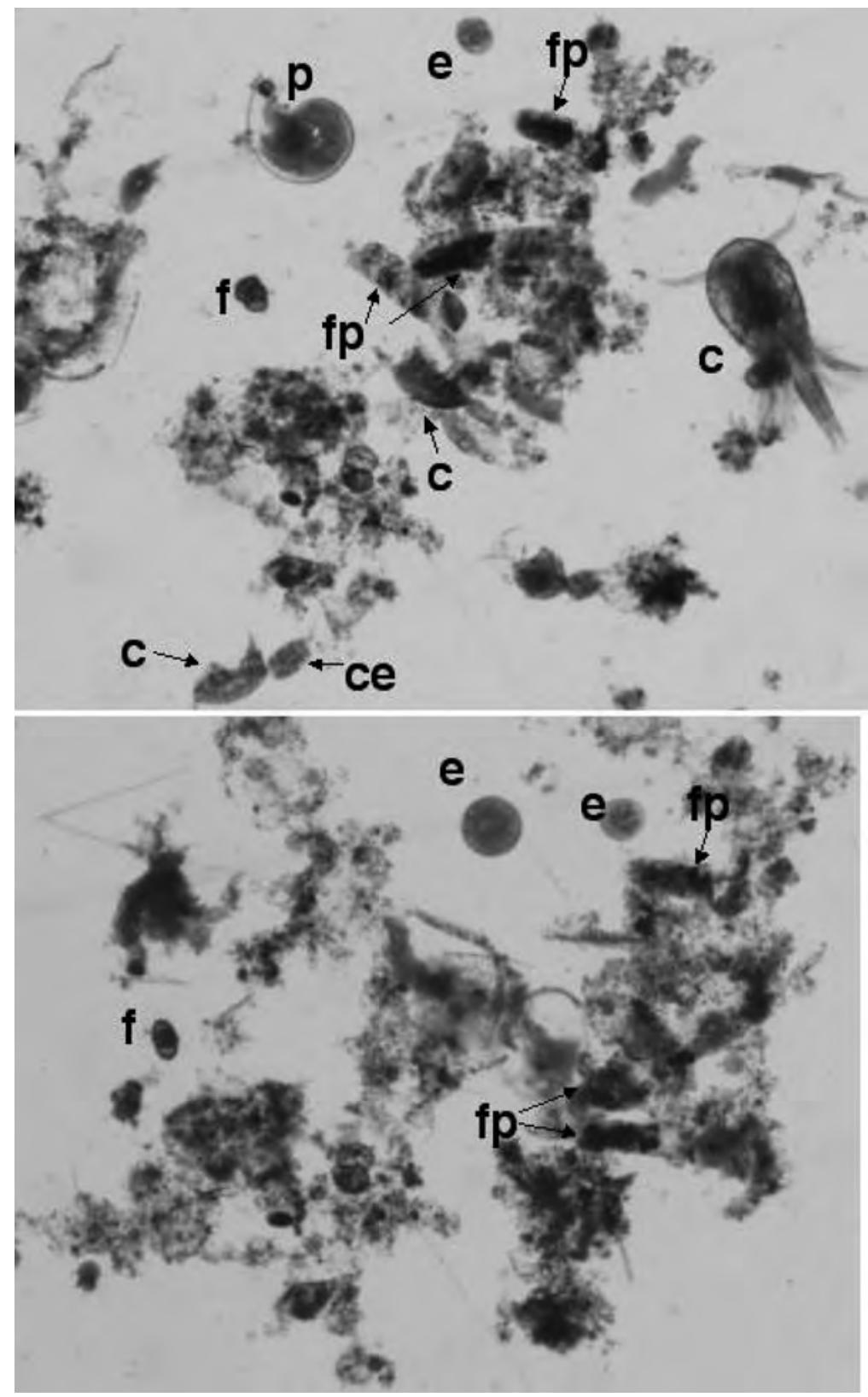

Figure 3.1. Sediment trap sample before picking swimmers (upper photo) and after picking (lower photo). Sample from $150 \mathrm{~m}$ PIT from station ALOHA in North Pacific subtropical gyre. Magnification $=40 x$. c-copepod; e-egg; f-foraminifera; fp-fecal pellet; p-pteropod. (Note- some particles moved in or out of view during picking process, e.g., additional larger egg and detritus in bottom image; photographs by S.E. Wilson). 


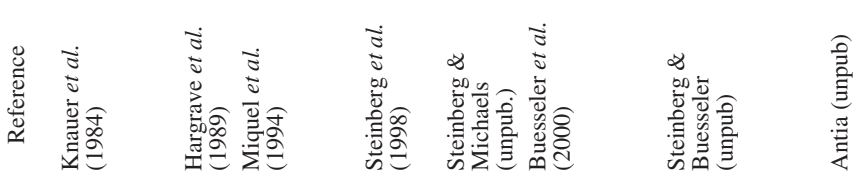

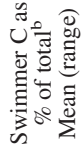

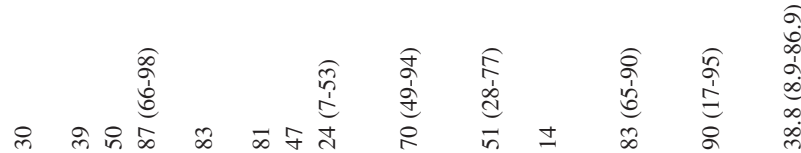

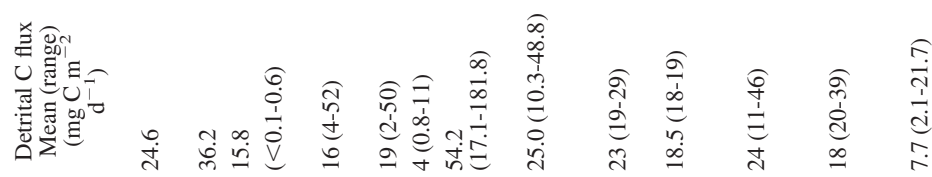

至空

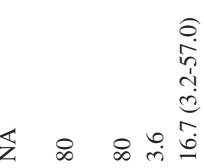

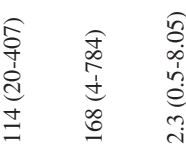

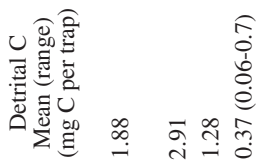

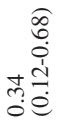

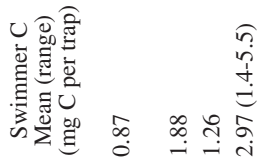

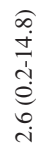

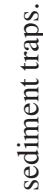

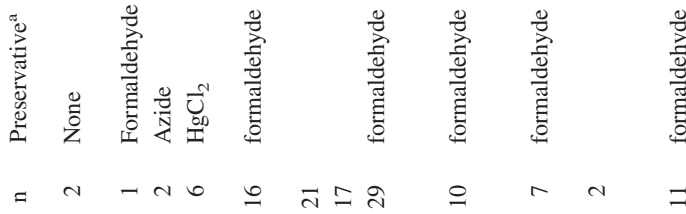

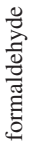

高

$\widehat{c}$
$\stackrel{+}{+}$
$\dot{d}$
$\stackrel{d}{d}$
$\infty$
0

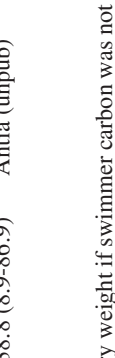

5
0
0
3
0
0
0
0
0
0
0
0
0
0
0
0
0
0
0

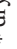

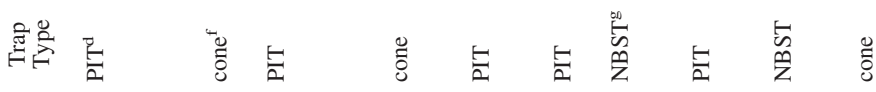

串节总

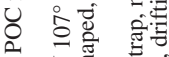

.

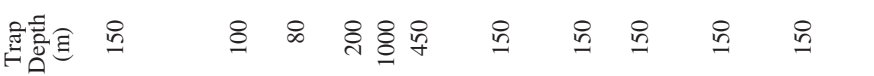
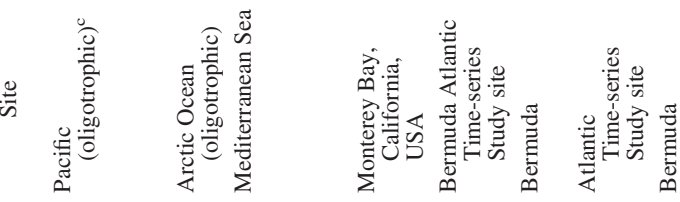

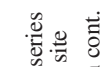

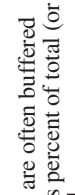

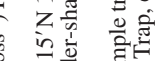

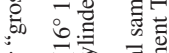

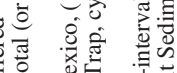

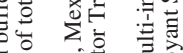

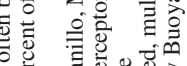
웜

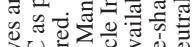

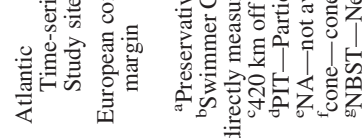


environments, such as the North Atlantic gyre (BATS) and the oligotrophic Arctic Ocean, swimmers constitute the highest proportion of the carbon flux, with swimmer carbon an order of magnitude higher than detrital carbon. In more eutrophic environments such as Monterey Bay off the U.S. west coast, or the NW Mediterranean Sea, swimmer C is still substantial but does not constitute as high a proportion of the total flux. Swimmers are also more of a problem in shallow compared to deep sediment traps. The average contribution of swimmer C to total sediment trap C in shallow traps (200 m or less) is $30-90 \%$, while in deeper traps $(z=450-1000 \mathrm{~m})$ it ranges from $24-47 \%$.

While poisons (e.g., mercuric chloride) and preservatives (e.g., formaldehyde) are effective in inhibiting microbial activity and killing zooplankton entering sediment traps, poisoned or preserved traps also collect more swimmers than unpoisoned traps (Knauer et al., 1984; Lee and Cronin, 1984; Lee et al., 1992). Swimmers entering unpoisoned traps may feed on material in the trap (Lee et al., 1988). Some of this material would then be remineralized through the animal's metabolism, thus causing an underestimate of the true flux. A $43 \%$ loss of carbon over a two-week period in an unpoisoned sediment trap at $3 \mathrm{~m}$ in a shallow lake was assumed to be a result of zooplankton feeding, although the loss was less, 2-3\%, at deeper depths of $8.5 \mathrm{~m}$ and $10.5 \mathrm{~m}$ (Lee et al., 1987). In unpoisoned traps, live zooplankton may also disrupt aggregates and alter the size spectrum of particles collected, or break apart particles and release DOM. Zooplankton swimmers can also release fecal pellets directly in the trap, either resulting from feeding previously outside the trap, or from ingesting particles within the trap, which can alter the chemical composition of trap material.

More commonly, traps are poisoned and brine solutions are used in the bottom of the collection tube or cups to inhibit diffusive loss of poison during deployment. As a consequence, upon sinking into the toxic brine copepods can herniate releasing their stomach contents, and thus cause a significant apparent increase in pigment flux (Peterson and Dam, 1990; see Section 4).

Another bias not resulting from swimmers being directly inside the trap, is anecdotal evidence of fecal pellets inside traps originating from either barnacles or other encrusting organisms growing on the mooring line above the trap opening, or from fish attracted to the line. Shallow traps may be particularly subject to epifaunal growth problems, both above and inside the trap opening. In this regard, the common use of short deployments of only a few days in the upper ocean avoids epifaunal growth problems. An interesting observation has been reported of large numbers of postlarval ophiuroids (brittle stars) collected by deep-sea sediment traps on the NE Atlantic continental slope (Lampitt et al., 2002). The ophiuroids became progressively larger with time (sampling interval was 7 days, over a 3.5 month period), suggesting feeding and growth within the collection funnel, before eventually falling into the preservative below. Ophiuroids contributed up to $7 \%$ at $1,000 \mathrm{~m}$ and almost $30 \%$ at $1,400 \mathrm{~m}$ of the total daily POC flux, and based on requirements for growth and respiration, were estimated to consume up to $16 \%$ of the daily POC flux in the trap. 


\section{c. Progress in avoiding the swimmer problem}

The best method to reduce a flux bias due to swimmers would be to create a sediment trap that somehow decreases the number of swimmers collected. Karl and Knauer (1989) used screens at the mouth of sediment traps to exclude swimmers before they entered the traps and suggest a ratio method using replicate screened vs. non-screened traps to calculate a swimmer-free flux. However, other studies have shown that screened traps still have an abundance of smaller swimmers, and collect less aggregate material than non-screened traps (Michaels et al., 1990). It is also not known if the particulate material passing through the screened and unscreened traps is qualitatively different (Silver et al., 1991). It has been suggested that baffles at the mouth of sediment traps, used to minimize turbulence, can also act as swimmer deterrents (Martin et al. unpublished results cited in GOFS, 1989); however, this hypothesis has not been supported by a more recent comparison of numbers of swimmers in baffled and un-baffled cylindrical traps (Nodder and Alexander, 1999).

Another possibility researchers have considered is that not all swimmers actively swim into traps but instead act as "surfers" that are carried into traps as a result of flow into and out of the mouth of the trap (Buesseler et al., 2000; see Section 2). As mentioned previously, the NBST is a free vehicle that flows with the currents and thus minimizes internal flow (Valdes and Price, 2000). In the first deployments of the NBSTs, significantly fewer swimmers were caught in the NBSTs (16\% of the net, or $14 \%$ of the gross POC flux ) than in the standard PIT traps (50-250\% of net, 28-77\% of gross POC flux) (Buesseler et al., 2000; Table 1). However, recent data have indicated mixed results, with swimmers in NBSTs occasionally higher than in PITs (Table 1). Further tests of the NBSTs are underway, but the impact on reduced internal flow and thus collection of "surfers" will likely vary with hydrodynamic conditions and zooplankton variability.

Several different traps have been designed for segregating swimmers from sinking detritus prior to entering the sample collection area at the bottom of the trap. The "labyrinth of doom" cylindrical sediment trap contains a series of internal funnels designed to separate the active, randomly swimming zooplankton from the trap sample (Coale, 1990). Analysis of the amino acid C content of the inner (trap sample) and outer (containing swimmers) collection tubes indicated that $26-65 \%$ of the swimmers were successfully separated from the sample at VERTEX 3 and 4 sites in the Pacific (Lee et al., 1988; Wakeham and Lee, 1989; Coale, 1990). Another trap similar in design to the labyrinth of doom also segregates swimmers from sinking particles with a series of funnels and plates (Hansell and Newton, 1994). The efficiency with which swimmers were excluded from the particle collection chamber in this trap was $>70 \%$ for copepods in coastal waters, but only $37-72 \%$ for copepods in open ocean waters.

Another swimmer avoidance trap contains a microprocessor-controlled indented rotating sphere (IRS) valve designed to keep swimmers separate from the lower part of the trap (Peterson et al., 1993). When rotated, indentations on the surface of the sphere allow the collected sinking particles to fall into the lower collection chamber, but not active 
swimming zooplankton. The IRS valve reduced mass flux $>850 \mu \mathrm{m}$, which was almost exclusively large zooplankton, by an average of $88 \%$, and small zooplankton $<850 \mu \mathrm{m}$ by $>80 \%$ (estimated by reduced pigments, amino acids, and lipids in valved compared to non-valved traps; Peterson et al., 1993). A potential problem with the IRS design is when detritus remains on the surface of the sphere before the sphere is rotated (generally every 0.25- $1 \mathrm{~h}$ in swimmer avoidance mode; Peterson et al., 1993), sinking materials could be consumed by visiting zooplankton and will continue to be degraded by bacteria until the detritus drops into the poisoned brine below (Andrews et al., 2006). More careful study of the IRS design under differing conditions is warranted, as it offers a high degree of swimmer exclusion, and any method that can exclude swimmers directly is preferred over post sampling removal.

\section{d. Progress in correcting for swimmer biases}

The "art and Zen" of swimmer removal is a tricky (and sticky) business for two main reasons. The first is that conceptually there is a spectrum of what should be considered a zooplankton swimmer and removed. The second is the widely varying methodology for use in swimmer removal (if it is even done at all) that can result in significant differences in measurement of flux. Each is examined below.

i. What should be considered a swimmer? There is arguably a spectrum of swimmers caught in sediment traps, with true intruders at one end of the spectrum, and genuine associates of detritus that arguably should be included in the flux at the other end (Silver and Gowing, 1991). Active intruders that swim into traps and die in poisoned traps are appropriately not included in the flux and should be removed. Vertical migrators may get caught in sediment traps and although their descent is a downward flux, most of these organisms also ascend to the surface waters again as part of the diel cycle so they should be removed. Sinking eggs or other non-motile life history stages are difficult to handle as presumably they would eventually hatch and the motile stage return to surface waters. Some eggs enter traps attached to swimmers (e.g., copepod egg sacs, see Figure 3.1) but become dislodged when the animal enters a trap, and therefore should be removed. Unfortunately, many eggs can be difficult to remove as they are often small and can adhere to sticky particles, so for practical reasons eggs are often included as part of the sinking flux.

Moribund or dead organisms are arguably part of the flux and should be included, but it is difficult to determine which organisms were already dead upon entering a trap. Some researchers do not remove animals that appear to have been dead for some time (e.g., copepods with almost no insides and appear almost as a molt), while others remove all because of the difficulty of determining whether they were dead or alive when they entered the trap.

The microbial community on particles such as bacteria and small protozoa derive their nutrition from the particle (Gowing, 1986; Silver and Gowing, 1991) and are included in 
flux measurements (also for practical reasons, as they can not be removed). There are also a number of taxa of metazoan zooplankton that associate with and remineralize detritus, and thus could be included as part of the flux (Steinberg et al., 1998). These include the copepod genera Oncaea and Corycaeus, some harpacticoid copepods (e.g., genus Microsetella), calanoid copepods in the family Scolecitrichidae, and some worms (nematodes and polychaetes) and hyperiid amphipods (Alldredge, 1976; Ohtsuka et al., 1993; Steinberg et al., 1994; Shanks and Walters, 1997; Kiørboe, 2000). These zooplankton "detrital associates" on average made up less than $2 \%$, and a maximum of $11 \%$ of the total POC flux at $450 \mathrm{~m}$ in Monterey Bay, California (Steinberg et al., 1998). There is still much to learn about these metazoan decomposer communities, and making decisions about which metazoan decomposer taxa should be included requires taxonomic expertise.

ii. Removal of swimmers by picking or screening. It is very difficult to remove swimmers without removing some of the organic detritus adhering to them (Lee et al., 1988). Particles adhering to setae on the antennae of copepods and to sticky gelatinous zooplankton are particularly difficult to remove (Steinberg, pers. obs.). Thus, not removing swimmers will overestimate flux while complete removal of swimmers, if there are attached detrital particles, will underestimate flux. The extent that swimmer removal methods are a source of error will likely vary with size spectrum and the species present (D. Karl, in Gardner, 2000).

Swimmers that should be removed from sediment trap material are listed in Table 2. This is not an exhaustive list as traps in some areas may contain other more rarely collected groups (e.g., flatworms, re-suspended benthic larvae, etc.). As a general rule, if the animal swims (automotive) then it should be picked. However, some of the groups in this list are troublesome. For example, pteropod (see Fig. 3.1) and heteropod shells with the animal inside do not belong in the trap, whereas empty shells do (Harbison and Gilmer, 1986; Gardner, 2000). Because this is often so difficult to tell it is suggested to pick all shells. Crustacean molts should not be picked, but as discussed above this can be hard to determine for some crustacea (e.g. some taxa of copepods) which have very transparent carapaces. Egg sacs from copepods are usually assumed to enter attached to a swimmer and then dislodged so they are picked. One notable benefit to carefully removing swimmers from trap material is that foreign material, such as hard, black soot particles from smoke stacks of the ship, lint, or tiny paint chips, can be recognized and removed which is particularly important for subsequent trace element analysis. Note that there is also a "real" black carbon flux that does not originate from the smoke stack of the local research vessel, but rather enters surface waters via long-range atmospheric transport and therefore is found in open ocean trap samples (Masiello and Druffel, 1998; Middelburg et al., 1999).

The methods for swimmer removal vary widely and several are listed in Table 3. Screens are commonly used as a first step (or only step) during processing to remove swimmers. The sample is placed through a large mesh sieve to remove large swimmers (several hundred micron mesh screen). Sometimes a second, smaller mesh screen is used. In some 
Table 2. Examples of swimmer taxa that should be removed from sediment traps.

Crustacean zooplankton

Amphipods

Copepods and copepod nauplii

Crustacean larvae (Barnacle, Crab, etc.)

Euphausiids

Mysids

Ostracods

Shrimps
Gelatinous zooplankton

Cheatognaths

Ctenophores

Doliolids

Heteropods and all pieces of shells

Larvaceans (Appendicularians)

Medusae (Hydrozoa and Scyphozoa)

Pteropods and all pieces of shells

Salps

Siphonophores
Other

Amphioxus (Lancelet eel)

Bivalve and gastropod larvae (including shells)

Copepod egg sacs

Fish larvae

Polychaetes and polychaete larvae

Tintinnids

Adapted from the Bermuda Atlantic Time-series Study-BATS

cases screening is all that is done, or the screen is picked under a binocular microscope. For the latter, a magnification of at least 50x is typically used. Large particles such as salp fecal pellets, large diatoms or diatom chains, and large aggregates are removed from the screen and added back to the sample. Failure to return these large detrital components to the flux sample will lead to an underestimate of the true flux.

As an alternative (or in addition) to screening, swimmers are picked off filtered trap samples or directly from trap solution under a binocular microscope. The latter allows dark field illumination to be used, which is particularly useful for seeing cryptic swimmers (Michaels et al., 1990). Picking conditions and time spent on each sample (10's of minutes to several hours) vary widely, however, and the expertise required to identify and remove all swimmers from upper ocean traps can be considerable. Thus some consider picking to be the preferred swimmer removal method since, if done properly, it removes only identifiable swimmer components; however, other investigators prefer screening as it is an operational procedure that requires considerably less time and expertise.

A comparison of swimmer removal methods used at the BATS and HOT stations illustrates the difference in flux measurements at one site made with screening or picking (Table 4). Replicate PIT tubes were deployed at $150 \mathrm{~m}$ at the BATS site for the standard 4 day deployment. Swimmers were removed from one trap using the BATS method by picking from filters under 120x and then 250x magnification. Swimmers were removed from the second PIT trap tube using the HOT protocol of screening through a $350 \mu \mathrm{m}$ mesh (with no picking). The POC flux using picking for swimmer removal method was on average 60\% lower than screening, and the PON flux after picking 30\% lower than after screening (Table 4). That the $\mathrm{C}, \mathrm{N}$ ratio was also different $(\mathrm{C}, \mathrm{N}$ by weight $=5.9$ with picking, 7.8 with screening) indicates swimmer removal method can affect the chemical composition of the material analyzed. It is surprising, however, that the $\mathrm{C}, \mathrm{N}$ ratio of trap samples with presumably less swimmers (picked samples) is lower, since the $\mathrm{C}, \mathrm{N}$ ratio of zooplankton is generally lower than that of detritus (e.g., $\sim 5.0$ for mesozooplankton at BATS and HOT; Landry et al., 2001; Madin et al., 2001) and thus the opposite trend would be expected. While this finding requires further investigation, it does suggest caution in 

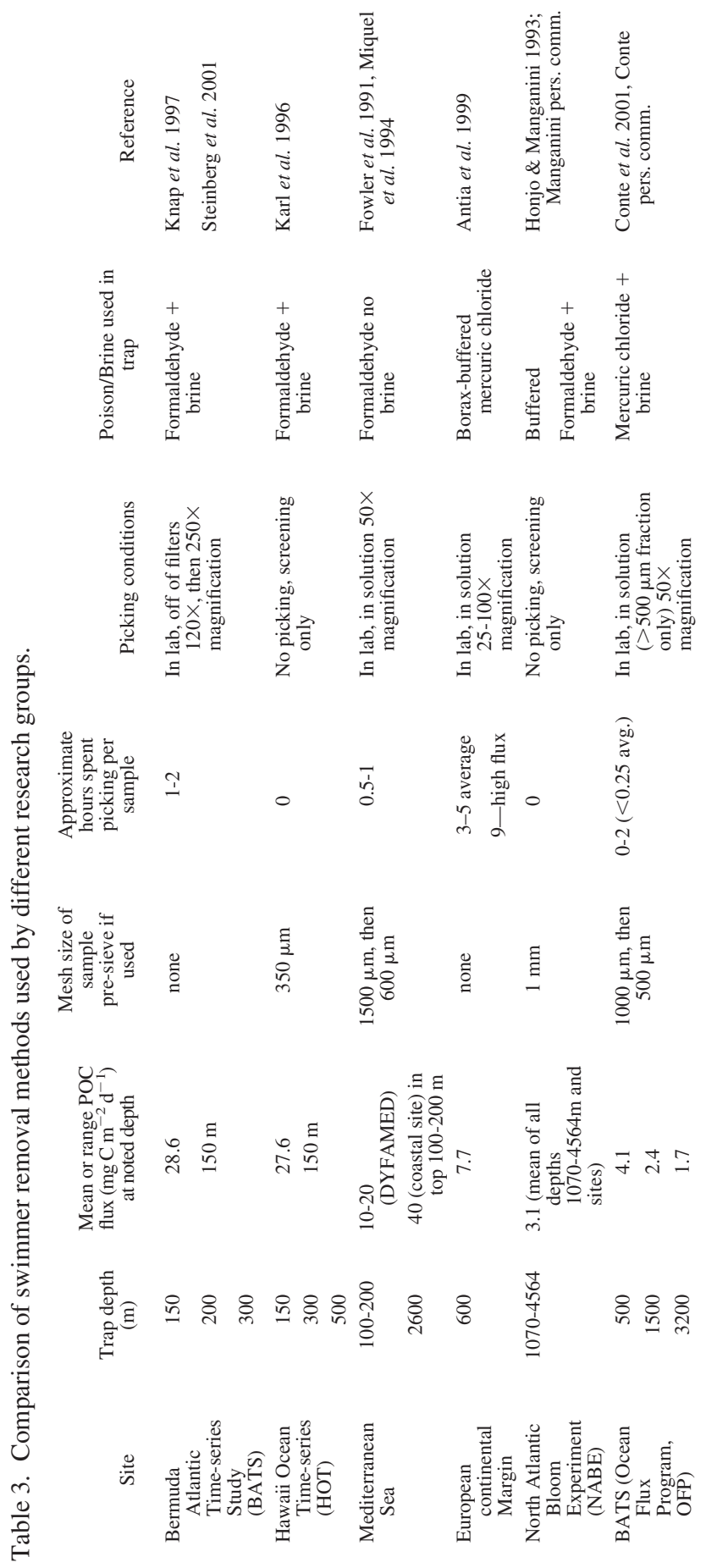
Table 4. Comparison of $150 \mathrm{~m}$ sediment trap fluxes measured on replicate BATS PIT sediment traps using the BATS (picked) vs. HOT (screened) protocols for swimmer removal.

$\begin{array}{ccccc}\begin{array}{c}\text { Date } \\ \text { (month/year) }\end{array} & \begin{array}{c}\text { POC } \\ \left(\mathrm{mg} \mathrm{C} \mathrm{m}^{-2} \mathrm{~d}^{-1}\right)\end{array} & \text { Flux } & \begin{array}{c}\text { PON } \\ \left(\mathrm{m} \mathrm{N} \mathrm{m}^{-2} \mathrm{~d}^{-1}\right)\end{array} & \begin{array}{c}\text { flux } \\ \text { Screened }\end{array} \\ 8 / 92 & \text { Picked } & \text { Screened } & \text { Picked } & 3.9 \\ 5 / 95 & 21.4 & 33.1 & 2.6 & 5.6 \\ 6 / 95 & 27.2 & 48.3 & 5.3 & 4.9 \\ 7 / 95 & 23.1 & 34.5 & 4.3 & 4.2 \\ 8 / 95 & 21.3 & 36.9 & 3.7 & 5.1 \\ 9 / 95 & 21.9 & 35.3 & 4.4 & 5.1 \\ \text { Mean } & 21.4 & 38.5 & 2.6 & \mathbf{4 . 8}\end{array}$

choice of swimmer removal methods, as the method may impact apparent flux estimates using upper ocean traps.

There will be different requirements for swimmer removal depending on the ocean system studied. In general, traps deployed in shallow (within top $200 \mathrm{~m}$ ) or coastal eutrophic environments will collect more swimmers than in deep traps or those collecting in oligotrophic environments. Screening is often used for deep sediment traps (Table 3) as many of the swimmers are large and can be readily removed using screens. Swimmers caught in shallower and in oligotrophic environments tend to be smaller, and traps used there will require picking to remove all the swimmers. In general, thorough documentation on trap sample composition, more standardized swimmer removal protocols, and continued development of swimmer avoidance traps are important aspects that need to be considered in order to improve our estimates of in situ particle flux (see Section 6).

\section{Solubilization}

\section{a. The solubilization issue}

As pointed out in previous sections of this review, hydrodynamic effects and swimmers potentially bias the collection of sinking particles due to processes taking place around and within the trap. Also, once particles are collected in the sample collection cups (at the bottom of conical traps) or tubes (in the case of cylindrical traps), they may be further modified in ways that affect the measurement of elemental concentrations and thus the apparent sinking flux. The term "solubilization" describes the loss of a proportion of elements from the particulate phase to the overlying supernatant. Processes that impact the degree of solubilization from particles include trap depth, particle type, sample age prior to processing, handling effects and poison/preservative used. To the extent that the element in question undergoes solubilization, and to the extent that the degree of loss differs between 
elements, not accounting for this process can underestimate both the absolute level of flux as well as the elemental stoichiometry of export.

Solubilization in traps has always been of concern (Gardner et al., 1983; Knauer et al., 1984), but a systematic study of its effect on measurements of the major elements in traps has only recently been undertaken (Antia, 2005). However, even when poisons and preservatives were used as a way to minimize changes in particles during long trap deployments and storage periods (Lee et al., 1992), a number of observations continued to suggest that some form of solubilization was taking place after sample collection. The most direct evidence for solubilization has been the observation of an increase in the concentration of dissolved elements in the supernatant overlying the trap particulate samples. This increase in dissolved elements, henceforth called the "excess elemental concentration" is measured against a sample of the solution used to fill the trap collection cups/tubes at deployment (i.e. generally this is filtered or artificial seawater with added poison, preservatives, and/or buffers). In deep-water moorings (where swimmer abundances are low and passively sinking particles account for the bulk of material collected in the trap cup), this excess elemental concentration is assumed to have originated from the sinking particle pool and can be used to correct for total flux (summarized in Antia, 2005). The cause of the excess elemental concentration (e.g. leaching of pore fluids or particle degradation) is essentially irrelevant to the correction, since in either case the elements are associated with sinking particles and will be missed by not measuring the soluble pools.

A complicating factor in upper ocean sediment traps is that zooplankton swimmers often dominate mass in the collection cups, equaling or exceeding the passive flux (Section 3; Table 1). Since excretion, defecation, herniation and/or leaching of swimmer body mass into the trap supernatant can be the dominant contributions to dissolved elements in the supernatant, the excess elemental concentration cannot be ascribed to solubilization of sinking particles alone. In addition, the ratio of particles to supernatant is low in traps with a small diameter and short deployment periods typical of upper ocean studies, as compared to large area conical traps used for longer time-series deployments in the deep ocean. Additionally, deployment of open trap tubes, where mixing during deployment and recovery can take place, would alter supernatant concentrations within the tubes. Thus while shallow traps collect particles that are expected to be more labile, with potential for greater or more rapid solubilization, it is much more difficult to assess solubilization with the open tube designs used to minimize hydrodynamic biases in the upper ocean. Hence in this section we also examine evidence from deep traps where the impact of solubilization on fluxes has been better documented.

\section{b. Progress in understanding solubilization}

Excess elemental concentration attributed to solubilization in traps has been reported for individual elements in a number of studies, namely for carbon and nitrogen (Gardner et al., 1983; Hansell and Newton, 1994; Honjo et al., 1995; Noji et al., 1999; Kähler and Bauerfeind, 2001) amino acids (Lee and Cronin, 1984; Lee et al., 1992), fatty acids 
(Kortzinger et al., 1994), phosphorus (Knauer et al., 1984; von Bodungen et al., 1991; O'Neill et al., 2005), dissolved inorganic nitrogen (primarily ammonium; Knauer et al., 1990; von Bodungen et al., 1991), silicate (von Bodungen et al., 1991; Bauerfeind et al., 1997; Antia et al., 1999) and trace metals (Knauer et al., 1984; Pohl et al., 2004).

The excess elemental concentration in traps can be ascribed to at least four main processes. First, marine aggregates have pore fluids that are generally enriched with dissolved organic and inorganic nutrients over surrounding seawater (factors of $>1$ up to several hundred; Simon et al., 2002; Brzezinski et al., 1997; Alldredge, 2000). After sedimentation in the trap cups, diffusion causes a net loss of dissolved elements from the aggregates. The emphasis on using traps to measure "particle flux" has meant that this particle associated "dissolved flux" is commonly neglected, though its importance as an elemental pool is recognized (Alldredge, 2000). The time scales of passive leaching of interstitial fluids in sediment traps are poorly known, and depend on the element in question and its affinity to particles. This attention to time scales is important, as the impact of dissolved pore fluids as a vector for sinking flux will be determined by the balance between in situ particle degradation rates and sinking speed (i.e. time required to build up pore fluids carried into traps on particles) and diffusion and exchange rates in the trap (i.e. loss rates to supernatant post collection).

Secondly, free bacterial exoenzymes may continue to produce dissolved material within the sample. The extent to which this takes place is unclear, and depends on the type and concentration of poison or preservative added to the traps. In unpoisoned traps, enzymatic activity will continue to both degrade particles and modify the dissolved and colloidal compounds. Measurements of the hydrolization of particulate amino acids in surface marine snow indicate rapid turnover times ranging from 0.2 to 2.1 days (Smith et al., 1992), pointing to the need to poison the traps and a preference for rapid sample processing.

The third source of excess elemental concentrations in trap supernatants are zooplankton swimmers. Zooplankton may herniate (if brines are used), defecate, and leach dissolved organic and inorganic compounds into the trap cups (see Section 3), and either swim out (of unpoisoned traps) or die in the samples where their carcasses may leach an array of particle-reactive metals and organic molecules into the sample. While defecation by swimmers is quite rapid, the time scales of solubilization releases from dead swimmers can vary from hours to days. Reinfelder et al. (1993) found solubilization of metals associated with zooplankton carcasses took between 1 and 10 days (half-retention times) in unpoisoned samples, whereas Noji et al. (1999) found rapid release of DOC from zooplankton within 2 days, but ceasing after 10 days. Interestingly, in the latter study the addition of mercuric chloride to the samples did not alter DOC release rates compared to unpoisoned samples.

The extent of swimmer contributions to excess elemental concentrations in supernatant varies greatly. In one study from the European continental margin, time-integrated swimmer carbon was ca. $10 \%$ of the passive carbon flux; if swimmers egested/leached ca. 
$20 \%$ of their body carbon into the traps, the effect would add a maximum of $2 \%$ to the carbon flux estimate (Antia, 2005). In other studies, the extent of swimmer contributions to POC flux and hence excess DOC can be $>5$ times higher, even in mid/deep water traps (Table 1).

Fourth, physical-chemical processes, such as dissolution of biominerals, disassembly of organic membranes and disassociation of dead cells by physical processes can also release dissolved molecules into solution, possibly enhanced by sample handling, higher temperatures and physical disruption during transport. Some investigators believe that these are the main processes by which solubilization within trap samples takes place (for example, for phosphorus (O'Neill et al., 2005)). The use of buffers is advised to control shifts in $\mathrm{pH}$ which impact chemical dissolution; however, it is not clear how buffers will impact gradients in $\mathrm{pE}$ and $\mathrm{pH}$ within aggregates.

Our focus is on trapping characteristics in the upper ocean, but since there are few data to assess solubilization in shallow traps, we also examine here data from deep trap deployments to make a better assessment of the potential magnitude of solubilization (Fig. 4.1; expanded from data summarized in Antia, 2005). These studies, involving deep, conical time-series traps, include longer term deployments (several months to one year) where solubilization effects might be expected to be greater and hence easier to quantify. The trend in the excess elemental concentrations for these deep trap results is for decreasing or constant solubilization losses with depth (with the exception of DOC from the Greenland Sea- ID \#13 in Fig. 4.1) with significant variability in magnitude between sites (for example, $<10$ to $>50 \%$ for $\mathrm{Si}$ ).

Based upon these data from deep water traps shown in Figure 4.1, and data compiled from the literature, Antia (2005) concluded that, (i) the degree of loss to the dissolved phase as a proportion of total particle flux decreases with increasing trap depth with a single exception; (ii) at the base of the winter mixed layer, $70-90 \%$ of total phosphorus, ca. $47 \%$ of total nitrogen, $35-60 \%$ of total particulate silica, $30 \%$ of total organic carbon, and $7-10 \%$ of total calcium were found as excess elemental concentrations in the cup supernatants; (iii) strongly particle-reactive elements such as iron show negligible excess elemental concentrations in cup supernatant (evidence from Pohl et al., 2004); (iv) accounting for solubilization changes the estimation of the stoichiometric ratios of elements $(\mathrm{C}, \mathrm{N}, \mathrm{P})$ in sinking particles; and $(\mathrm{v})$ correcting for selective losses of organic and inorganic carbon alters the $\mathrm{C}_{\text {org }} / \mathrm{C}_{\text {inorg }}$ rain ratio (a key variable in net atmospheric $\mathrm{CO}_{2}$ sequestration by the biological pump) by a factor of about four. These conclusions are site specific, and no single correction factor can be inferred due to variability in the extent of solubilization, even among these deeper long term deployments.

A quite different environment was recently studied for solubilization of phosphorus in traps that were deployed in the suboxic $(275 \mathrm{~m})$ and anoxic $(455 \mathrm{~m}, 930 \mathrm{~m}$ and $1255 \mathrm{~m}$ ) waters of the Cariaco Basin (ID \#18 in Fig. 4.1; O'Neill et al., 2005). Excess supernatant concentrations were measured in formalin-preserved traps that were deployed for periods of about 6 months. In this study only $30 \%$ of total phosphorus was found in the trap 


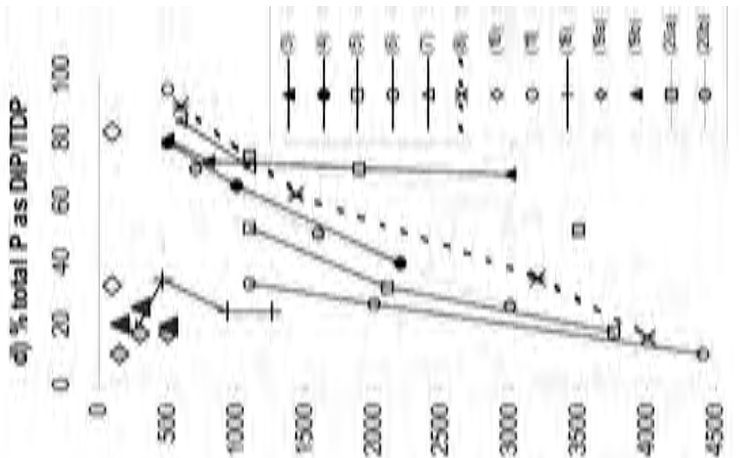

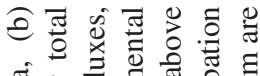

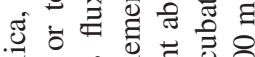
ज.

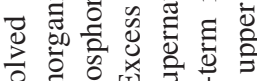
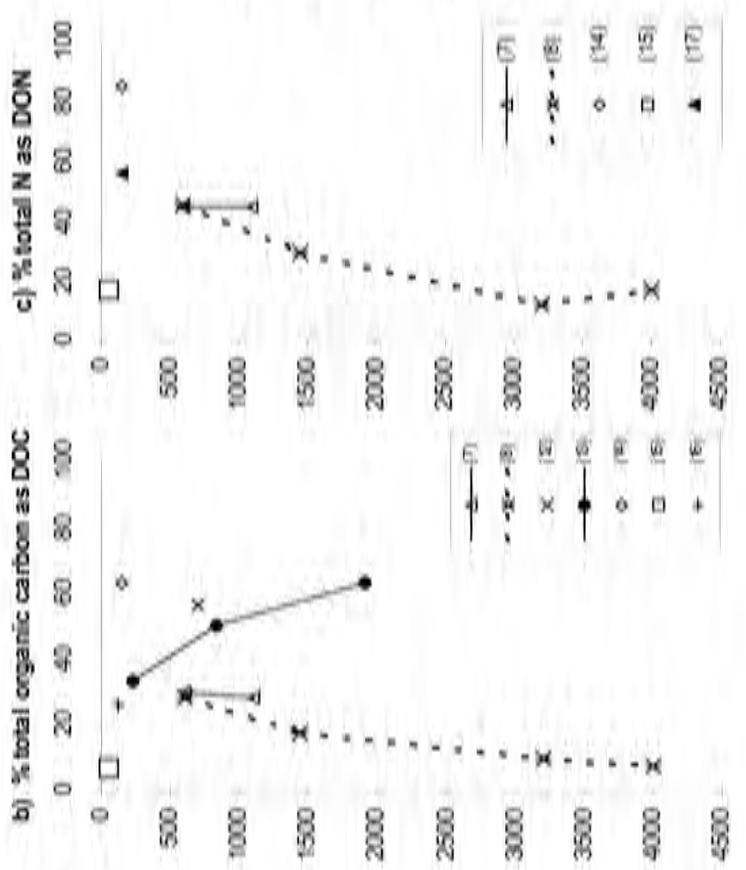

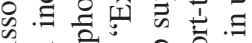
ป

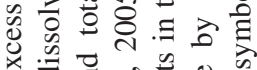

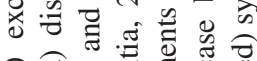

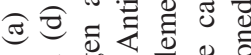
Ч ป ป

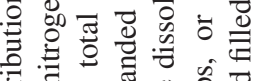

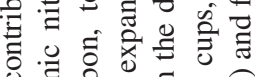

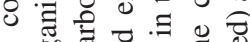
Ð $\Xi$ 己 凹

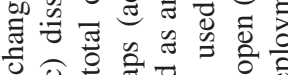

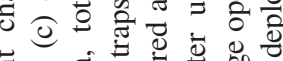

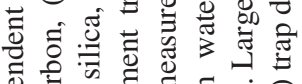

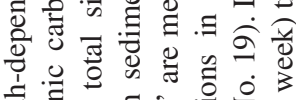
䒕芯。.

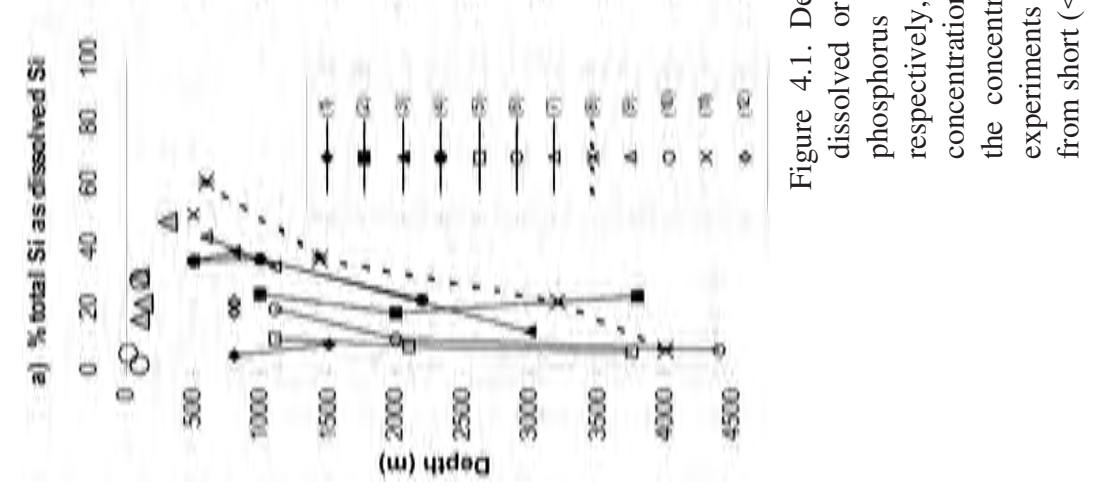

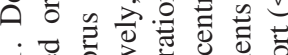


supernatant, with inorganic phosphorus being the primary dissolved species as has been previously reported in other studies (von Bodungen et al., 1991; Antia, 2005). The extent of solubilization did not decrease in the deeper traps where swimmers were absent due to the anoxia of the surrounding water.

Traps shallower than $500 \mathrm{~m}$ also show a large range in the extent of solubilization (Fig. 4.1). However, comparisons are complicated in part due to the varying conditions of each study (poisoned/unpoisoned traps, deployment intervals ranging from 1 to 8 days), wider differences in sample processing (immediate or delayed sample splitting), and the fact that swimmer contributions of dissolved substances to the supernatant may be quite variable. For example variability in $\mathrm{P}$ released ranges from $<10 \%$ to $>80 \%$ in the three studies summarized in Figure 4.1.d. Some of this variability may be due to the shorter trap deployments used in most shallow trap studies, since variations in the food web, and thus

\section{Key to Figure 4.1 data is as follows,}

\begin{tabular}{|c|c|c|c|c|c|}
\hline No. & Site & Reference & $\begin{array}{l}\text { Moored } \\
\text { (m)/drifting } \\
\text { (d) }\end{array}$ & $\begin{array}{l}\text { Deployment } \\
\text { period }\end{array}$ & Poison/Fixative \\
\hline 1 & $52 \mathrm{~S} ; 141 \mathrm{E}$ & Bray et al. (2000) & M & $1 \mathrm{yr}$ & Mercuric chloride \\
\hline 2 & $46 \mathrm{~S} ; 142 \mathrm{E}$ & Bray et al. (2000) & M & $1 \mathrm{yr}$ & Mercuric chloride \\
\hline 3 & Norwegian Basin & Bauerfeind et al. (unpublished) & M & $1 \mathrm{yr}$ & Mercuric chloride \\
\hline 4 & E. Greenland Sea & Bauerfeind et al. (unpublished) & M & $1 \mathrm{yr}$ & Mercuric chloride \\
\hline 5 & $48 \mathrm{~N} ; 21 \mathrm{~W}$ & Honjo \& Manganini (1993) & M & $1 \mathrm{yr}$ & Formaldehyde \\
\hline 6 & $34 \mathrm{~N} ; 21 \mathrm{~W}$ & Honjo \& Manganini (1993) & M & $1 \mathrm{yr}$ & Formaldehyde \\
\hline 7 & $\begin{array}{l}\text { European Continental } \\
\text { Margin (OMEX 2) }\end{array}$ & Antia (2005) & M & $1 \mathrm{yr}$ & Mercuric chloride \\
\hline 8 & $\begin{array}{l}\text { European Continental } \\
\text { Margin (OMEX 3) }\end{array}$ & Antia (2005) & M & $1 \mathrm{yr}$ & Mercuric chloride \\
\hline 9 & E. Greenland Sea & Bauerfeind et al. (unpublished) & M & 10 days & Mercuric chloride \\
\hline 10 & E. Greenland Sea & Bauerfeind et al. (unpublished) & $\mathrm{D}$ & 1 day & None \\
\hline 11 & E. Greenland Sea & von Bodungen et al. (1991) & M & $1 \mathrm{yr}$ & Mercuric chloride \\
\hline 12 & unspecified & $\begin{array}{l}\text { Dymond \& Collier in GOFS } \\
(1989)^{1}\end{array}$ & M & unspecified & Sodium azide \\
\hline 13 & E. Greenland Sea & Noji et al. (1999) ${ }^{2}$ & M & $1 \mathrm{yr}$ & Mercuric chloride \\
\hline 14 & E. Greenland Sea & Kähler \& Bauerfeind (2001) ${ }^{2}$ & M & $1 \mathrm{yr}$ & Mercuric chloride \\
\hline 15 & Monterey Bay & Hansell \& Newton (1994) & $\mathrm{D}$ & 1.7 days & None \\
\hline 16 & Baltic Sea & Pohl et al. (2004) & M & $1 \mathrm{yr}$ & Sodium Azide \\
\hline 17 & VERTEX & Knauer et al. (1990) & $\mathrm{D}$ & 2-4 months & $\begin{array}{l}\text { With and without } \\
\text { Formaldehde }\end{array}$ \\
\hline 18 & Cariaco Basin & O`Neill et al. (2005) & M & 6 months & Formaldehyde \\
\hline $19 \mathrm{a}$ & Hawaii & $\begin{array}{l}\text { Lamborg \& Buesseler } \\
\quad \text { (unpublished) }\end{array}$ & $\mathrm{D}$ & 1-3 days & Formaldehyde \\
\hline $19 b$ & Hawaii & $\begin{array}{l}\text { Lamborg \& Buesseler } \\
\quad \text { (unpublished) }\end{array}$ & D & 1-3 days & Mercuric chloride \\
\hline $20 \mathrm{a}$ & Equatorial Pacific & Dymond \& Collier (1988) & M & $1 \mathrm{yr}$ & Sodium Azide \\
\hline $20 \mathrm{~b}$ & Equatorial Pacific & Dymond \& Collier (1988) & M & $1 \mathrm{yr}$ & Sodium Azide \\
\hline
\end{tabular}

${ }^{1}$ Taken as the mean value reported, range $39-68 \%$

${ }^{2}$ In these studies an attempt was made to separate the swimmer contribution from the contribution of sinking particles to excess dissolved organic nutrients in the cups. This was not the case in other studies. 
the geochemical character of sinking particles, is expected. In this regard, deep trap data, when examined on a sample cup by cup basis, also show this same type of variability (in Figure 4.1 data $>500 \mathrm{~m}$ are averages over many cups). For example, solubilization for total fatty acids ranges from 15-75\% in different sample cups during a 14 month trap deployment at $2200 \mathrm{~m}$ (Kortzinger et al., 1994). The cup-to-cup variability is also substantial for other variables, and is higher for dissolved inorganic phosphorus $(<10 \%$ to $>90 \%$ solubilization within a single trap) and dissolved inorganic nitrogen than for DOC and DON or for silicate (here the variability within one trap is less than the difference between traps at different depths; Antia, 2005). From these data we can only conclude that solubility can be significant for some elements, but that there is considerable variability in the few current estimates of the magnitude of solubilization in traps.

Thus far we have been focusing on measurement of excess elemental concentration in moored conical time-series traps with sealed cups and long deployments where there are more data. In the upper ocean, open cylinders are the preferred trap design for hydrodynamic reasons (Section 2). Measured changes in concentration in the brine after deployment can thus be due to mixing with variable seawater end members, swimmers, or solubilization of trap material, and the impacts of each are difficult to separate.

Due to these complications, an alternative approach was undertaken to look at the time-course of leaching of phosphorus from trap-collected particles in a recent experiment off Hawaii (Lamborg et al., 2005; Andrews et al., 2006). Samples were collected using free-drifting cylindrical traps similar to the VERTEX design deployed at depths of 150, 300 and $500 \mathrm{~m}$, for periods of 3, 4, and 5 days, respectively. Within 24 hours of recovery, trap samples were screened to remove swimmers (verified by microscopic examination), wet split and incubated in the original poison/brine solution at in situ temperatures. After 1, 3 and 5 days of incubation, the splits were filtered as per standard protocols and particulate variables measured (Fig. 4.2). Data are normalized to aluminum to correct for any variability in the particle concentrations introduced during processing.

Using this incubation approach, Lamborg et al. (2005) found, for both formalin and mercuric chloride treatments, that total phosphorus shows a consistent decrease over time, with P/Al decreasing by $30 \%$ on average at all depths during the 5 day incubation experiment (Fig. 4.2). There is some variability for a given time course for any given depth, but no apparent difference for the $\mathrm{P}$ decrease between depths or poisons/preservatives. Fitting this decrease in $\mathrm{P}$ as a first order solubilization rate constant, we can apply this as a correction factor to the measured $\mathrm{P}$ flux (note that time of actual deployments differ at different depths, from 3-5 days, so the solubilization correction must be adjusted as a function of deployment time). This correction results in a net increase in the derived total $\mathrm{P}$ flux of 11 to $23 \%$ for these depths and deployment times. For comparison, a parallel experiment with unpoisoned large particles $(>53 \mu \mathrm{m})$ collected via in situ pumping, showed a 400-500\% decrease in P/Al in 5 days under the same conditions as the $150 \mathrm{~m}$ trap (Lamborg et al., 2005). The observed decrease in P flux with depth between the 150 and $500 \mathrm{~m}$ traps was also roughly a factor of 5 (Buesseler et al., 2007). 


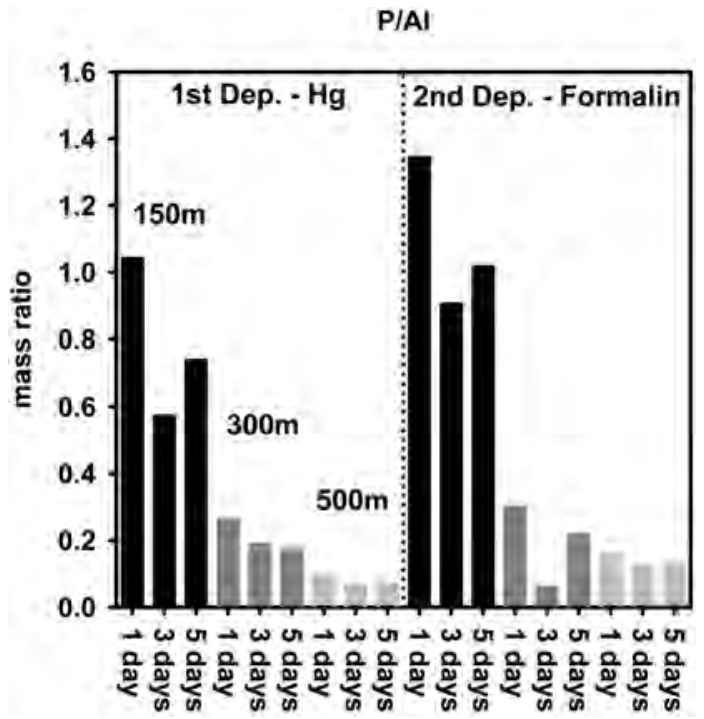

Figure 4.2. Changes over time in particulate elemental $\mathrm{P}, \mathrm{Al}$ concentrations ( $\mathrm{P}$ normalized to aluminum) of material collected from "CLAP" traps during VERTIGO '04 determined by incubation of trap materials in poisoned brine for 1, 3 and 5 days (Lamborg et al., 2005; Andrews et al., 2006). Data are from two deployments at depths of 150, 300, $500 \mathrm{~m}$ with $\mathrm{Hg}$ (left) and formalin (right) poisons. Particles were screened to remove swimmers, split and incubated in the dark at in situ temperatures $\left(15,9,5^{\circ} \mathrm{C}\right.$ respectively).

The conclusion of this study is that, while a P solubilization artifact can be measured by incubation of poisoned trap samples, the solubilization losses are small (an 11-23\% impact on P fluxes) relative to the natural flux gradients and degradation rates of sinking particles (factors of 4-5 for P). For calcium, iron, and other elements, evidence for solubilization on these time scales is even weaker (Lamborg et al., 2005). We can only speculate as to why these incubation experiments suggest a smaller solubilization effect for $\mathrm{P}$ than some of the other studies in Figure 4.1. One difference is that swimmers have been removed prior to incubation. Secondly, and perhaps most importantly, samples were processed quickly at sea relative to the longer moored deployments with post-cruise processing. Since solubilization likely decreases over time, these short-term incubations are maximum estimates of solubilization rates that should not be extrapolated directly to longer deployment periods.

Taken together, all of these studies suggest that for the major nutrients, variable but potentially significant losses from sinking particles may take place, at maximum rates in the first few weeks after collection. In shallow trap deployments, the sample will typically represent a mix of material that is anywhere from $<1$ day to a few days old, so the extent of solubilization in situ or while awaiting processing will depend upon this mean age and the rate of change. 


\section{c. Approaches to minimize or correct for solubilization}

Recognizing that solubilization can impact accurate measurement of sinking particle fluxes, the question arises as to how to deal with this, either through avoidance of and/or correction for this effect. As discussed previously, two approaches may be used. The first is to measure and correct for solubilization by analyzing excess elemental concentrations in the trap supernatant. This approach can be used in mid-water and deep traps where swimmer numbers are low compared to the passive flux. Here, cups must be poisoned, effectively sealed to the outside to prevent exchange of supernatant, and the time between sample collection in situ and analysis should ideally exceed 2-3 months, the best estimate for the time after which exchange with any dissolved pore fluids is largely complete or at least in steady state (Antia, unpublished data). Most moored time-series traps meet these criteria. Results of routine measurements in the overlying supernatant of all elements that are to be measured, can be added to the particulate fraction to estimate the total elemental flux. The choice of poison/preservative and use of brine will play an important role in the ability to make certain dissolved analyses. Formaldehyde, for example, a widespread fixative used in traps, precludes organic carbon and nitrogen measurements. In this approach swimmers are effectively ignored, though carbon and nitrogen analyses of the picked swimmers should ideally be done in order to estimate their maximal influence in the cup.

A different approach is necessary in most shallow traps, when open tubes are used and the ratio of swimmer biomass to sinking detrital flux is very high. The use of effective swimmer deterrents such as the IRS trap (Section 3c) can dramatically reduce swimmer numbers but complete swimmer avoidance is unlikely especially in oligotrophic, highzooplankton environments and where zooplankton are intimately associated with sinking particles (see Section 3). Currently, there is no effective way of determining whether excess elemental concentrations are swimmer-derived or particle-derived, though the use of zooplankton-specific lipids or fatty acids may potentially provide one means of doing this. For shallow traps, short deployment times (1-3 days) and immediate processing of samples upon recovery will minimize solubilization from particles. Incubation experiments allow one to at least determine the extent of possible solubilization for different elements, though few studies of this nature have been reported.

In practice, there is no standardized method for correcting for solubilization and it is most often ignored in upper ocean flux studies. In deeper traps, dissolution of silica has, almost without comment, been corrected for in a number of studies (Honjo and Manganini, 1993; Bauerfeind et al., 1997; Antia et al., 1999). In contrast, an assessment of the effect of solubilization on the ratios of major elements has been undertaken for a single site only (Antia, 2005).

Finally, it should be noted that the same caveats apply to filtration of trap particles as in other marine particle studies, namely that high filtration pressure should be avoided as loss of internal fluids needs to be minimized. Since filtration alone may cause loss of internal fluids and squeezing of non-rigid particles through filter pores, more controlled studies 
which examine filtration artifacts and losses to the filtrate during processing are needed. Filtration artifacts would impact particle concentrations and, if losses occur, would lead directly to an underestimation of total elemental fluxes. Thus it is a potential artifact that has a different cause, but similar bias, as solubilization effects would have (i.e. an underestimate of flux)on accurately quantifying particle fluxes.

\section{Field-based assessments of sediment trap collection efficiency}

\section{a. Independent assessments of sediment trap collection efficiency}

In the previous sections we have detailed how processes such as hydrodynamics, swimmers, and solubilization may affect how accurately material caught in a sediment trap represents true gravitational flux. Given this potential for inaccurate collection, independent approaches have been sought to evaluate the collection efficiency of sediment traps in the field. There are two main classes of evaluation methods, those based upon mass balances of stable elements or particle distributions, and those employing comparisons using naturally occurring particle-reactive radionuclides. In each case, it is important to examine to what extent, (i) the independent method is tracking gravitational settling alone (vs. some combination of settling and water mixing); (ii) the collection efficiency factor is appropriate for other elements, potentially being carried by different classes of sinking particles; and (iii) the trap and independent flux estimate are measuring particle export over similar space and time scales.

\section{b. Comparisons between trap flux, particle distributions and the mass balance of major} bioactive elements

Given that many studies are concerned with the fluxes of biogeochemically active elements ( $\mathrm{C}$ and major/minor nutrients), sediment trap fluxes have often been compared to the upper ocean budgets of these same elements. These approaches can broadly be grouped into two classes, namely studies that compare the flux of element $\mathrm{X}$ to a time-series mass balance of $\mathrm{X}$ during the course of a given season or annual cycle or, less commonly, studies that use inverse methods to derive an independent particle flux estimate that is consistent with the observed vertical and horizontal gradients of $\mathrm{X}$ in the ocean and an assumed or similarly calculated transport model. Both of these methods rely on knowledge of the distribution of $\mathrm{X}$ in the sum of the dissolved and particulate pools, and particle export is derived by what are often small differences in the total stocks of the element over time and space. In principle, a more direct approach for estimating particle-settling flux would be through the combination of knowing the particle concentration field along with estimates of particle settling velocities.

i. Suspended particle field and estimates of particle settling. Estimates of particle flux from measurement of the suspended particle field and assumed settling velocity function have been attempted (Bishop et al., 1978; Jackson et al., 2005) and this approach is 
commonly applied in coupled models of aggregation and sedimentation (Farley and Morel, 1986; Jackson, 1990; Hill, 1992; Jackson and Burd, 1998). There has been progress over the past decade in our ability to describe particle dynamics in models, including demonstration of qualitatively similar trends in modeled and trap-observed bulk particle flux (e.g. Jackson and Burd, 1998). However, application of Stoke's law to empirical or modeled estimates of the suspended particle field does not seem a viable method for independently checking the quantitative accuracy of particle fluxes obtained from sediment traps. This is due to uncertainties in both measuring particle abundances and a lack of knowledge of in situ sinking rates for all particle classes in the oceans.

Alternatively, some sampling techniques have been developed to directly assess sinking rates, thus eliminating the need to apply a theoretical model of aggregation and settling behavior. For example, SPLITT (split flow thin-cell fractionation) methods separate particles based on their settling properties in a laminar flow (e.g., Gustafsson et al., 2000) and thus strive to measure directly the desired functionality of the particles (i.e. settling flux). Results from SPLITT in surface waters have demonstrated varying particle composition (e.g. Si/Al, POC/Al, POC/ ${ }^{234} \mathrm{Th}$ ) across evaluated settling velocity spectra ( $<1$ to $>10$ $\mathrm{m} \mathrm{d}^{-1}$; Gustafsson et al., 2000, 2006).

A modified IRS trap has recently been developed that separates particles based upon sinking rate much like a settling column, but under in situ conditions (as described in Section 2d; Cochran et al., 2004). However, as a trap, the device itself is subject to the same hydrodynamic and other biases as regular traps; thus, it is not an independent calibration method per se, but can assist in quantifying the sinking rates of natural particles in the ocean.

Attempts have been made to collect water samples in situ and measure settling rates of particle classes using optical methods (Bartz et al., 1985; Agrawal and Pottsmith, 2000; Fugate and Friedrichs, 2002; Waite et al., 2005). The greatest challenge is to collect a representative sample of the entire particle spectrum, especially the rarer rapidly settling particles that carry most of the flux (McCave, 1975). Sampling these rare particles was one rationale for developing large volume in situ pumps and sediment traps.

ii. Estimates of particle settling from major bioactive elements. Integrated over appropriate time scales, there are several metrics of the upper ocean carbon cycle that may be employed for comparison to fluxes obtained with shallow water sediment traps. First, rates of primary production provide upper limits to compare with sediment trap records of carbon flux. The seasonal variations in the ratio of trap flux to primary production (the e-ratio; Eppley, 1989) can be used in concert with other measures of the upper ocean biogeochemistry and plankton ecology to infer how well the traps are reflecting the true gravitational flux. These two sets of observations must be integrated over seasonal to annual time scales as there is frequently a time offset between production and export. Furthermore, estimates of primary production have their own sources of uncertainty, including bottle effects. Ultimately, comparisons between primary production and export 
are of limited use for trap calibration, since the true e-ratio must lie between 0 and 1 , and only ratios $>1$ would be cause for rejecting outright a trap flux measurement.

Another approach to test the validity of upper ocean sediment trap carbon fluxes is to follow the changing inventories of both inorganic and organic carbon forms and account for the exchange of atmospheric $\mathrm{CO}_{2}$, diffusive export of DOC, and export via migrating zooplankton. The flux of POC measured by PITs at BATS is too low by a factor of three to close the upper ocean carbon balance (Michaels et al., 1994a). This suggests either a low trapping efficiency, or the importance of horizontal processes in removing $\mathrm{C}$ which were not considered in the 1-D seasonal mass balance for $\mathrm{C}$ at this site.

At the HOT program in the North Pacific subtropical gyre, decadal records of upper ocean particulate carbon export based on sediment traps (Karl et al., 1996; Christian et al., 1997) are a factor of two lower than estimates of total carbon export based on upper ocean carbon and oxygen mass balances (Emerson et al., 1997; Sonnerup et al., 1999). At this site, the offset has been suggested to stem from the formation and export of DOC, rather than sediment traps having missed a component of the sinking particulate carbon flux (Emerson et al., 1997; Church et al., 2002).

The upper ocean nitrogen budget provides yet another possibility to compare with trap-derived export fluxes as new production should balance settling particulate organic nitrogen and DON export (and by Redfield-conversion also carbon) over "appropriate space and time scales" (Eppley and Peterson, 1979). However, estimates of annual new production are uncertain due to several factors, including the brevity of ${ }^{15} \mathrm{NO}_{3}{ }^{-}$incubations (generally 12 hours) and the difficulty of quantifying the contribution of nitrogen fixation (e.g. Capone and Carpenter, 1982; Larsson et al., 2001; Dore et al., 2002; Hansell et al., 2004).

In general, any approach using upper ocean elemental budgets to obtain independent estimates of particle export faces considerable uncertainty. In addition to issues discussed above, there is significant debate over the parameterization of physical exchange across both the air-water interface (for $\mathrm{O}_{2}$ or $\mathrm{CO}_{2}$ budgets) and across the pycnocline (for all of these $\mathrm{C}, \mathrm{O}$ and $\mathrm{N}$ budgets). Further uncertainty is introduced in the conversion of the $\mathrm{O}$ and $\mathrm{N}$ fluxes to $\mathrm{C}$ fluxes, as the element ratios in settling particles may deviate significantly from canonical Redfield ratios (Goldman, 1988; Sambrotto et al., 1993).

iii. Inverse modeling. Inverse modeling offers a promising new approach for independently estimating ocean particle fluxes. However, it must be stated upfront that any flux derived from this approach is a long term average and may not be applicable for calibration of any particular set of trap data (discussed further below). However, the general particle flux patterns derived from this method are informative and provide a check on the measured fluxes that can prove illuminating.

The technique to use inverse modeling to obtain the best fit between an ocean circulation model including particulate fluxes and available hydrographic data was developed by Schlitzer (1993) and Matear and Holloway (1995). Schlitzer (2000) presented a global 
adjoint model including particulate fluxes of organic carbon, calcite, and biogenic Si. In his model, export production rates and mineralization rates are optimized together with the physical current field to reproduce temperature, salinity, and nutrient measurements in the world ocean. Resulting fields of particle flux have been published by Schlitzer (2000), Schlitzer et al. (2004), and Usbeck (1999). In general, the optimized export production rates resemble the pattern of observed primary production with highest particle exports in coastal, equatorial and frontal upwelling regions.

As the divergence of the horizontal field in the adjoint model leads to vertical transport, small current differences can have large effects (Matear and Holloway, 1995). If the physical current field were first optimized and then applied to interpret the nutrient field, this could create erratic particle fluxes. This problem is much reduced when the chemical reaction rates are optimized along with the physical current field (Usbeck, 1999; Schlitzer, 2000).

There are large differences between the predicted particle fluxes, as obtained from the adjoint model, and fluxes measured by sediment traps (Usbeck, 1999; Schlitzer et al., 2004). Usbeck assimilated the sediment trap data into the adjoint model to find the best fit to both the nutrient distribution and the flux data (Usbeck, 1999; Usbeck et al., 2003), and concluded that model fluxes are systematically higher than trap fluxes. When allowed by the horizontal resolution and coherence of particle behavior, the model would tend to fit the trap data only very locally and would produce higher fluxes at larger distances. When the sediment trap constraint was removed, the model fluxes relaxed rapidly to higher values. This general result of higher predicted vs. measured flux is consistent with estimates of low upper ocean trap collection efficiency based upon comparison of ${ }^{234} \mathrm{Th}$ water column deficiencies and trap fluxes (see Section 5c.i).

It should be noted that a comparison of model fluxes and observed fluxes at individual stations can have very erratic results. This has two causes, the grid resolution of the model is just 200-500 km and the concentration field used in the adjoint modeling is an average, including datasets that may have been collected any time of the year over a period of many decades. In contrast, trap deployments give point values in space and typically for periods as short as a few days to seasonal, or at best several years. In general, flux estimates of the adjoint method are better constrained in the surface ocean where there are larger vertical gradients in nutrient concentrations and currents than in the deep ocean. In the deep ocean, the ${ }^{230} \mathrm{Th}$ calibration gives better constraints on the trap collection efficiency (see Section 5c.iii).

\section{c. Estimates of particle settling fluxes using radionuclide disequilibria}

Several studies have demonstrated that the distributions and fluxes of the particle reactive radionuclides are strongly dependent on the rates of particle production, transformation and subsequent sedimentation (e.g. Coale and Bruland, 1987). The particle reactive radionuclides of the U-Th decay series serve as valuable tracers for studying the rates of particle-associated chemical scavenging processes. These tracers are introduced in the 
water column as dissolved species from radioactive decay of their parent nuclides dissolved in seawater, and are redistributed among the dissolved and particulate phases depending on their affinity toward particle surface ligands and availability of such surfaces. The number and types of surfaces depend on the rates of primary production, particle transformation and net downward flux. It is thus possible to use the rates of radionuclide production (from dissolved parent) and decay, along with precise measurement of their activity in the ocean, to estimate particle export fluxes for a given radionuclide. These calculated radionuclide fluxes may be directly compared to radionuclide fluxes measured in the traps.

i. In situ assessment of sediment trap collection efficiency using ${ }^{234} \mathrm{Th}$. The ${ }^{234} \mathrm{Th}$ proxy offers a possibility to test the in situ collection efficiency of upper ocean sediment traps and has been broadly recommended (e.g., GOFS, 1989; Buesseler, 1991; Gardner, 2000). The tetravalent cation and thus particle-sorptive ${ }^{234} \mathrm{Th}\left(\tau_{1 / 2}=24.1 \mathrm{~d}\right)$ is produced at a constant rate from its seawater-conservative parent ${ }^{238} \mathrm{U}$ and is thus suitable for tracing upper ocean particle processes on timescales from less than a week to one month or more. In essence, the ${ }^{238} \mathrm{U}^{234} \mathrm{Th}$ radioactive disequilibrium in the surface ocean is a reflection of the ${ }^{234} \mathrm{Th}$ flux on settling particles to strata below. Comparing this estimate of ${ }^{234} \mathrm{Th}$ flux from the surface ocean with the flux of ${ }^{234} \mathrm{Th}$ that is collected by a sediment trap positioned just below the chosen depth, provides an estimate of the in situ collection efficiency of the sediment trap with respect to ${ }^{234} \mathrm{Th}$ bearing particles (Buesseler, 1991). Mathematically this can be expressed as,

$$
E f f_{\text {trap }}=\frac{F_{\text {Th,trap }}}{F_{\text {Th,mix }}}=\frac{\left\{{ }^{234} T h\right\} /\left(A_{\text {trap }} \cdot t\right)}{\lambda \cdot z_{\text {mix }} \cdot\left(\left[{ }^{238} U_{\text {tot }}\right]-\left[{ }^{234} T h_{\text {tot }}\right]\right)}
$$

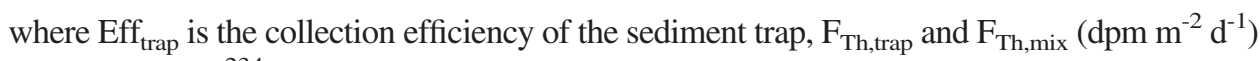
are the flux of ${ }^{234} \mathrm{Th}$ activity collected in the sediment trap and estimated to have been exported from the mixed surface layer, respectively, $\left\{{ }^{234} \mathrm{Th}\right\}$ is the activity (dpm) of ${ }^{234} \mathrm{Th}$ in the trapped material decay-corrected to the mid-point of the deployment period, $\mathrm{A}_{\text {trap }}$ $\left(\mathrm{m}^{2}\right)$ is the surface area of the trap mouth, $\mathrm{t}(\mathrm{d})$ is the deployment time, $\lambda$ is the ${ }^{234} \mathrm{Th}$ radioactive decay constant $\left(0.0288 \mathrm{~d}^{-1}\right), \mathrm{z}_{\text {mix }}$ is the sub-photic-zone/mixed-layer trap deployment depth $(\mathrm{m}),\left[{ }^{238} \mathrm{U}_{\text {tot }}\right]$ and $\left[{ }^{234} \mathrm{Th}_{\mathrm{tot}}\right]\left(\mathrm{dpm} \mathrm{m} \mathrm{m}^{-3}\right)$ are the total radioactivity concentrations in the overlying water of ${ }^{238} \mathrm{U}$ and ${ }^{234} \mathrm{Th}$, respectively.

In some specific regimes, we need to consider non-steady state (e.g. Buesseler et al., 1992) and other advection/dispersion processes (e.g. Gustafsson et al., 1998; BenitezNelson et al., 2000; Gustafsson et al., 2004) to correctly estimate the ${ }^{234} \mathrm{Th}$ export flux $\left(\mathrm{F}_{\mathrm{Th}, \mathrm{z}}\right)$ from the water column activity balance. Further details on the ${ }^{234} \mathrm{Th}$ flux models can be found in a recent summary by Savoye et al. (2006) .

One additional attribute of ${ }^{234} \mathrm{Th}$ as a trap efficiency testing tool, is that its flux in traps is not significantly impacted by swimmers (Section 3), since swimmers normally have a much lower ${ }^{234} \mathrm{Th}$ content compared to detritus caught in sediment traps. For example, 
swimmers are reported to make up 12\% (Coale, 1990), 5-25\% (Buesseler et al., 1994), and 1.5 - 8\% (Murray et al., 1996) of total ${ }^{234}$ Th flux in shallow traps.

We focus here on the comparison between the ${ }^{234} \mathrm{Th}$ flux measured in traps and the flux calculated from its water column distribution. We stress that the application of total ${ }^{234} \mathrm{Th}$ activities for this comparison (Eq. 2) does not require knowledge of the relationship between $\mathrm{Th}$ and other elements. Issues that are debated regarding variations in the $\mathrm{POC} /{ }^{234} \mathrm{Th}$ ratio that are significant to the use of ${ }^{234} \mathrm{Th}$ to derive upper ocean POC export without traps (Buesseler et al., 2006), are not relevant when comparing predicted vs. measured Th fluxes (see below on the application of ${ }^{234} \mathrm{Th}$ trap collection efficiencies to other elements). A difference between the water column derived and trap ${ }^{234} \mathrm{Th}$ fluxes in equation 2 allows us to conclude that either, a) the traps are over-collecting ${ }^{234} \mathrm{Th}$ (i.e., $\mathrm{EFF}_{\text {trap }}>1$ ) or under-collecting ${ }^{234} \mathrm{Th}$ (i.e., $\mathrm{EFF}_{\text {trap }}<1$ ) due to a sampling bias; or b) the calculated ${ }^{234} \mathrm{Th}$ flux is not appropriate for comparison to an individual trap flux. The latter situation could result from improper assumption of steady-state conditions or the lack of inclusion of physical transport in the ${ }^{234}$ Th flux model (e.g., Savoye et al., 2006). Likewise, the ${ }^{234} \mathrm{Th}$ activity in the water column at sampling reflects particle scavenging that has taken place in the days to weeks prior to sampling. If, as is common, a single ${ }^{234} \mathrm{Th}$ profile is collected and compared to a short-term trap deployed at the same time, then there may be a mismatch of space/time scales of integration. In essence, the trap flux of a given day may be higher/lower than the flux prior to arrival at site, which is reflected in the ${ }^{234} \mathrm{Th},{ }^{238} \mathrm{U}$ ratio in the water column at the start of a given trap deployment. Therefore, both estimates of flux could differ and each still be correct.

The ${ }^{234}$ Th trap studies up to year 1990 that were summarized in Buesseler (1991) showed differences between the trap-derived and model-derived ${ }^{234} \mathrm{Th}$ fluxes as large as a factor of $3-10$. Despite the strongly articulated recommendation of the JGOFS program to perform these types of in situ trap calibrations (GOFS, 1989; Gardner, 2000), there have been relatively few ${ }^{234} \mathrm{Th}$ trap comparison studies since that time period. As with the datasets collated by Buesseler (1991), most of the newer ${ }^{234}$ Th-based sediment trap tests involve a few coupled observations, covering a time period less than the characteristic lifetime of ${ }^{234} \mathrm{Th}$ (Buesseler et al., 1994; Murray et al., 1996; Coppola et al., 2002; Hung et al., 2004).

Buesseler et al. (1994) attempted to address the potential for temporal mismatch between predicted and measured trap fluxes by conducting a time-series 3-D sampling grid for ${ }^{234} \mathrm{Th}$ around two separate drifting PIT arrays near the BATS station, thus following spatial and temporal activity changes that corresponded directly with the 4-day deployment period of the PITs. The conclusion in this case was that the trap over-collected ${ }^{234} \mathrm{Th}$ during what was predicted to be a low flux period, and that this over-collection could not be ascribed to lateral advection or time changes of the ${ }^{234} \mathrm{Th}$ inventory. Under certain circumstances, such as in studies inside cold-core or warm-core rings (i.e., eddies), ${ }^{234} \mathrm{Th}$ trap comparisons may yield useful information from shorter campaigns (e.g., Hung et al., 2004). However, a prerequisite is not only to perform a Lagrangian study in an isolated 


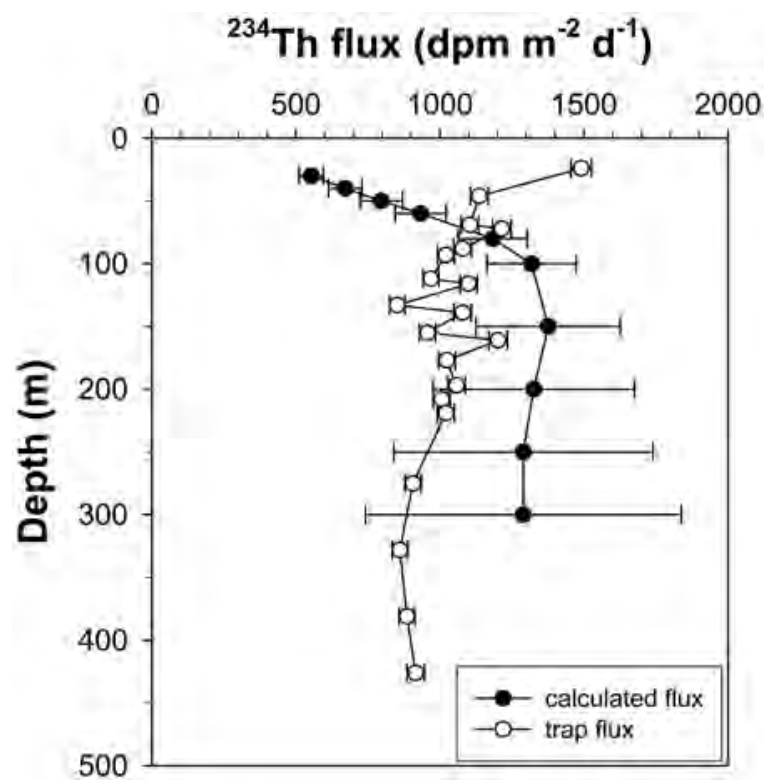

Figure 5.1. An example of fluxes calculated from water column ${ }^{234} \mathrm{Th}$ data in comparison to ${ }^{234} \mathrm{Th}$ fluxes measured by using free-drifting cylindrical traps on a single surface-tethered array in the subarctic Western Pacific during spring (May) 1998 (K. Harada, unpublished data). The traps slightly under-collect ${ }^{234} \mathrm{Th}$ in comparison to calculated fluxes, except just below the upper mixed layer ( $\sim 25 \mathrm{~m}$ deep during the experiment) where over-collection occurred. Error bars for the trap flux are from counting errors in the ${ }^{234} \mathrm{Th}$ analyses, whereas error bars for the calculated flux are derived from the error on the difference between total ${ }^{238} \mathrm{U}$ and ${ }^{234} \mathrm{Th}$ activities.

water mass, but also to follow the ${ }^{234} \mathrm{Th}$ water column deficit and measure trap fluxes over at least a characteristic radionuclide lifetime, i.e. $>3$ weeks, to better capture possible non-steady state changes to ${ }^{234} \mathrm{Th}$ activities and fluxes.

If hydrodynamics are a potential source of trap error, then one might expect trap efficiency to change with depth, given that current velocities generally decrease with depth. A good example of a ${ }^{234} \mathrm{Th}$ calibration study that is highly resolved with respect to depth can be found in the Japanese KNOT Program (Fig. 5.1). The shallowest traps were found to be over-collecting ${ }^{234} \mathrm{Th}$, and at depths below $100 \mathrm{~m}$, there was a constant offset of $20 \%$ higher predicted fluxes than measured. Because the difference between the depth integral of ${ }^{238} \mathrm{U}$ and ${ }^{234} \mathrm{Th}$ becomes smaller with increasing depth, the error on the ${ }^{234} \mathrm{Th}$ flux prediction increases with depth. This is the main reason why the ${ }^{234} \mathrm{Th}$ calibration approach generally only works well in the upper 100-200 m, and parent/daughter radionuclide pairs with longer half lives are needed for traps in deeper waters (see Sections 5 c.ii and 5 c.iii).

When longer term ${ }^{234} \mathrm{Th}$ trap comparisons are made, one can arguably better match the predictions of ${ }^{234} \mathrm{Th}$ export with multiple measurements of ${ }^{234} \mathrm{Th}$ flux in traps. Of the four published ${ }^{234} \mathrm{Th}$ trap comparison studies with well resolved seasonal sampling during at 
least one annual cycle, two are in the center of oligotrophic subtropical gyres (BATS North Atlantic and HOT - North Pacific) and two are on the continental shelf (Dabob Bay, Puget Sound, off Washington State and Landsort Deep, open Baltic Sea). The first year-round study was conducted in 1987 in Dabob Bay (11 observations; water depth $115 \mathrm{~m}$; Wei and Murray, 1992). The 40-m trap data suggest an average trap undercollection for ${ }^{234} \mathrm{Th}$ flux by a factor of two. However this difference could also be due to boundary-scavenging effects that are not incorporated in the ${ }^{234} \mathrm{Th}$ flux estimates, e.g. the predicted flux could be too high if there is more intense removal of Th in regions of higher particle load that result in a 2-D lateral loss of Th that is not included in the standard 1-D flux model.

The other long-term ${ }^{234} \mathrm{Th}$ trap study over the shelf was conducted during 24 months between 1998 and 2000 in the open Baltic Sea (25 sampling intervals; trap depth 40 m; water depth 459 m depth; Gustafsson et al., 2004). At this site, the ${ }^{234} \mathrm{Th}$ collection efficiencies for cylindrical traps exhibited a seasonal cycle, ranging from 50-120\% in the winter and spring to as low as 10-40\% during the summer and fall.

Benitez-Nelson et al. (2001) performed a ${ }^{234} \mathrm{Th}$ trap comparison at the HOT site off Hawaii (9 observations; 150 m PITS trap; site described in Karl et al., 1996). They found traps under-collected the annual ${ }^{234} \mathrm{Th}$ flux by nearly a factor of two, with most of the missing flux being attributed to two large export events not caught in the traps, but evidenced by larger ${ }^{234} \mathrm{Th},{ }^{238} \mathrm{U}$ disequilibria in the water column. Thus from these data alone it is difficult to conclude whether the traps have a general under-collection bias, or are simply missing some episodic flux events.

Another long-term open ocean ${ }^{234} \mathrm{Th}$ trap comparison was performed between 19931995 at BATS time-series site in the Sargasso Sea (19 observations; 150 m PITS trap; site described in (Michaels and Knap, 1996). Buesseler et al. (2000) noted separate periods of under- and over-collection for ${ }^{234} \mathrm{Th}$ and suggested a seasonal pattern with trap undercollection during higher flux summer months and over-collection during the lower flux period in the spring and fall. Again, missing episodic flux events may be part of the reason for an apparent under-collection record, but after 3 years of sampling, one would also have expected periods of sampling high flux in the trap and a lower predicted flux, but this was not the case (see annual flux-weighted averages below).

The ${ }^{234} \mathrm{Th}$ trap collection efficiencies for all four studies are compared in Figure 5.2a and $5.2 \mathrm{~b}$ as a function of season. Each of the four records displays occasions of both over-trapping, under-trapping, and periods where there is a balance between the measured and predicted fluxes. The extreme ranges vary from over-trapping by over a factor of twenty (at BATS) to under-trapping by nearly a factor of ten (Baltic Sea). For the individual time-series studies, the ranges in ${ }^{234} \mathrm{Th}$ collection efficiency were, BATS, 34-2400\% ( $n=19)$; HOT, 21-122\% ( $n=9)$; Dabob Bay, 17-191\% $(n=10)$; and Baltic, $13-163 \%$ ( $n=35$ of which about ten observations were from parallel trap arrays). Hence, within any given upper ocean sediment trap program and location, despite using a single trap array design and constant protocols of trap deployment/retrieval, swimmer removal, 

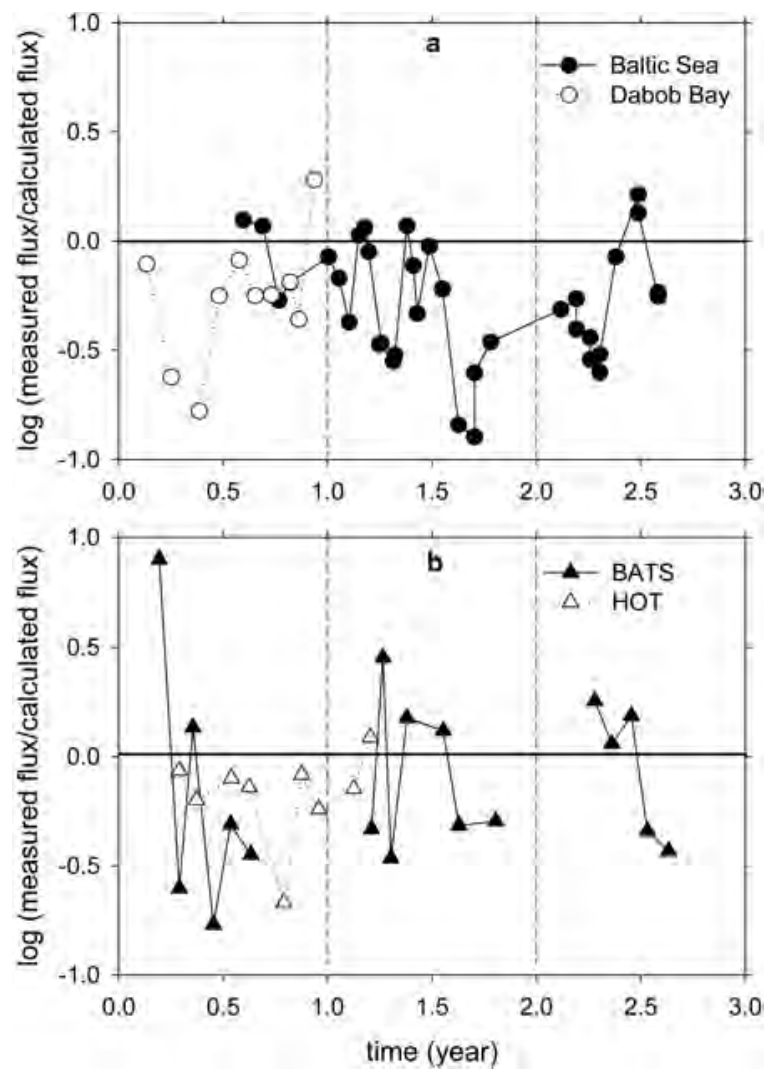

Figure 5.2. Time-series of sediment trap collection efficiency (measured trap ${ }^{234} \mathrm{Th}$ flux /calculated ${ }^{234} \mathrm{Th}$ flux plotted on log scale) vs. the relative time of year for two coastal ocean sites (a. upper panel) and two open ocean sites (b. lower panel). Note BATS winter data are not plotted since the comparison breaks down when the winter mixed layer is deeper than the $150 \mathrm{~m}$ trap.

preservation, and chemical analysis, year-round variations in ${ }^{234} \mathrm{Th}$-derived collection efficiencies span a wide range.

A long term flux-weighted collection efficiency can be derived from these four trap records by averaging the collection efficiencies over the time interval between sampling points. Specifically, the flux-weighted collection efficiencies, with respect to ${ }^{234} \mathrm{Th}$, for the individual records are BATS, 69\%, HOT, 54\%, Dabob Bay, 63\% and Baltic Sea, 44\%. Hence, the four available year-long trap calibration records have in common roughly a factor of 2 undertrapping of ${ }^{234} \mathrm{Th}$-bearing particles.

We can use these data to further investigate whether any particular process can explain the observed variations in collection efficiency. A first hypothesis is that hydrodynamics govern the collection efficiencies (see Section 2). A complete record of the horizontal approach velocity at the trap depth was only available for the Baltic Sea (Gustafsson et al., 
2004). As discussed therein, there was no correlation $(p=0.27)$ between the current speed (median advection at $40 \mathrm{~m}$ trap depth was only $2.8 \mathrm{~cm} \mathrm{~s}^{-1}$; range $0.1-27 \mathrm{~cm} \mathrm{~s}^{-1}$ ) and the collection efficiency. At BATS, no correlation was found between measured carbon flux and current speeds over the trap mouth (summarized in Gardner, 2000)

A second hypothesis is that collection efficiencies reflect settling particle velocities. Gustafsson et al. (2004) observed in the Baltic study that collection efficiencies agree better in winter-spring, coincident with a larger contribution of mineral particles and diatom tests which may be acting as ballast and thus increase the average particle sinking velocity. To further test the extent that sinking velocity could explain some of the observed long-term variations in trap collection efficiencies, the collection efficiency was regressed as a function of the percent POC (i.e., POC, mass ratio of trap-obtained material), assuming that particles with a lower organic content were denser while organic-rich particles were settling slower. This data type was only available for the BATS and the Baltic time-series, and neither showed any significant correlations $(p>0.5)$.

Finally, it has been proposed that under-trapping is more common in higher flux periods and over-trapping during lower flux periods (e.g. Buesseler et al., 2000). Therefore, we compare the calculated ${ }^{234} \mathrm{Th}$ fluxes derived from water column data against the difference between the calculated and measured flux, i.e. does the over- or under-collection depend upon the magnitude of the ${ }^{234} \mathrm{Th}$ water column deficit (Fig. 5.3). In this plot we have included BATS and HOT data discussed above as well as data from an additional shorter-term sediment trap deployment in the Arabian Sea (Sarin et al., 1994). For all of these sites we find that as the calculated flux increases, so does the difference between what is collected and what is predicted. This almost linear relationship is due to the fact that the trap-measured fluxes in these time-series are almost flat, so when the calculated flux based on the water column ${ }^{234} \mathrm{Th}$ deficit increases, so does the difference. Essentially, the water column data indicate that there has been ${ }^{234} \mathrm{Th}$ removal, but this is not reflected by an increase in flux in the traps.

One possible explanation for this trend is that we missed the high-flux events in the traps, as suggested for HOT (Benitez-Nelson et al., 2001). With an increasing number of data we would expect that such systematic undersampling of high predicted flux periods should disappear, but it may be that the trap sampling programs at BATS and HOT have insufficient temporal coverage to catch the rare high flux events in the traps. An alternative explanation is that the high flux events (i.e. low ${ }^{234} \mathrm{Th},{ }^{238} \mathrm{U}$ conditions) are due to export via slowly settling aggregates that are systematically undertrapped due to a hydrodynamic bias (Section 2). This latter mechanism was consistent with periods of largest undertrapping in the Baltic time-series, co-occurring with organic-rich (and presumably slower settling) aggregates compared with periods of better agreeing collection efficiencies in periods with larger lithogenic particle compositions (Gustafsson et al., 2004). Higher POC,Al in settling particles isolated with SPLITT (minimized hydrodynamic bias) than with simultaneously deployed sediment traps is also consistent with an under-trapping of organic-rich, slowly settling particles (Gustafsson et al., 2006). 


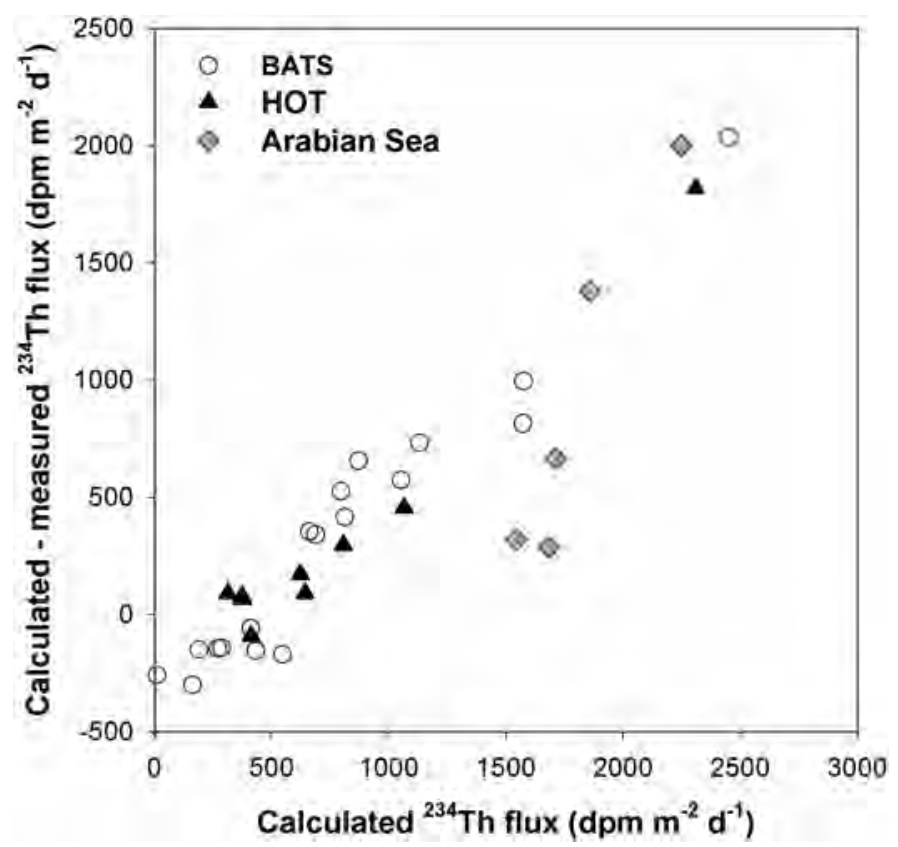

Figure 5.3. Relationship between the calculated ${ }^{234} \mathrm{Th}$ flux (based upon water column ${ }^{234} \mathrm{Th}^{238} \mathrm{U}$ data) and the difference between the calculated and measured trap flux. BATS results are from data in Buesseler et al. (2000); HOT results are from data in Benitez-Nelson et al. (2001); Arabian Sea results are from NE Arabian Sea data in Sarin et al. (1994).

Both shelf stations (not included in Fig. 5.3) show on average conditions of undercollection, but no clear decrease with increasing flux. In these cases the behavior may be obscured by horizontal exchanges, resuspension and contact with nearby shallower sediments. For these shelf stations it may also be that the more enclosed environment and the shallow trap depth make the trap flux more closely tied to the overlying water column processes, reducing the risk of missing an event that has a small spatial extent (see Section 2e). Another difference is that the Baltic data are from a continuous collection of ${ }^{234} \mathrm{Th}$ in traps (3-4 week deployments), thus the integrated ${ }^{234} \mathrm{Th},{ }^{238} \mathrm{U}$ activity profile should be better matched to the trap time-series, hence the under-collection in this case cannot be attributed to missed episodic flux events.

This summary of all available studies to date with at least year-long ${ }^{234} \mathrm{Th}$ trap comparisons suggests a flux-weighted under-trapping bias for ${ }^{234} \mathrm{Th}$ of approximately a factor of two. Evaluation of the metadata sets from these studies do not allow us to assign a single process to the cause of this discrepancy. However taken collectively, the decrease in collection efficiency at higher predicted fluxes suggests that we are either missing episodic flux events, and/or that ${ }^{234} \mathrm{Th}$-bearing sinking particles are being under-collected in shallow traps, and/or possibly solubilization is occurring within the trap after collection 
(see Section 4), but this is less likely for particle reactive elements (Pohl et al., 2004). One must also take care in applying any ${ }^{234} \mathrm{Th}$-based collection efficiency as a generic "trap yield" estimator for other elements, since if the flux bias is related to sinking speed or other hydrodynamic property, the correction is only appropriate for ${ }^{234} \mathrm{Th}$ bearing particles. To illustrate, if ${ }^{234} \mathrm{Th}$ is preferentially associated with slow sinking particles that are being inefficiently collected by traps, the collection bias might be different for total mass or $\mathrm{C}$ flux, if the bulk of this material is carried by particles or aggregates with other sinking speeds that are not impacted in the same way (see Section 2).

ii. Other radionuclides for in situ calibration of sediment traps: ${ }^{210} \mathrm{~Pb}$. An independent test of the trapping efficiency can be achieved from the measured ${ }^{210} \mathrm{~Pb}$ flux in the traps. In most regions of the ocean (with exception of very remote areas like the Southern Ocean) the in situ production of ${ }^{210} \mathrm{~Pb}$ from the decay of ${ }^{226} \mathrm{Ra}$ in surface waters is insignificant compared to its delivery via atmospheric fallout; therefore trap fluxes of ${ }^{210} \mathrm{~Pb}$ are a direct measure of its atmospheric deposition. The ${ }^{210} \mathrm{~Pb}$ supplied to surface waters is adsorbed onto particles and removed with a residence time of several weeks up to years (Bacon et al., 1976).

During the Indian JGOFS cruises in the Arabian Sea, ${ }^{210} \mathrm{~Pb}$ deposition fluxes were measured at 130-150 m by drifting cylindrical sediment traps deployed for 3-5 days during April-May 1994 (inter-monsoon), February-March 1995 and 1997 (late NE-monsoon). During the inter-monsoon, the measured ${ }^{210} \mathrm{~Pb}$ flux $\left(22 \mathrm{dpm} \mathrm{m}^{-2} \mathrm{~d}^{-1}\right.$, Fig. 5.4a) is similar to that based on atmospheric delivery predictions (Turekian et al., 1977). During the same season, the ${ }^{234} \mathrm{Th}$ export flux measured by the floating traps matches the predicted. In contrast, a gross-mismatch for both ${ }^{234} \mathrm{Th}$ and ${ }^{210} \mathrm{~Pb}$ fluxes in the traps is observable during the late NE monsoon (Fig. 5.4b). The traps record considerably lower collection efficiencies using both isotope systems, lending some confidence to the conclusion of low trap collection efficiency in this period.

In principle, the ${ }^{210} \mathrm{~Pb}$ constraint is less accurate than the ${ }^{234} \mathrm{Th}$ constraint because atmospheric supply may change with time and because small differences in the ${ }^{210} \mathrm{~Pb}$ inventory in the surface water cannot be measured with sufficient accuracy to allow a non-steady state calculation to be made. Nevertheless, this application of ${ }^{210} \mathrm{~Pb}$ provides an additional constraint to confirm periods of over- or under-collection as indicated by ${ }^{234} \mathrm{Th}$.

iii. Other radionuclides for in situ calibration of sediment traps: ${ }^{230}$ Th and ${ }^{231} \mathrm{~Pa}$. Calibration of sediment traps with U-series radionuclides has the advantage that we know exactly how much activity is produced in the water column above the trap. ${ }^{234} \mathrm{Th}$ has distinct advantages in the upper ocean; however, given its 24 day half life the integrated ${ }^{234} \mathrm{Th}^{238} \mathrm{U}$ ratio becomes closer to 1 at depth as particle flux decreases relative to ${ }^{234} \mathrm{Th}$ production and decay rates. For this reason, we can rarely use ${ }^{234} \mathrm{Th}$ to calibrate traps below the upper $100-200 \mathrm{~m}$ (c.f. Fig. 5.1). For the long-lived isotopes ${ }^{230} \mathrm{Th}$ and ${ }^{231} \mathrm{~Pa}$, decay in the water column can be neglected. All activity produced in the water column eventually reaches the 


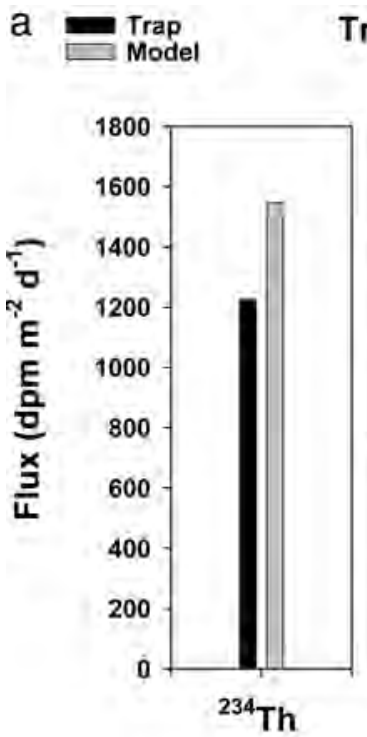

$\operatorname{Trap}^{234} \mathrm{Th} \&{ }^{210} \mathrm{~Pb}$ Fluxes
Pre SW monsoon
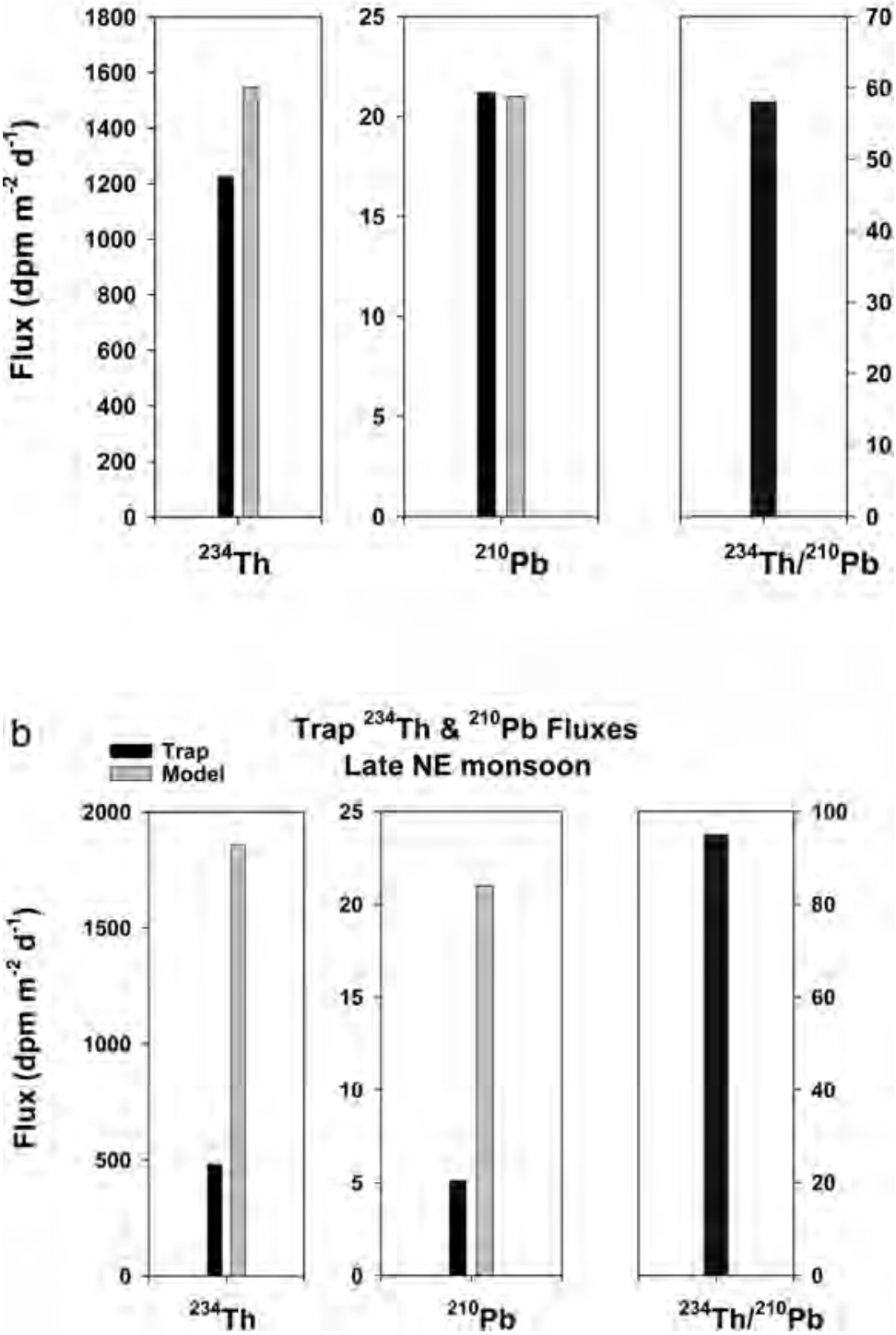

Trap ${ }^{234} \mathrm{Th} \&{ }^{210} \mathrm{~Pb}$ Fluxes

\section{Late NE monsoon}
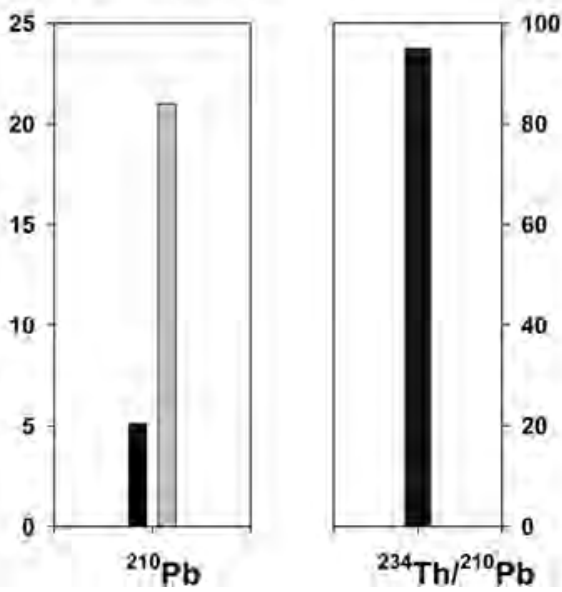

Figure 5.4. A comparison of measured (=Trap) vs. calculated (=Model) ${ }^{234} \mathrm{Th}$ and ${ }^{210} \mathrm{~Pb}$ fluxes and ${ }^{234} \mathrm{Th} /{ }^{210} \mathrm{~Pb}$ ratios during the early SW Monsoon (upper panels) and later NE Monsoon (lower panels) in the Arabian Sea. 
sediment. In the case of these isotopes, our uncertainties are not in the percent exported, but in the horizontal and seasonal distribution of the flux and the advective supply from deeper layers.

Both Th and $\mathrm{Pa}$ are scavenged by the sinking particles, but the scavenging residence time of ${ }^{230} \mathrm{Th}$ in the ocean is on the order of 30 years and clearly shorter than that of ${ }^{231} \mathrm{~Pa}$ $\left(\sim 150\right.$ years, Anderson et al., 1983). As a consequence, ${ }^{231} \mathrm{~Pa}$ is transported laterally by mixing and ocean currents to a larger extent than ${ }^{230} \mathrm{Th}$ before it is removed to the sediment. This enhanced removal in high particle regions, termed 'boundary scavenging', has two consequences. First, the flux of ${ }^{230} \mathrm{Th}$ in any ocean region is closer to the production rate in the overlying water column than is the case with ${ }^{231} \mathrm{~Pa}$. Henderson et al. (1999) estimate that in $70 \%$ of the world ocean the predicted vertical ${ }^{230}$ Th flux would be within $\sim 30 \%$ of the production rate in the water column.

A second consequence of measuring both ${ }^{230} \mathrm{Th}$ and ${ }^{231} \mathrm{~Pa}$ is that the $\mathrm{Th} / \mathrm{Pa}$ ratio in water and suspended matter can be used to model the lateral transport of both nuclides (Bacon, 1988), and thus improve our estimate of particle collection efficiency in the deep ocean. This $\mathrm{Th} / \mathrm{Pa}$ procedure has been used to calibrate sediment traps in the world ocean (Scholten et al., 2001; Yu et al., 2001). These analyses suggest low collection efficiency for moored conical traps in shallower waters $(<1500 \mathrm{~m}$ depth, Fig. 5.5). Site to site variability is large, but for any given site the efficiency of the shallower traps is consistently lower than that of the deep traps at the same site (see trap sets from a single site in Fig. 5.5). As a consequence, the apparent increase in lithogenic (=Al) flux with depth, which has been reported in some prior sediment trap studies, could be attributed to a lower trap collection efficiency at shallower depths (e.g., Yu et al., 2001). This common finding of lower collection efficiency at shallower depths in moored deep ocean conical traps is likely to be due to a combination of the effects described in the previous sections. For instance, at shallow depths one finds faster currents, which could result in a negative hydrodynamic bias and/or higher swimmer abundances, which in turn may feed on and remove sedimenting particles from the walls of the collection cone.

The often recorded large seasonal variations in particle flux cause a seasonal change in scavenging rate as well. This is clearly the case in the scavenging of ${ }^{234} \mathrm{Th}$ (and consequently also of ${ }^{230} \mathrm{Th}$ ) from the surface layer of the ocean, but it was a surprise that seasonality affected scavenging processes throughout the entire water column (Bacon et $a l ., 1985$ ). As is the case for ${ }^{234} \mathrm{Th}$, this implies that a trap calibration based on ${ }^{230} \mathrm{Th}$ (and ${ }^{231} \mathrm{~Pa}$ ) cannot be made with a single short trap deployment but is only valid if at least a full seasonal cycle is examined.

A case study using multiple $\mathrm{U}$ - and Th-series radionuclides to look at trap efficiency has been reported by Sarin et al. (2000) in a study of time-series sediment traps in the Bay of Bengal over two years (1990-1991). The traps were deployed at two depths at 3 sites, $900-1100$ and $\sim 2100-3000 \mathrm{~m}$ at $\sim 15 \mathrm{~N} 89 \mathrm{E}$ (NBBT), $\sim 13 \mathrm{~N} 84 \mathrm{E}$ (CBBT) and $\sim 5 \mathrm{~N} 87 \mathrm{E}$ (SBBT). At the NBBT site, the observations show that, (i) the authigenic flux of ${ }^{230} \mathrm{Th}$ in the deep trap (in this study no correction for boundary scavenging using ${ }^{231} \mathrm{~Pa}$ was applied) 


\section{Trapping efficiency}

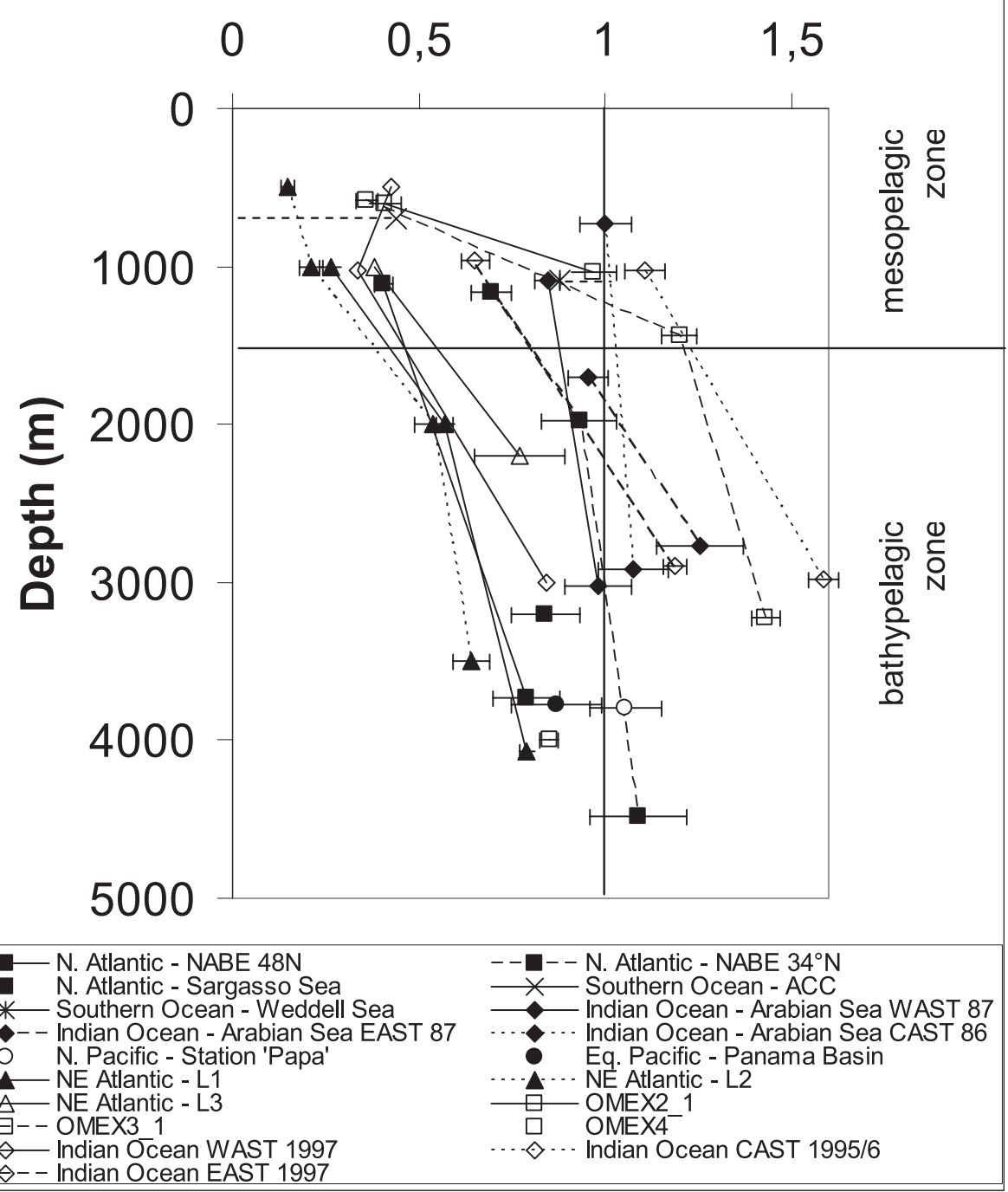

Figure 5.5. Trap collection efficiencies derived from ${ }^{230} \mathrm{Th}$ and ${ }^{231} \mathrm{~Pa}$ measurements in sediment trap and water column samples according to Bacon (1988). Data from Yu et al. (2001); Scholten et al. (2001, 2005). Arabian Sea data are from deployments generally shorter than one year but they include the monsoon period and may be overestimated. OMEX deployments are near the continental margin where deeper traps may be influenced by lateral advection. 
roughly balances its production in the water column above the trap depth; (ii) the differences in the ${ }^{210} \mathrm{~Pb}$ fluxes between the shallow and deep traps match the in situ production in the water column; and (iii) the mass, $\mathrm{Al}$ and ${ }^{228} \mathrm{Th}$ fluxes are similar in the shallow and deep traps. These results suggest that at this site ${ }^{230} \mathrm{Th}$ and ${ }^{210} \mathrm{~Pb}$ produced in the water column are removed predominantly by vertical particle flux and support the argument that the trap functioned accurately. At the CBBT site, there is a consistent increase in the mass, $\mathrm{Al}$ and ${ }^{228} \mathrm{Th}$ fluxes in the deep trap relative to those in the shallow trap. In the deep trap, the deposition rates of ${ }^{210} \mathrm{~Pb}$ and ${ }^{230} \mathrm{Th}$ were found to be considerably in excess of their production rates. This apparent over-collection may be due to enhanced particle aggregation in the intermediate waters, re-suspension of "nascent" sedimentary material or focusing of particles in the region of the deep traps, and can be quantified with the ${ }^{230} \mathrm{Th}$ flux. When the deep trap $\mathrm{Al}$ flux is corrected accordingly, it is similar to the shallower flux.

Taken together, radionuclide-based in situ assessments of sediment trap collection efficiencies are informative regarding both the direction and scale of possible trapping biases. The four available year-long ${ }^{234} \mathrm{Th}$-based upper ocean trap calibration studies each report flux-weighted year-round under-trapping of about a factor of 2. Future radionuclidebased trap assessments should be accompanied with process-oriented studies to resolve whether offsets reflect a general under-collection of slowly-settling aggregates (a hydrodynamic effect), or a result of discontinuous trapping programs missing episodic events (see Section 6b.viii), and examine how well these $\mathrm{Th}$ (or $\mathrm{Pb}, \mathrm{Pa}$ ) based assessments of collection efficiency can be applied to other elemental fluxes.

\section{Summary and recommendations}

\section{a. Summary}

Considerable advances in understanding the ocean's biological pump can be attributed to the use of sediment traps for directly sampling sinking particles in the ocean. The assumption in these studies is that traps serve as unbiased collectors of sinking material, both the quantity and quality thereof. This assumption cannot be easily proven, but consistency in the patterns of decreasing flux vs. depth, pulsed fluxes after blooms, and regional differences in flux and composition all suggest that the general patterns of flux derived from traps are "reasonable." However, we know from theoretical, experimental and field studies that sediment trap measurements are not always accurate, especially in some settings and, in particular, at shallower depths.

It is at depths between the surface euphotic zone and roughly $1000 \mathrm{~m}$ where most sinking particles are remineralized, and where trap accuracy is most likely to be an issue. This is because the processes that can bias the collection of sinking particles by traps are more likely to be significant at these depths. For example, ocean currents are generally faster in shallower waters, thus increasing the chance of hydrodynamic biases for moored and drifting traps in the upper ocean. Zooplankton are found in the highest abundances in 
surface waters, while decreasing numbers are found to migrate daily or live permanently down to $800-1200 \mathrm{~m}$. Thus it is at the shallower depths where zooplankton swimmers are more likely to actively enter traps and compromise both particle load and remineralized components. Finally, flux decreases with depth presumably due to the rapid remineralization of the more labile biogenic components, so the impact of solubilization artifacts in the trap are expected to be greater in the upper ocean, but this is not well documented.

While we recognize these potential biases, they can be difficult to quantify. It is thus challenging to develop post-sampling corrections appropriate for each trap experiment, particle component, and specific set of physical and biological conditions. Experiments to quantify flux biases using independent methods are subject to their own errors related to experimental design and interpretation of the data. Thus using multiple independent methods for estimating flux is informative. Unfortunately, carrying out these types of independent calibrations is often as much, or more, effort than the trap sampling itself. Finally, even at seemingly uniform open ocean sites, there is a dynamic continuum from the smallest colloids to larger sinking and non-sinking materials, most of which are biologically derived. Due to natural biological cycles, the characteristics of marine particles vary with season and depth, and reflect changes in community structure and physical conditions. Therefore, a single or universal calibration would not necessarily hold for different times of the year, even at the same site.

The last major review of upper ocean trapping (Gardner, 2000) summarized studies from 1980-mid 90's. Since then there has been progress in resolving some issues by improved trap and experimental design, or by correcting trap fluxes using independent methods. These results, when examined collectively here, show new progress in improving our understanding of the capabilities and limitations of sediment traps. For example, examination of long term ${ }^{234} \mathrm{Th}$ calibration studies shows consistent undertrapping of ${ }^{234} \mathrm{Th}$ by roughly a factor of two using cylindrical traps in the upper 40-150 m in both open ocean and coastal settings.

Most major sediment trapping programs, however, have changed little in the past decade despite the knowledge that better practices are available. This is in part due to the considerable effort and cost associated with best practices or independent calibration studies. In addition, researchers are reluctant to change practices, particularly at time-series sites, where overlapping protocols would be needed to establish a new flux time-series even after minor changes have been made (for example, see difference in screening vs. picking swimmers at BATS and HOT, Table 4). Consequently we make some specific recommendations below regarding the use of traps, which are particularly relevant to studies of particle flux out of the surface ocean down to depths of $1000 \mathrm{~m}$, although they generally apply to deeper traps as well.

\section{b. Recommendations}

i. Trap designs and field protocols to reduce hydrodynamic bias. The JGOFS program has repeatedly made recommendations for improved practices in the design, deployment and 
documentation of sediment traps related to hydrodynamic issues (GOFS, 1989; Gardner, 2000). We can only echo those recommendations here. Unfortunately, "best practice" remains difficult to achieve, involving at a minimum the expensive additions of current and tilt meters, drogues, minimum drag designs, and the avoidance of more than one trap depth on a surface-tethered array. The desirable use of NBSTs may at first appear to increase costs, but not relative to fully-instrumented drifting PIT arrays at a single depth. There are no shortcuts to achieving best practice, nor does it appear that there are oceanic environments which do not require its application. As in previous reviews, we can only recommend that the best achievable effort be made to meet the goals of minimizing hydrodynamic biases, and that every effort be undertaken to document the conditions of deployment and to discuss their probable influences on collection characteristics by reference to the field and laboratory studies of biases in the magnitude of collections, and discrimination against different particle types.

ii. Further research to understand, avoid and correct for hydrodynamic biases. We consider that the advent of NBSTs represents the best path forward to avoid hydrodynamic biases, and their simultaneous deployment with surface-tethered and moored traps could further help quantify hydrodynamic effects. Improvements have been made to reduce their costs, extend their deployment lifetimes, and expand the suite of in situ measurements that can be undertaken on particle characteristics (Buesseler et al., 2000; Bishop et al., 2004; Lampitt et al., 2004; Stanley et al., 2004).

Because progress in understanding hydrodynamic biases is intimately linked to progress in understanding particle properties, it is also clear that efforts to document these properties should be expanded. Promising avenues include the further development of methods to characterize sinking rates and their relation to chemical and biological properties of particles (Gustafsson et al., 2000), especially using in situ techniques (Peterson et al., 2005). An important aspect of these efforts is the further development of the use of natural radionuclides as possible means for evaluating particle collection efficiencies (see 6b.viii below), via improved understanding of which particle types contribute most importantly to radionuclide budgets and how these budgets differ from those of nutrients and other elements.

iii. Trap designs and field protocols to reduce swimmer artifacts. The best choice of methods for solving the swimmer problem in sediment trap research is to keep swimmers out of the traps. While swimmer avoidance traps such as the IRS are a viable and at least partial solution to the swimmer problem, they are more expensive and not widely used at present. Further testing of swimmer avoidance traps with simple designs should be encouraged. Design of swimmer avoidance traps should further exploit swimming behaviors to minimize the problem (e.g., darkened chambers with light emitting diodes to lure zooplankton away as suggested by Coale, 1990). Swimmer avoidance traps should be tested under different flux and flow regimes and compared with the more commonly used sediment traps. Avoiding swimmers also helps reduce solubilization artifacts (see 6b.v). 
$i v$. Further research to understand, avoid and correct for swimmer artifacts. Swimmers should be removed from all trap samples and investigators should report the method used for removal in the literature. When reporting swimmer removal methods, details should include whether the sample was screened or picked, the microscope magnification used for picking, and whether swimmers were picked from solution or removed from filters. The method of removal depends on the environment and magnitude of POC flux and thus the extent of the swimmer problem. The sample should be carefully examined first before deciding on the method. Samples containing many small swimmers should be picked rather than solely screened.

When screening, screens should be carefully examined for large detrital particles (e.g., fecal pellets) or aggregates adhering to the screen, and these should be added back to the sample. Magnification used for picking swimmers should be at least 50x, and a photograph of a representative sample before and after picking is recommended. When detrital material is adhering to a swimmer, the swimmer should be rinsed gently with filtered seawater to detach the detritus, or the detritus gently removed with fine forceps, being careful not to squeeze or tear the animal.

Swimmers should be saved (preserved in formaldehyde) and/or quantified for their contribution to each trap sample. Swimmers are very useful, for example, in the study of deep-sea ecology, as many zooplankton caught in deep-sea sediment traps are not easily sampled by other methods. This method of collection, albeit biased for certain taxa, is underutilized by deep-sea ecologists and taxonomists. More intercomparisons of swimmer removal techniques are needed (Gardner, 2000). Use of homogenous sub-samples from the same trap tube in such an intercomparison would be instructive (but likely only feasible in higher flux environments).

Finally, while we recommend using preservatives in sediment trap deployments, there are human health considerations in using any poison or preservative, and some prevent desirable measurements (e.g., use of formaldehyde precludes measurement of stable isotopes ((Marguillier, 1998) and DOC). Thus, further rigorous testing of poisoned vs. unpoisoned traps for at least short-term (1-2 day) sediment trap deployments should be carried out to quantify the extent of the error introduced by zooplankton entering unpoisoned traps.

v. Trap designs and field protocols to quantify solubilization. Solubilization effects can be studied by looking either at increases in excess elemental concentrations in the trap supernatant, or by controlled incubation studies of poisoned trap particles. For shallow traps, emphasis should be placed on short-term deployments and ensuring rapid postrecovery treatment of samples. Traps should be effectively poisoned and swimmeravoidance mechanisms optimized (see 6b.c), since swimmers can lead to an excess in dissolved materials that should not be attributed to the sinking particles. Upon recovery, samples should be rapidly picked for swimmers, split and filtered under low pressure. Swimmers picked out of the samples should be measured (preferably for carbon, nitrogen 
and other elements in addition to mass; see 6b.iv) and their maximal contribution to the trap supernatant can be estimated based on biomass and other estimates of excretion. Incubation studies are one way to assess possible losses to solution when the use of open sampling tubes precludes the accurate determination of excess elemental concentrations.

Closed sampling tubes and swimmer avoidance designs, if applied in the upper ocean, will allow for the effects of solubilization to be assessed by quantifying excess elemental concentration in the supernatant. However, at present, this method is only applied to deep traps on long-term moorings where swimmer abundances are low. In these settings, trap cups should be sealed from the surrounding water and contain appropriate poison or preservative that allows measurements of all of the elements in the supernatant that will be measured in the particulate fraction. Analysis of samples should ideally be made several months after in situ sample collection to allow for exchange of pore fluids between particles and supernatant. A blank value of the solution used to fill the cups should also be measured. As with shallow traps, swimmer carbon and nitrogen should be measured to estimate their maximal impact on dissolved elemental concentrations. For any method that includes filtration of what may be fragile or non-rigid particles, care should be taken to ensure that during filtration, material is not released into the filtrate either by leakage of internal fluids or break up of particles.

vi. Further research to understand, minimize and correct for solubilization artifacts. Our understanding of whether, how, and to what extent elements in sinking particulate matter is solubilized in traps is very incomplete. More data are needed from a range of environments on the excess dissolved elements in trap cups, and the means by which these are produced/released. More experimental studies are recommended to look at trapped particle degradation rates over time at in situ temperatures and under differing poisoned and unpoisoned conditions. A major gap in knowledge of the concentrations of dissolved elements brought into traps with particles prevents making an accurate estimation of the importance of this process. More data on the dissolved/particulate ratios of elements in sinking aggregates from different depths would also be useful.

vii. Experiments to assess in situ trap efficiency using stable elements and particle abundances. It remains extremely difficult to quantify the 3-D chemical balance of any stable element in the ocean or to quantify particle abundances and in situ sinking rates. Thus attempts to calculate flux from an upper ocean mass balance of $\mathrm{C}$ or $\mathrm{N}$ or from particle abundance and a sinking rate model should be seen as an exercise that can only quantify fluxes with considerable uncertainty, and thus identify sediment trap fluxes that are grossly in error. The agreement between multiple methods suggests that the biases are not large, or at least not too different between each method.

The inverse model offers a powerful approach to determine export fluxes that are in line with nutrient budgets, hydrographical data and transport models. Given its broad integration over time and space, it is not a suitable approach for calibrating any specific sediment trap study. However inverse modeling can tell us whether export fluxes derived with other 
methods, such as traps, can be reconciled with the long-term fluxes expected for that area. The adjoint method is used at present for a steady state ocean. In principle, this approach can be extended to determine time-varying fluxes; however, much larger datasets including time-series stations and repeat surveys are required to reliably constrain these fluxes.

viii. Further research to understand and use radionuclides to assess in situ trap efficiency. Annual time-series ${ }^{234} \mathrm{Th}$ trap studies suggest that a flux-weighted average of under-trapping by approximately a factor of two for ${ }^{234} \mathrm{Th}$ is common in the four studies undertaken to date. Given the utility of upper ocean sediment traps and the need to understand the accuracy of the trap-obtained fluxes, as recommended by Gardner (2000) future sediment trap programs would benefit from determining the collection efficiencies with the ${ }^{234} \mathrm{Th}$ proxy. Another recommendation concerning appropriate time and space scales is to match the trap deployment periods with the ${ }^{234} \mathrm{Th}$ residence time, and to establish more continuous (ideally year-round) trapping and ${ }^{234} \mathrm{Th}$-based testing programs. For instance, the trap deployments in the BATS and HOT time-series programs are only collecting the flux for about $10 \%$ of the total time (e.g., monthly 3-day deployments). This may be an additional reason why the observed trap fluxes do not match the fluxes estimated from upper ocean mass balances, since episodic flux events can be missed. For less-than seasonal trap efficiency experiments, the time-series 3-D approach such as in Buesseler et al. (1994) and/or Lagrangian studies in isolated water masses such as inside eddies (e.g., Hung et al., 2004) are recommended. In such cases, it is also recommended that the ${ }^{234} \mathrm{Th}$ water column activities and trap fluxes be followed at least over the characteristic time scale for ${ }^{234} \mathrm{Th}$ decay ( $>3$ weeks) in order to capture non-steady state changes in the ${ }^{234} \mathrm{Th}$ activity balance.

For traps deployed at depths > approximately $200 \mathrm{~m}$, the particle collection efficiency can be better judged using ${ }^{230} \mathrm{Th}$. Furthermore in order to average out seasonal variation in the ${ }^{230} \mathrm{Th}$ flux, only long-term deployments will suffice. This procedure is improved if boundary scavenging of ${ }^{230} \mathrm{Th}$ is quantified and corrected for using the distribution of both ${ }^{230} \mathrm{Th}$ and ${ }^{231} \mathrm{~Pa}$ in the trap and water column. It should be noted that this ${ }^{231} \mathrm{~Pa}$-based correction for boundary scavenging may be compromised by variations in particle composition which affect the ${ }^{231} \mathrm{~Pa} /{ }^{230} \mathrm{Th}$ fractionation (Chase et al., 2002).

Both measured (trap) and expected (from water column U-Th disequilibria) radionuclide fluxes should be reported along with the calculated collection efficiencies. Also, it is recommended that future ${ }^{234} \mathrm{Th}$ trap calibration programs include ancillary datasets so that processes impacting collection efficiencies (e.g. current flow, zooplankton number, and particle sinking rate) may be evaluated. Improvement of ${ }^{234} \mathrm{Th}$ flux models to include non-steady state and physical effects is also recommended.

A final recommendation is that the radionuclide-based estimate of trap collection efficiency should be applied with care to other components of the settling flux. As noted in Buesseler (1991), "a calibration of particle flux using ${ }^{234} \mathrm{Th}$ may not hold for organic carbon or other elements if the particle classes that carry these elements differ." More recently, the Baltic Sea ${ }^{234} \mathrm{Th}$ trap investigation implied that there were different collection 
离

告

웅
.

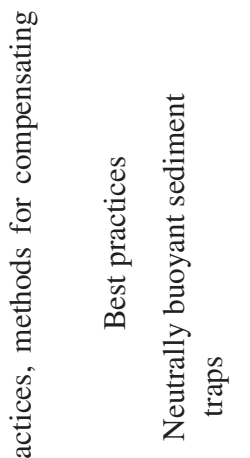

‡ี

茞

.

苛 का

गे पे

莺 $\quad$ 苛

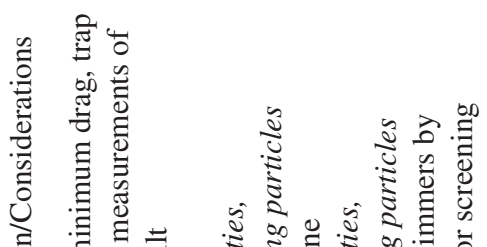

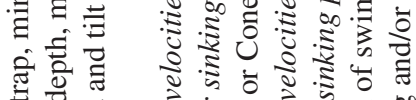

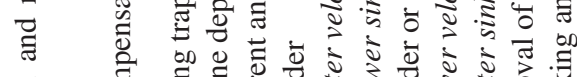

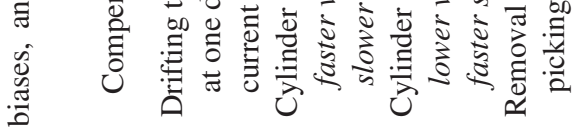

这

范

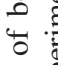

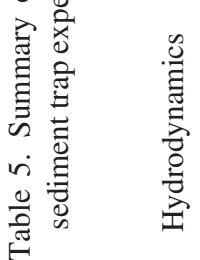

శ్్ㅂ

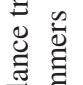

즐

is

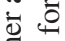

范

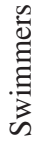

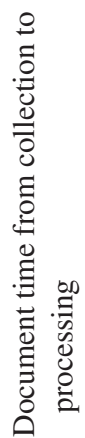

हैํำ

$\stackrel{\overrightarrow{0}}{\stackrel{0}{0}}$

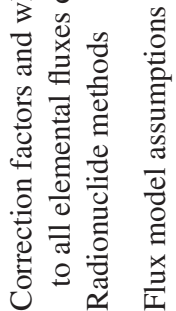

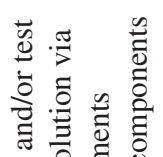

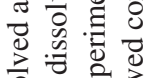

范

를.

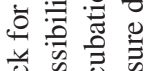

苞

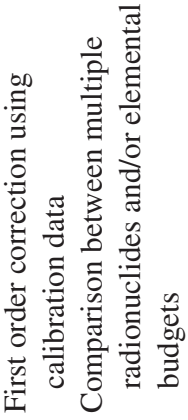

$\frac{\pi}{2}$

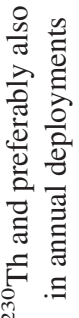

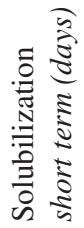

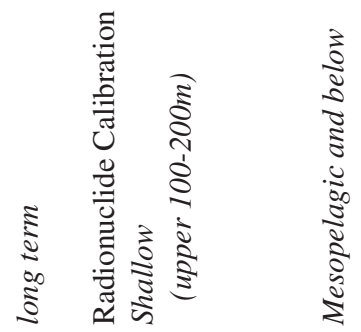


efficiencies for organic carbon and ${ }^{234} \mathrm{Th}$ (Gustafsson et al., 2004, 2006); however, with continued progress it may be plausible to use the ${ }^{234} \mathrm{Th}$-based estimates of collection efficiencies to correct the sediment trap fluxes of other elemental fluxes.

ix. Summary of recommendations. Considerable progress is being made in improving understanding of in situ trap behavior, trap designs, and estimating and correcting for potential biases. Since reliable estimates of sinking particle flux are an important parameter needed to answer many of ocean science's most pressing questions, it is imperative that we continue to improve upon the use of these devices and other proxies for measuring the sinking flux. However, applying best practices for upper ocean trapping studies can be difficult, time consuming and expensive. Independent calibration is also not an easy task and often multiple methods are needed to gain confidence in the results. Table 5. summarizes much of what we have compiled, assessed and recommended in this review on best practices, methods to compensate for biases, and what to document with sufficient detail so that future researchers will know with some degree of confidence the conditions and comparisons that can be made between different sediment trap studies. Generally, it is better to avoid a particular bias than to have to correct for it (e.g. use of swimmer avoidance traps vs. manual removal of swimmers; use of NBSTs vs. correcting trap fluxes for hydrodynamic biases). In the end, the extent of use of best practices will depend upon the questions one is asking and the practical limits of the particular project. Differences in the magnitude and composition of the flux as well as the physical setting and trap depth will also be important in setting limits on what are the most pressing issues to address. This variability makes it difficult to come up with universal correction factors or experimental designs that are suited to all conditions. Also, variability in practices is common, and some standardization of trap designs and processing protocols should be undertaken to facilitate relative comparisons of different flux studies. In sum, sediment traps serve as a valuable tool in ocean sciences, but as with every tool there are design limitations. With careful study we are making progress in both understanding the limits of sediment traps and in improving their designs.

Acknowledgments. Working Group \#116 wishes to acknowledge support for travel and WG meetings from SCOR and the offices of Ed Urban that facilitated these requests. At each meeting, our local hosts and sponsors made the scientific exchanges both productive and enjoyable, and in this regard we are indebted to the Wrigley School of Environmental Sciences, USC; the Woods Hole Oceanographic Institution; Drs. H. S. Hong and M. Dai; and the State Key Laboratory of Marine Environmental Science, Xiamen University. WG meetings and production of this report was partially supported by the U.S. National Science Foundation via grants to the SCOR. Individuals and science efforts discussed herein were supported by many national science programs, including the U.S. National Science Foundation, Swedish Research Council, the International Atomic Energy Agency through its support of the Marine Environmental Laboratory that also receives support from the Government of the Principality of Monaco, and the Australian Antarctic Science Program. K.B. was supported in part by a WHOI Ocean Life Institute Fellowship. Individuals who helped with the content and/or editing of this review are also greatly acknowledged, and this group of supporting scientists includes, Drs. C. Lamborg, P. Andersson, U. Larsson, D. Karl, M. Conte, S. Manganini, R. Rengarajan, V. Ramaswamy and S. Clifford. Also, comments by JMR reviewers helped improve this review. 


\section{REFERENCES}

Agassiz, A. 1888. Three cruises of the United States Coast and Geodetic Survey steamer Blake in the Gulf of Mexico, in the Caribbean Sea, and along the Atlantic coast of the United States from 1877 to 1880. Bull. Museum Comp. Zoology Harvard, 1, 1-314.

Agrawal, Y. C. and H. C. Pottsmith. 2000. Instruments for particle size and settling velocity observations in sediment transport. Mar. Geol., 168, 89-114.

Alldredge, A. L. 1976. Discarded appendicularian houses as sources of food, surface habitats, and particulate organic matter in planktonic environments. Limnol. Oceanogr., 21, 14-23.

- 2000. Interstitial dissolved organic carbon (DOC) concentrations within sinking marine aggregates and their potential contribution to carbon flux. Limnol. Oceanogr., 21, 14-23.

Alldredge, A. L. and M. W. Silver. 1988. Characteristics, dynamics and significance of marine snow. Prog. Oceanogr., 20, 41-82.

Al-Mutairi, H. and M. R. Landry. 2001. Active export of carbon and nitrogen by diel migrant zooplankton at Station ALOHA. Deep-Sea Res. I, 48, 2083-2103.

Anderson, R. F., M. P. Bacon and P. G. Brewer. 1983. Removal of ${ }^{230} \mathrm{Th}$ and ${ }^{231} \mathrm{~Pa}$ at ocean margins. Earth Planet. Sci. Lett., 62, 7-23.

Anderson, T. R. and P. Pondaven. 2003. Non-Redfield carbon and nitrogen cycling in the Sargasso Sea, pelagic imbalances and export flux. Deep-Sea Res. I, 50, 573-591.

Andrews, J., C. Lamborg, S. Pike, D. Steinberg, S. Wilson, J. R. Valdes and K. O. Buesseler. 2006. An examination of sediment trap accuracy issues during VERTIGO. Eos Trans. AGU, Ocean Sci. Meeting Suppl., 87(36), Abstract OS26A-05.

Angel, M. V. 1989. Does mesopelagic biology affect the vertical flux? in Productivity of the Ocean, Present and Past, W. H. Berger, V. S. Smetacek and G. Wefer, eds., John Wiley and Sons, 155-173.

Angel, M. V. and A. D. C. Baker. 1982. Vertical distribution of the standing crop of plankton and micronekton at three stations in the northeast Atlantic. Biol. Oceanogr., 2, 1-29.

Antia, A. N. 2005. Particle-associated dissolved elemental fluxes, revising the stoichiometry of mixed layer export. Biogeosci. Discussions, 2, 275-302.

Antia, A. N., W. Koeve, G. Fischer, T. Blanz, D. Schulz-Bull, J. Scholten, S. Neuer, K. Kremling, J. Kuss, R. Peinert, D. Hebbeln, U. Bathmann, M. Conte, U. Fehner and B. Zeitzschel. 2001. Basin-wide particulate carbon flux in the Atlantic Ocean, regional export patterns and potential for atmospheric $\mathrm{CO}_{2}$ sequestration. Global Biogeochem. Cy., 15, 845-862.

Antia, A. N., B. von Bodungen and R. Peinert. 1999. Particle flux across the mid-European continental margin. Deep-Sea Res. I, 46, 1999-2024.

Armstrong, R. A., C. Lee, J. I. Hedges, S. Honjo and S. G. Wakeham. 2002. A new, mechanistic model for organic carbon fluxes in the ocean based on the quantitative association of POC with ballast minerals. Deep-Sea Res. I, 49(1-3), 219-236.

Asper, V. L. 1987. Measuring the flux and sinking speed of marine snow aggregates. Deep-Sea Res. I, 34, 1-17.

1996. Particle flux in the ocean, oceanographic tools, in Particle Flux in the Ocean, V. Ittekkot,, P. Schäfer, S. Honjo and P. J. Depetris, eds., Wiley and Sons, Chichester, 71-81.

Asper, V. L., W. G. Deuser, G. A. Knauer and S.A. Lohrenz. 1992. Rapid coupling of sinking particle fluxes between surface and deep ocean waters. Nature, 357, 670-672.

Bacon, M. P. 1988. Tracers of chemical scavenging in the ocean, boundary effects and large-scale chemical fractionation. Phil. Trans. Roy. Soc. London A, 325, 147-160.

Bacon, M. P., C. A. Huh, A. P. Fleer and W. G. Deuser. 1985. Seasonality in the flux of natural radionuclides and plutonium in the deep Sargasso Sea. Deep-Sea Res., 32, 273-286.

Bacon, M. P., D. W. Spencer and P. G. Brewer. $1976 .{ }^{210} \mathrm{~Pb} /{ }^{226} \mathrm{Ra}$ and ${ }^{210} \mathrm{Po} /{ }^{210} \mathrm{~Pb}$ disequilibria in seawater and suspended particulate matter. Earth Planet. Sci. Lett., 32, 277-296. 
Baker, E. T., H. B. Milburn and D. A. Tennant. 1988. Field assessment of sediment trap efficiency under varying flow conditions. J. Mar. Res., 46, 573-592.

Bartz, R., J. R. V. Zaneveld, I. N. McCave, F. R. Hess and A.R.M. Nowell. 1985. ROST and BEAST, devices for in-situ measurement of particle settling velocity. Mar. Geol., 66, 381-395.

Bauerfeind, E., C. Garrity, M. Krumbholz, R. O. Ramseier and M. Voss. 1997. Seasonal variability of sediment trap collections in the northeast water polynya, Part 2, Biochemical and microscopic composition sedimenting matter. J. Mar. Syst., 10, 371-389.

Benitez-Nelson, C., K. O. Buesseler and G. Crossin. 2000. Upper ocean carbon export, horizontal transport, and vertical eddy diffusivity in the southwestern Gulf of Maine. Cont. Shelf Res., 20, 707-736.

Benitez-Nelson, C., K. O. Buesseler, D. Karl and J. Andrews. 2001. A time-series study of particular matter export in the North Pacific Subtropical Gyre based upon ${ }^{234} \mathrm{Th},{ }^{238} \mathrm{U}$ disequilibrium. Deep-Sea Res., 48, 2595-2611.

Berelson, W. M. 2002. Particle settling rates increase with depth in the ocean. Deep-Sea Res. I, 49, 237-251.

Berger, W. H. 1971. Sedimentation of planktonic foraminifera. Mar. Geol., 11, 325-388.

Bishop, J. K. B., D. R. Ketten and J. M. Edmond. 1978. The chemistry, biology, and vertical flux of particulate matter from the upper $400 \mathrm{~m}$ of the Cape Basin in the southeast Atlantic Ocean. Deep-Sea Res., 25, 1121-1161.

Bishop, J. K., S. Wilson and T. J. Wood. 2006. Optical assessment of particles and sedimentation processes of the twilight zone. Eos Trans. AGU, Ocean Sci. Meeting Suppl., 87(36), Abstract OS32H-06.

Bishop, J. K. B., T. J. Wood, R. E. Davis and J. T. Sherman. 2004. Robotic observations of enhanced carbon biomass and export at $55^{\circ} \mathrm{S}$ during SOFeX. Science, 304, 417-420.

Blomqvist, S. and C. Kofoed. 1981. Sediment trapping - a subaquatic in situ experiment. Limnol. Oceanogr., 26, 585-590.

Bonnin, J., H. van Haren, P. Hosegood, G.-J. A. Brummer. 2006. Burst resuspension of seabed material at the foot of the continental slope in the Rockall Channel. Mar. Geol., 226, 167-184.

Bonnin, J., W. van Raaphorst, G.-J. A. Brummer, H. van Haren, H. Malschaert. 2002. Intense mid-slope resuspension of particulate matter in the Faeroe-Shetland Channel, short-term deployment of near-bottom sediment traps. Deep-Sea Res. I., 49, 1485-1505.

Boyd, P. and P. Newton. 1995. Evidence of the potential influence of planktonic community structure on the interannual variability of particulate organic carbon flux. Deep-Sea Res. I, 42, 619-639.

Bray, S., T. Trull and S. Manganini. 2000. SAZ project moored sediment traps, results of the 1997-1998 deployments. Antarctic CRC Research Report No. 15.

Brzezinski, M., A. A. Alldredge and L. M. O’Bryan. 1997. Silica cycling within marine snow. Limnol. Oceanogr., 42, 1706-1713.

Buesseler, K. O. 1991. Do upper-ocean sediment traps provide an accurate record of particle flux? Nature, 353, 420-423.

1998. The decoupling of production and particulate export in the surface ocean. Global Biogeochem. Cy., 12, 297-310.

Buesseler, K. O., M. P. Bacon, J. K. Cochran and H. D. Livingston. 1992. Carbon and nitrogen export during the JGOFS North Atlantic Bloom Experiment estimated from ${ }^{234} \mathrm{Th},{ }^{238} \mathrm{U}$ disequilibria. Deep-Sea Res. I, 39, 1115-1137.

Buesseler, K. O., C. R. Benitez-Nelson, S. B. Moran, A. Burd, M. Charette, J. K. Cochran, L. Coppola, N. S. Fisher, S. W. Fowler, W. D. Gardner, L. D. Guo, O. Gustafsson, C. Lamborg, P. Masque, J. C. Miquel, U. Passow, P. H. Santschi, N. Savoye, G. Stewart and T. Trull. 2006. An assessment of particulate organic carbon to thorium-234 ratios in the ocean and their impact on the application of ${ }^{234} \mathrm{Th}$ as a POC flux proxy. Mar. Chem., 100, (3-4), 213-233.

Buesseler, K. O., C. H. Lamborg, P. W. Boyd, P. J. Lam, T. W. Trull, R. R. Bidigare, J. K. B. Bishop, K. L. Casciotti, F. Dehairs, M. Elskens, M. Honda, D. M. Karl, D. Siegel, M. W. Silver, D. K. 
Steinberg, J. Valdes, B. Van Mooy and S. Wilson. 2007. Revisiting carbon flux through the ocean's twilight zone. Science, 316, 567-570.

Buesseler, K., A. F. Michaels, D. A. Siegel and A. H. Knap. 1994. A three dimensional timedependent approach to calibrating sediment trap fluxes. Global Biogeochem. Cy., 8, 179-193.

Buesseler, K. O., D. K. Steinberg, A. F. Michaels, R. J. Johnson, J. E. Andrews, J. R. Valdes and J. F. Price. 2000. A comparison of the quantity and quality of material caught in a neutrally buoyant versus surface-tethered sediment trap. Deep-Sea Res. I, 47, 277-294.

Butman, C. A. 1986. Sediment trap biases in turbulent flows: Results from a laboratory flume study. J. Mar. Res., 44, 645-693.

Butman, C. A., W. D. Grant and K. D. Stolzenback. 1986. Predictions of sediment trap biases in turbulent flows, a theoretical analysis based on observations from the literature. J. Mar. Res., 44, 601-644.

Capone, D. G. and E. J. Carpenter. 1982. Nitrogen fixation in the marine environment. Science, 217, 1140-1142.

Carlson, C. A., H. W. Ducklow and A. F. Michaels. 1994. Annual flux of dissolved organic carbon from the euphotic zone in the northwest Sargasso Sea. Nature, 371, 405-408.

Chase, Z., R. F. Anderson, M. Q. Fleisher and P. W. Kubik. 2002. The influence of particle composition and particle flux on scavenging of Th, $\mathrm{Pa}$ and $\mathrm{Be}$ in the ocean. Earth Planet. Sci. Lett., 204, 215-229.

Christian, J. R., M. R. Lewis and D. M. Karl. 1997. Vertical fluxes of carbon, nitrogen, and phosphorus in the North Pacific Subtropical Gyre near Hawaii. J. Geophys. Res., 102, 15,667-15,677.

Church, M. J., H. W. Ducklow and D. M. Karl. 2002. Multiyear increases in dissolved organic matter inventories at Station ALOHA in the North Pacific Subtropical Gyre. Limnol. Oceanogr., 47, 1-10.

Coale, K. H. 1990. Labyrinth of doom, A device to minimize the "swimmer" component in sediment trap collections. Limnol. Oceanogr., 35, 1376-1381.

Coale, K. H. and K.W. Bruland. 1987. Oceanic stratified euphotic zone as elucidated by ${ }^{234} \mathrm{Th},{ }^{238} \mathrm{U}$ disequilibria. Limnol. Oceanogr., 32, 189-200.

Cochran, J. K., J.-C. Miquel, S. W. Fowler, B. Gasser, J. E. Szlosek, A. Rodriguez-y-Baena, D. J. Hirschberg, G. M. Stewart and P. Masque. 2004. MEDFLUX, Relationships among ballast, particulate organic carbon and ${ }^{234} \mathrm{Th}$ activities and fluxes in the upper water column. ASLO/TOS Ocean Sciences Conference, Honolulu, Hawaii, 30 pp.

Conte, M. H., N. Ralph and E. H. Ross. 2001. Seasonal and interannual variability in deep ocean particle fluxes at the Oceanic Flux Program (OFP)/Bermuda Atlantic Time Series (BATS) site in the western Sargasso Sea near Bermuda. Deep-Sea Res. II, 48, 1471-1505.

Coppola, L., M. Roy-Barman, P. Wassmann, S. Mulsow and C. Jeandel. 2002. Calibration of sediment traps and particulate organic carbon export using ${ }^{234} \mathrm{Th}$ in the Barents Sea. Mar. Chem., 80, 11-26.

Dam, H. G., M. R. Roman and M. J. Youngbluth. 1995. Downward export of respiratory carbon and dissolved inorganic nitrogen by diel-migrant mesozooplankton at the JGOFS Bermuda time-series station. Deep-Sea Res., 42, 1187-1197.

Deuser, W. G., F. E. Muller-Karger, R. H. Evans, O. B. Brown, W. E. Esaias and G. C. Feldman. 1990. Surface-ocean color and deep-ocean carbon flux, how close a connection? Deep-Sea Res., 37, 1331-1343.

Doney, S. E. 1999. Major challenges confronting marine biogeochemical modeling. Global Biogeochem. Cy., 13, 705-714.

Dore, J. E., J. R. Brum, L. M. Tupas and D. M. Karl. 2002. Seasonal and interannual variability in the sources of nitrogen supporting export in the oligotrophic subtropical North Pacific Ocean. Limnol. Oceanogr., 47, 1595-1607.

Dugdale, R. C. and J. J. Goering. 1967. Uptake of new and regenerated forms of nitrogen in primary productivity. Limnol. Oceanogr., 12, 196-206. 
Dymond, J. and R. Collier. 1988. Biogenic particle fluxes in the equatorial Pacific: Evidence for both high and low productivity during the 1982-1983 El Nino. Global Biogeochem. Cy., 2, 129-137.

- 1989. The easily soluble fraction of the settling particle flux. Sediment Trap Technology and Sampling, U.S. GOFS Planning Report No. 10, 84-85.

Dymond, J., K. Fischer, M. Clauson, R. Cobler, W. D. Gardner, M. J. Richardson, W. Berger, A. Soutar and and R. Dunbar. 1981. A sediment trap intercomparison study in the Santa Barbara Basin. Earth Planet. Sci. Lett., 53, 409-418.

Emerson, S., P. Quay, D. Karl, C. Winn, L. Tupas and M. Landry. 1997. Experimental determination of the organic carbon flux from open-ocean surface waters. Nature, 389, 951-954.

Eppley, R. W. 1989. New production, history, methods, problems, in Productivity of the Ocean, Present and Past, W. H. Berger, V. S. Smetacek and G. Wefer, eds., Wiley, NY, 85-97.

Eppley, R. W. and B. J. Peterson. 1979. Particulate organic matter flux and planktonic new production in the deep ocean. Nature, 282, 677-680.

Falkowski, P. G., R. T. Barber and V. Smetacek. 1998. Biogeochemical controls and feedbacks on ocean primary production. Science, $281,200-206$.

Farley, K. J. and F. M. M. Morel. 1986. Role of coagulation in the kinetics of sedimentation. Environ. Sci, Technol., 20, 187-195.

Feely, R. A., C. L. Sabine, K. Lee, W. M. Berelson, J. Kleypas, V. J. Fabry and F. J. Millero. 2004. Impact of anthropogenic $\mathrm{CO}_{2}$ on the $\mathrm{CaCO}_{3}$ system in the oceans. Science, 305, 362-366.

Fields, E., D. A. Siegel and K. O. Buesseler. 2006. A bottom-up view of the biological pump, modeling collection funnels above ocean sediment traps. Eos Trans. AGU Ocean Sci. Meeting Suppl., 87(36), Abstract OS22H-04.

Fowler, S. W. and G. A. Knauer. 1986. Role of large particles in the transport of elements and organic compounds through the oceanic water column. Prog. Oceanogr., 16, 147-194.

Fowler, S. W., L. F. Small and J. La Rosa. 1991. Seasonal particulate carbon flux in the coastal northwestern Mediterranean Sea, and the role of zooplankton fecal matter. Oceanologica Acta 14, 77-85.

Francois, R., S. Honjo, R. Krishfield and S. Manganini. 2002. Factors controlling the flux of organic carbon to the bathypelagic zone of the ocean. Global Biogechem. Cy., 16, 1087.

Fugate, D. C. and C. T. Friedrichs. 2002. Determining concentration and fall velocity of estuarine particle populations using ADV, POBS and LISST. Cont. Shelf Res., 22, 1867-1886.

Gardner, W. D. 1980a. Sediment trap dynamics and calibration, a laboratory evaluation. J. Mar. Res., 38, 17-39.

1980b. Field assessment of sediment traps. J. Mar. Res., 38, 41-52.

1985. The effect of tilt on sediment trap efficiency. Deep-Sea Res., 32, 349-361.

2000. Sediment trap technology and surface sampling in surface waters, in The Changing Ocean Carbon Cycle, A Midterm Synthesis of the Joint Global Ocean Flux Study, R. B. Hanson, H. W. Ducklow and J. G. Field, eds., Cambridge University Press, 240-281.

Gardner, W. D., P. E. Biscaye and M. J. Richardson. 1997. A sediment trap experiment in the Vema Channel to evaluate the effect of horizontal particle fluxes on measured vertical fluxes. J. Mar. Res., 55, 995-1028.

Gardner, W.D., K.R. Hinga and J. Marra. 1983. Observations on the degradation of biogenic material in the deep ocean with implications on the accuracy of sediment trap fluxes. J. Mar. Res., 41, 195-214.

Gardner, W. D. and Y. Zhang. 1997. The effect of brine on the collection efficiency of cylindrical sediment traps. J. Mar. Res., 55, 1029-1048.

GOFS. 1989. Sediment Trap Technology and Sampling, Report of the U.S. GOFS Working Group on Sediment Trap Technology and Sampling. U.S. GOFS Planning Report No. 10.

Goldman, J. C. 1988. Spatial and temporal discontinuities of biological processes in pelagic surface waters, in Towards a Theory on Biological-Physical Interactions in the World Ocean, B. Rothschild,ed., Kluwer, 273-296 
Goldthwait, S., J. Yen, J. Brown, and A. Alldredge. 2004. Quantification of marine snow fragmentation by swimming euphausiids. Limnol. Oceanogr., 49, 940-952.

Gowing, M. M. 1986. Trophic biology of phaeodarian radiolarians and flux of living radiolarians in the upper $20000 \mathrm{~m}$ of the North Pacific central gyre. Deep-Sea Res. I, 33, 655-674.

Guidi, L., L. Stemmann, L. Legendre, M. Picheral, L. Prieur and G. Gorsky. 2007. Vertical distribution of aggregates $(>110 \mu \mathrm{m})$ and mesoscale activity in the northeastern Atlantic: Effects on the deep vertical export of surface carbon. Limnol. Oceanogr., 52, 7-18.

Gust, G., W. Bowles, S. Giordano and M. Huettel. 1996. Particle accumulation in a cylindrical sediment trap under laminar and turbulent steady flow, An experimental approach. Aquatic Sci., 58, 297-326.

Gust, G., R. H. Byrne, R. E. Bernstein, P. R. Betzer and W. Bowles. 1992. Particle fluxes and moving fluids, experience from synchronous trap collections in the Sargasso Sea. Deep-Sea Res. I, 41, 831-857.

Gust, G. and H.-P. Kozerski. 2000. In situ sinking-particle flux from collection rates of cylindrical traps. Mar. Ecol. Prog. Ser., 208, 93-106.

Gustafsson, Ö., P. Andersson, P. Roos, Z. Kukulska, D. Broman, U. Larsson, S. Hajdu and J. Ingri. 2004. Evaluation of the collection efficiency of upper ocean sub-photic-layer sediment traps, A 24-month in situ calibration in the open Baltic Sea using ${ }^{234}$ Th. Limnol. Oceanogr. Methods, 2, 62-74.

Gustafsson, Ö., K. O. Buesseler, W. R. Geyer, S. B. Moran and P. M. Gschwend. 1998. An assessment of the relative importance of horizontal and vertical transport of particle-reactive chemicals in the coastal ocean. Cont. Shelf Res., 18, 805-829.

Gustafsson, Ö., A. Duker, J. Larsson, P. Andersson and J. Ingri. 2000. Functional separation of colloids and gravitoids in surface waters based on differential settling velocity, Coupled cross-flow filtration-split flow thin cell fractionation (CFF-SPLITT). Limnol. Oceanogr., 45, 1731-1742.

Gustafsson, Ö., J. Larsson, P. Andersson and J. Ingri. 2006. The POC/ ${ }^{234}$ Th ratio of settling particles isolated using split flow-thin cell fractionation (SPLITT). Mar. Chem., 100(3-4), 314-322.

Hansell, D. A., N. R. Bates and D.B. Olson. 2004. Excess nitrate and nitrogen fixation in the North Atlantic Ocean. Mar. Chem., 84, 243-265.

Hansell, D. A., C. A. Carlson, N. R. Bates and A. Poisson. 2002. Dissolved organic carbon export with North Pacific Intermediate Water formation. Global Biogeochem. Cy., 16, 10.1029/ 2000GB001361.

Hansell, D.A. and J.A. Newton. 1994. Design and evaluation of a "swimmer"-segregating particle interceptor trap. Limnol. Oceanogr., 39, 1487-1495.

Harbison, G. R. and R. W. Gilmer. 1986. Effects of animal behavior on sediment trap collections, implications for the calculation of aragonite fluxes. Deep-Sea Res., 33, 1017-1024.

Hargrave, B. T. and N. M. Burns. 1979. Assessment of sediment trap collection efficiency. Limnol. Oceanogr., 24, 1124-1136.

Hargrave, B. T., B. von Bodungen, R. J. Conover, A. J. Fraser, G. Phillips and W. P. Vass. 1989. Seasonal changes in sedimentation of particulate matter and lipid content of zooplankton collected by sediment trap in the Arctic Ocean off Axel Heiberg Island. Polar Biol., 9, 467-475.

Hawley, N. 1988. Flow in cylindrical sediment traps. J. Great Lakes Res., 14, 76-88.

Henderson, G. M., C. Heinze, R. F. Anderson and A. M. E. Winguth. 1999. Global distribution of the ${ }^{230} \mathrm{Th}$ flux to ocean sediments constrained by GCM modeling. Deep-Sea Res. I, 46, 1861-1893.

Hill, P. 1992. Reconciling aggregation theory with observed vertical fluxes following phytoplankton blooms. J. Geophys. Res., 97, 2295-2308.

Honjo, S. 1976. Coccoliths, primary production, transportation and sedimentation. Mar. Micropaleontology, 1, 65-79.

Honjo, S., J. Dymond, R. Collier and S. J. Manganini. 1995. Export production of particles to the interior of equatorial Pacific Ocean during 1992 EqPac experiment. Deep-Sea Res. I, 42(2-3), 831-870. 
Honjo, S. and S. J. Manganini. 1993. Annual biogenic particle fluxes to the interior of the North Atlantic Ocean; studies at $34^{\circ} \mathrm{N} 21^{\circ} \mathrm{W}$ and $48^{\circ} \mathrm{N} 21^{\circ} \mathrm{W}$. Deep-Sea Res. I, 40, 587-607.

Honjo, S., S. J. Manganini and J. J. Cole. 1982. Sedimentation of biogenic matter in the deep ocean. Deep-Sea Res., 29, 609-625.

Honjo, S., D. W. Spencer and W. D. Gardner. 1992. A sediment trap intercomparison experiment in the Panama Basin. Deep-Sea Res. I, 39, 333-358.

Hung, C.-C., L. D. Guo, K. A. Roberts and P. H. Santschi. 2004. Upper ocean carbon flux determined by size-fractionated ${ }^{234}$ Th data and sediment traps in the Gulf of Mexico. Geochem. J., 38, 601-611.

Ittekkot, V. 1993. The abiotically driven biological pump in the ocean and short-term fluctuations in atmospheric $\mathrm{CO}_{2}$ contents. Global Planet. Change, 8, 17-25.

Ittekkot, V. and V. Haake. 1992. Organic carbon removal in the sea, The continental connection, in Upwelling Systems, Evolution Since the Early Miocene, C. P. Summerhayes, W. L. Prell and K. C. Emeis, eds., Geol. Soc. Am., 167-176.

Jackson, G.A. 1990. A model of the formation of marine algal flocs by physical coagulation processes. Deep-Sea Res., 37, 1197-1211.

Jackson, G. A. and A. B. Burd. 1998. Aggregation in the marine environment. Environ. Sci. Technol., 32, 2805-2814.

2002. A model for the distribution of particle flux in the mid-water column controlled by subsurface biotic interactions. Deep-Sea Res. II, 49, 193-217.

Jackson, G. A., A. M. Waite and P.W. Boyd. 2005. Role of algal aggregation in vertical carbon export during SOIREE and in other low biomass environments. Geophys. Res. Lett., 32, L13607, doi,10.1029/2005GL023180.

Kähler, P. and E. Bauerfeind. 2001. Organic particles in a shallow sediment trap,Substantial loss to the dissolved phase. Limnol. Oceanogr., 46, 719-723.

Karl, D. M., J. R. Christian, J. E. Dore, D. V. Hebel, R. M. Letelier, L. M. Tupas and C. D. Winn. 1996. Seasonal and interannual variability in primary production and particle flux at Station ALOHA. Deep-Sea Res. I, 43(2-3), 539-568.

Karl, D. M. and G. A. Knauer. 1989. Swimmers, a recapitulation of the problem and a potential solution. Oceanography, 2, 32-35.

Kiørboe, T. 2000. Colonization of marine snow aggregates by invertebrate zooplankton, Abundance, scaling, and possible role. Limnol. Oceanogr., 45, 479-484.

Klaas, C. and D. E. Archer. 2002. Association of sinking organic matter with various types of mineral ballast in the deep sea, Implications for the rain ratio. Global Biogechem. Cy., 16, 1116, doi,10.1029/2001GB001765.

Knap, A. H., A. F. Michaels, D. K. Steinberg, F. Bahr, N. Bates, S. Bell, P. Countway, A. Close, A. Doyle, F. Howse, K. Gundersen, R. Johnson, R. Little, K Orcutt, R. Parsons, C. Rathbun, M Sanderson and S. Stone. 1997. BATS methods manual. U.S. JGOFS Planning Office, Woods Hole, MA.

Knauer, G. A., D. M. Karl, J. H. Martin and C.N. Hunter. 1984. In situ effects of selected preservatives on total carbon, nitrogen and metals collected in sediment traps. J. Mar. Res., 42, 445-462.

Knauer, G. A., J. H. Martin and K. W. Bruland. 1979. Fluxes of particulate carbon, nitrogen, and phosphorous in the upper water column of the northeast Pacific. Deep-Sea Res., 26, 97-108.

Knauer, G. A., D. G. Redalje, W.G. Harrison and D. M. Karl. 1990. New production at the Vertex time-series site. Deep-Sea Res., 37, 1121-1134.

Kortzinger, A., D. E. Schulz-Bull, G. Petrick and J. C. Duinker. 1994. Evidence for dissolution of fatty acids in sediment traps, impact on flux estimates. J. Geophys. Res., 99(C2), 3407-3415.

Lamborg, C. H., K. O. Buesseler, J. R. Valdes, T. Trull, J. K. B. Bishop, K. L. Casciotti, S. M. Pike, J. E. Andrews, S. J. Manganini and C. Bertrand. 2005. Particulate Element Fluxes and Recycling During Vertigo '04, Preliminary Results, ASLO 2005 Summer Meeting, Santiago de Campostela, http,//www.sgmeet.com/aslo/santiago2005/viewabstract2.asp?AbstractID $=462$ 
Lampitt, R. S., R. J. Sanders, B. Boorman, L. Brown, P. H. Guyard, F. J. Leaute, E. E. Popova, K. A. Saw, R. Turnewitsch and M. V. Zubkov. 2004. Particulate export in the northeast Atlantic, An integrated attack using production rates, tracers and a novel drifting sediment trap. ASLO/TOS Ocean Research Conference, Honolulu, HI, 87.

Lampitt, R. S., P. Y. G. Sumida and F. Perez-Castillo. 2002. Ophiuroid growth within deep-sea sediment traps, A problem for carbon flux measurements at continental margins. Limnol. Oceanogr., 47, 571-575.

Lampitt, R. S., K. F. Wishner, C. M. Turley and M.V. Angel. 1993. Marine snow studies in the northeast Atlantic, distribution, composition and role as a food source for migrating plankton. Mar. Biol., 116, 689-702.

Landry, M. R., H. Al-Mutairi, K. E. Selph, S. Christensen and S. Nunnery. 2001. Seasonal patterns of mesozooplankton abundance and biomass at Station ALOHA. Deep-Sea Res. I, 48, 2037-2062.

Larsson, U., S. Hajdu, J. Walve and R. Elmgren. 2001. Baltic Sea nitrogen fixation estimated from summer increase in upper mixed layer total nitrogen. Limnol. Oceanogr., 46, 811-820.

Lee, C. and C. Cronin. 1984. Particle amino acids in the sea: Effects of primary productivity and biological decomposition. J. Mar. Res., 42, 1075-1097.

Lee, C., J. I. Hedges, S. G. Wakeham and N. Zhu. 1992. Effectiveness of various treatments in retarding microbial activity in sediment trap material and their effects on the collection of swimmers. Limnol. Oceanogr., 37, 117-130.

Lee, C., J. A. McKenzie and M. Sturm. 1987. Carbon isotope fractionation and changes in the flux and composition of particulate matter resulting from biological activity during a sediment trap experiment in Lake Greifen, Switzerland. Limnol. Oceanogr., 32, 83-96.

Lee, C., S. G. Wakeham and J. I. Hedges. 1988. The measurement of oceanic particle flux-Are "swimmers" a problem? Oceanography, 1, 34-36.

Legendre, L. and J. LeFevre. 1989. Hydrodynamical singularities as controls of recycled versus export production in oceans in Productivity of the Oceans, Present and Past, W. H. Berger, V. S. Smetacek and G. Wefer, eds., John Wiley and Sons, Chichester, 49-63.

Lohrenz, S. E., G. A. Knauer, V. L. Asper, M. D. Tuel, A. F. Michaels and A.H. Knap. 1992. Seasonal variability in primary production and particle flux in the northwestern Sargasso Sea, U.S. JGOFS Bermuda Atlantic Time-series Study. Deep-Sea Res., 39, 1373-1391.

Longhurst, A. R., A. W. Bedo, W. G. Harrison, E. J. H. Head, D. D. Sameoto. 1990. Vertical flux of respiratory carbon by oceanic diel migrant biota. Deep-Sea Res., 37, 685-694.

Lutz, M., R. Dunbar and K. Caldeira. 2002. Regional variability in the vertical flux of particulate organic carbon in the ocean interior. Global Biogeochem. Cy., 16, 10.1029/2000GB001383.

Madin, L.P., E. F. Horgan, and D.K. Steinberg. 2001. Zooplankton at the Bermuda Atlantic Time-series Study (BATS) station, Seasonal and interannual variation in biomass 1994-1998. Deep-Sea Res. I, 48, 2063-2082.

Marguillier, S. 1998. Stable isotope ratios and food web structure of aquatic ecosystems. Ph.D Thesis, Vrije Universiteit Brussel, $211 \mathrm{pp.}$

Martin, J. H., G. A. Knauer, D. M. Karl and W. W. Broenkow. 1987. VERTEX, carbon cycling in the northeast Pacific. Deep-Sea Res., 34, 267-285.

Masiello, C. A. and E. R. M. Druffel. 1998. Black carbon in deep-sea sediments. Science, 280, 1911-1913.

Matear, R. and G. Holloway. 1995. Modeling the inorganic phosphorus cycle of the North Pacific using an adjoint data assimilation model to assess the role of dissolved organic phosphorus. Global Biogeochem. Cy., 9, 101-119.

McCave, I. N. 1975. Vertical flux of particles in the ocean. Deep-Sea Res., 22, 491-502.

Michaels, A. F., N. R. Bates, K. O. Buesseler, C. A. Carlson and A.H. Knap. 1994a. Carbon-cycle imbalances in the Sargasso Sea. Nature, 372, 537-540. 
Michaels, A. F. and A. H. Knap. 1996. Overview of the U.S. JGOFS Bermuda Atlantic Time-Series Study and the Hydrostation S program. Deep-Sea Res. I, 43(2-3), 157-198.

Michaels, A. F., A. H. Knap, R. L. Dow, K. Gundersen, R. J. Johnson, J. Sorensen, A. Close, G. A. Knauer, S. E. Lohrenz, V. A. Asper, M. Tuel and R. Bidigare. 1994b. Seasonal patterns of ocean biogeochemistry at the U.S. JGOFS Bermuda Atlantic Time-Series Study site. Deep-Sea Res. I, 41, 1013-1038.

Michaels, A. F., M. W. Silver, M. M. Gowing and G. A. Knauer. 1990. Cryptic zooplankton "swimmers" in upper ocean sediment traps. Deep-Sea Res., 37, 1285-1296.

Middelburg, J. J., J. Nieuwenhuize and P. Van Breugel. 1999. Black carbon in marine sediments. Mar. Chem., 65, 245-252.

Milliman, J. D., P. J. Troy, W. M. Balch, A. K. Adams, Y.-H. Li and F. T. Mackenzie. 1999. Biologically mediated dissolution of calcium carbonate above the chemical lysocline? Deep-Sea Res. I, 46, 1653-1669.

Miquel, J.-C., S. W. Fowler, J. La Rosa and P. Buat-Menard. 1994. Dynamics of the downward flux of particles and carbon in the open northwestern Mediterranean Sea. Deep-Sea Res. I, 41, 243-261.

Moore, W. S., K. W. Bruland and J. Michel. 1981. Fluxes of uranium and thorium series isotopes in the Santa Barbara Basin. Earth Planet. Sci. Lett., 53, 391-399.

Murray, J. W., J. Young, J. Newton, J. Dunne, T. Chapin and B. Paul. 1996. Export flux of particulate organic carbon from the central equatorial Pacific determined using a combined drifting trap $-{ }^{234} \mathrm{Th}$ approach. Deep-Sea Res. I, 43, 1095-1132.

Nagata, T., F. Hideki, F. Rumi and I. Koike, 2000. Bacterioplankton distribution and production in deep Pacific waters, Large-scale geographic variations and possible coupling with sinking particle fluxes. Limnol. Oceanogr., 45, 426-435.

Najjar, R.W., J. L. Sarmiento and J. R. Toggweiler. 1992. Downward transport and fate of organic matter in the ocean, simulations with a general circulation model. Global Biogeochem. Cy., 6, 45-76.

Nodder, S. D. and B. L. Alexander. 1999. The effects of multiple trap spacing, baffles and brine volume on sediment trap collection efficiency. J. Mar. Res., 57, 537-559.

Nodder, S. D., P. W. Boyd, S. M. Chiswell, M. H. Pinkerton, J. M. Bradford-Grieve and M. N. Greig. 2005. Temporal coupling between surface and deep-ocean biogeochemical processes in contrasting subtropical and subantarctic water masses, Southwest Pacific Ocean. J. Geophys. Res.-Oceans, 110, (C12017), doi: 1029/2004JC002833.

Nodder, S. D., M. A. Charette, A. M. Waite, T. W. Trull, P. W. Boyd, J. Zeldis and K. O. Buesseler. 2001. Particle transformations and export flux during an in situ iron-stimulated bloom in the Southern Ocean. Geophys. Res. Lett., 28, 2409-2412.

Noji, T. T., K. Y. Borsheim, F. Rey and R. Nortvedt. 1999. Dissolved organic carbon associated with sinking particles can be crucial for estimates of vertical carbon flux. Sarsia, 84, 129-135.

Ohtsuka, S., N. Kubo, M. Okada and K. Gushima. 1993. Attachment and feeding of pelagic copepods on larvacean houses. J. Oceanogr. Soc. Japan, 49, 115-120.

O’Neill, L. P., C. R. Benitez-Nelson, R. M. Styles, E. Tappa and R. C. Thunell. 2005. Diagenetic effects on particulate phosphorus samples collected using formalin poisoned sediment traps. Limnol. Oceanogr. Methods, 3, 308-317.

Pace, M. L., G. A. Knauer, D. M. Karl and J. H. Martin. 1987. Primary production, new production and vertical flux in the eastern Pacific Ocean. Nature, 325, 803-804.

Passow, U. 2004. Switching perspectives: Do mineral fluxes determine particulate organic carbon fluxes or vice versa? Geochem., Geophys., Geosys. (G-cubed) 5, Q04002, doi,10.1029/ 2003GC000670.

Passow, U. and C. L. De La Roche. 2006. Accumulation of mineral ballast on organic aggregates. Global Biogeochem. Cy., 20, (GB1013, doi, 10.1029/2005GB002579).

Peterson, M. L., P. J. Hernes, D. S. Thoreson, J. I. Hedges, C. Lee and S. G. Wakeham. 1993. Field 
evaluation of a valved sediment trap designed to minimize collection of swimming animals. Limnol. Oceanogr., 38, 1741-1761.

Peterson, M. L., S. G. Wakeham, C. Lee, M. A. Askea and J.-C. Miquel. 2005. Novel techniques for collection of sinking particles in the ocean and determining their settling rates. Limnol. Oceanogr. Methods, 3, 520-532.

Peterson, W. and H. G. Dam. 1990. The influence of copepod "swimmers" on pigment fluxes in brine-filled vs. ambient seawater-filled sediment traps. Limnol. Oceanogr., 35, 448-455.

Pilskaln, C. H., C. Lehmann, J. B. Paduan and M. W. Silver. 1998. Spatial and temporal dynamics in marine aggregate abundance, sinking rate, and flux, Monterey Bay, central California. Deep-Sea Res. I, 45, 1803-1837.

Pohl, C., A. Löffler and U. Hennings. 2004. A sediment trap flux study for trace metals under seasonal aspects in the stratified Baltic Sea (Gotland Basin; 57 $19.20^{\prime} \mathrm{N} ; 2^{\circ} 03.00^{\prime} \mathrm{E}$ ). Mar. Chem., 84, 143-160.

Reinfelder, J. R., N. S. Fischer, S. W. Fowler and J.-L. Teyssie. 1993. Release rates of trace elements and protein from decomposing debris. 2. Copepod carcasses and sediment trap particulate matter. J. Mar. Res., 51, 423-442.

Sambrotto, R. N., G. Savidge, C. Robinson, P. Boyd, T. Takahashi, D. M. Karl, C. Langdon, D. Chipman, J. Marra and L. Codispoti. 1993. Elevated consumption of carbon relative to nitrogen in the surface ocean. Nature, 363, 248-250.

Sarin, M. M., S. Krishnaswami, T. K. Dalai, V. Ramaswamy and V. Ittekkot. 2000. Settling fluxes of U- and Th-series nuclides in the Bay of Bengal, results from time-series sediment trap studies. Deep-Sea Res. I, 47, 1961-1985.

Sarin, M. M., S. Krishnaswami, R. Ramesh, and B. L. K. Somayajulu. 1994. ${ }^{238}$ U decay series nuclides in the northeastern Arabian Sea, Scavenging rates and cycling processes. Cont. Shelf Res., 14(2/3), 251-265.

Sarmiento, J. L. and J. R. Toggweiler. 1984. A new model for the role of the oceans in determining atmospheric $\mathrm{pCO}_{2}$. Nature, 308, 620-624.

Savoye, N., C. Benitez-Nelson, A. B. Burd, J. K. Cochran, M. Charette, K.O. Buesseler, G. Jackson, M. Roy-Barman, S. Schmidt and M. Elskens. 2006. ${ }^{234}$ Th sorption and export models in the water column, A review. Mar. Chem., 100(3-4), 234-249.

Schlitzer, R. 1993. Determining the mean, large-scale circulation of the Atlantic with the adjoint method. J. Phys. Oceanogr., 23, 1935-1952.

-2000. Applying the adjoint method for biogeochemical modeling, Export of particulate organic matter in the World Ocean, in Inverse Methods in Biogeochemical Cycles, P. Kasibhata, ed., AGU Monograph, 107-124.

Schlitzer, R., R. Usbeck and G. Fischer. 2004. Inverse modeling of particulate organic carbon fluxes in the South Atlantic, in The South Atlantic in the Late Quaternary-Reconstruction of Material Budget and Current Systems, G. Wefer, S. Mulitza and V. Rathmeyer, eds., Springer-Verlag, 1-19.

Schneider, B., R. Schlitzer, G. Fischer, and E.-M. Nothig. 2003. Depth-dependent elemental compositions of particulate organic matter (POM) in the ocean. Global Biogechem. Cy., 17, 1032, doi,10.1029/2002GB001871.

Schnetzer, A. and D.K. Steinberg. 2002. Active transport of particulate organic carbon and nitrogen by vertically migrating zooplankton in the Sargasso Sea. Mar. Ecol. Progr. Ser., 234, 71-84.

Scholten, J. C; J. Fietzke, A. Mangini, P. Stoffers, T. Rixen, B. Gaye-Haake, T. Blanz, V. Ramaswamy, F. Sirocko, H. Schulz and V. Ittekkot. 2005. Radionuclide fluxes in the Arabian Sea, the role of particle composition. Earth Planet. Sci. Lett., 230, (3-4), 319-337.

Scholten, J. C., J. Fietzke, S. Vogler, M. Rutgers van der Loeff, A. Mangini, W. Koeve, P. Stoffers, A.N. Antia, S. Neuer and J. Waniek. 2001. Trapping efficiencies of sediment traps from the deep eastern North Atlantic, The 230Th calibration. Deep-Sea Res. I, 48, 2383-2578. 
Shanks, A. L. and K. Walters. 1997. Holoplankton, meroplankton, and meiofauna associated with marine snow. Mar. Ecol. Prog. Ser., 156, 75-86.

Siegel, D.A. and W.G. Deuser. 1997. Trajectories of sinking particles in the Sargasso Sea, Modeling of statistical funnels above deep-ocean sediment traps. Deep-Sea Res. 44, 1,519-1,541.

Siegel, D. A., E. Fields and K. O. Buesseler. 2007. A bottom-up view of the biological pump, Modeling source funnels above ocean sediment traps. Deep Sea Res. I, (submitted) .

Siegel, D. A., T. C. Granata, A. F. Michaels and T. D. Dickey. 1990. Mesoscale eddy diffusion, particle sinking, and the interpretation of sediment trap data. J. Geophys. Res., 95, 5305-5311.

Siegenthaler, U. and J. L. Sarmiento. 1993. Atmospheric carbon dioxide and the ocean. Nature, 365, 119-125.

Silver, M. W. and M. M. Gowing. 1991. The "particle" flux, origins and biological components. Prog. Oceanogr., 26, 75-113.

Silver, M., C. Pilskaln and D. Steinberg. 1991. The biologists' view of sediment trap collections, problems of marine snow and living organisms, in Sediment Trap Studies in the Nordic Countries Symposium Proceedings. P. Wassmann, A. Heiskanen and O. Lindahl, eds., Helsinki, Finland, 76-93.

Simon, M., H. Grossart, B. Schweitzer, and H. Ploug. 2002.Microbial ecology of organic aggregates in aquatic ecosystems. Aquatic Microbial Ecol., 28, 175-211.

Smith, D. C., M. Simon, A. L. Alldredge and F. Azam. 1992. Intense hydrolytic enzyme activity on marine aggregates and implications for rapid particle dissolution. Nature, 358, 139-141.

Sonnerup, R. E., P. D. Quay and J. L. Bullister. 1999. Thermocline ventilation and oxygen utilization rates in the subtropical North Pacific based on CFC distributions during WOCE. Deep-Sea Res. I, 46, 777-805.

Soutar, A., S. A. Kling, P. A. Crill, E. Duffrin and K. W. Bruland. 1977. Monitoring the marine environment through sedimentation. Nature, 266, 136-139.

Stanley, R. H. R., K. O. Buesseler, S. J. Manganini, D. K. Steinberg and J. R. Valdes. 2004. A comparison of major and minor elemental fluxes collected using neutrally buoyant and surfacetethered traps. Deep-Sea Res. I, 51, 1387-1395.

Steinberg, D. K., C. A. Carlson, N. R. Bates, S. A. Goldthwait, L. P. Madin and A. F. Michaels. 2000. Zooplankton vertical migration and the active transport of dissolved organic and inorganic carbon in the Sargasso Sea. Deep-Sea Res. I, 47, 137-158.

Steinberg, D. K., C. A. Carlson, N. R. Bates, R. J. Johnson, A. F. Michaels, and A. H. Knap. 2001. Overview of the US JGOFS Bermuda Atlantic Time-Series Study (BATS), a decade-scale look at ocean biology and biogeochemistry. Deep-Sea Res. II, 48, 1405-1447.

Steinberg, D. K., C. H. Pilskaln and M. W. Silver. 1998. Contribution of zooplankton associated with detritus to sediment trap "swimmer" carbon in Monterey Bay, CA. Mar. Ecol. Prog. Ser., 164, 157-166.

Steinberg, D. K., M. W. Silver and C. H. Pilskaln. 1997. The role of mesopelagic zooplankton in the community metabolism of giant larvacean house detritus in Monterey Bay, California. Mar. Ecol. Prog. Ser., 147, 167-179.

Steinberg, D. K., M. W. Silver, C. H. Pilskaln, S. L. Coale and J. B. Paduan. 1994. Mid-water zooplankton communities on pelagic detritis (giant larvacean houses) in Monterey Bay, California. Limnol. Oceanogr., 39, 1606-1620.

Sukhodolov, A., H. Bungartz and C. Engelhardt. 2003. Comment on "Determination of areal sedimentation rates in rivers by using plate sediment trap measurements and flow velocity-settling flux relationship" by Hans-Peter Kozerski. Water Res., 37, 2794-2795

Takahashi, T. 2004. The fate of industrial carbon dioxide. Science, 305, 352-353.

Toggweiler, J. R., R. Murnane, S. Carson, A. Gnanadesikan, and J. L. Sarmiento. 2003. Representation of the carbon cycle in box models and GCMs 2. Organic pump. Global Biogeochem. Cy., 17, 1027, doi,10.1029/2001GB001841.

Trull, T., K. O. Buesseler, C. Lamborg, S. Pike, C. Moy, S. Bray, F. Ebersbach, and S. Manganini. 2006. In situ particle sinking rates at mesopelagic depths from the sub-tropical and sub-arctic Pacific. Eos Trans. AGU Ocean Sci. Meeting Suppl., 87(36), Abstract OS23H-05. 
Trull, T. and F. Ebersbach. 2007. Sinking particle properties determined from image analysis of polyacrylamide gels deployed in drifting sediment traps during KEOPS, implications for ecosystem controls on carbon export in an area of persistent natural iron inputs in the Southern Ocean. Limnol. Oceanogr., (submitted).

Turekian, K. K., Y. Nozaki and L. K. Benninger, 1977. Geochemistry of atmospheric radon and radon products. Ann. Rev. Earth Planet. Sci., 5, 222-255.

Usbeck, R. 1999. Modeling of marine biogeochemical cycles with an emphasis on vertical particle fluxes. Rep. Polar Res., 332, 105.

Usbeck, R., R. Schlitzer, G. Fischer and G. Wefer. 2003. Particle fluxes in the ocean, Comparison of sediment trap data with results from inverse modeling. J. Mar. Syst., 39, 167-183.

Valdes, J. R. and K. O. Buesseler. 2006. The neutrally buoyant sediment trap (NBST), a new tool for "Twilight Zone" particle exploration. Eos Trans. AGU Ocean Sci. Meeting Suppl., 87(36), Abstract OS26A-10.

Valdes, J. R. and J. F. Price. 2000. A neutrally buoyant, upper ocean sediment trap. J. Atmos. Oceanogr. Technol., 17, 62-68.

Vinogradov, M. E. 1968. Vertical distribution of the oceanic plankton. Acad. Sci. USSR, Inst. Oceanogr., Moscow. In Russian, translated by Israel Prog. Sci. Translation, Keter Press, Jerusalem.

Volk, T. and M. I. Hoffert. 1985. Ocean carbon pumps: Analysis of relative strengths and efficiencies in ocean-drive atmospheric CO2 changes. Geophys. Mono., 32, 99-110.

von Bodungen, B., M. Wunsch and H. Fürderer. 1991. Sampling and analysis of suspended and sinking particles in the northern north Atlantic in Marine Particles, Analysis and Characterization, D.C. Hurd and .D.W. Spencer, eds., American Geophysical Union, Washington, DC, 47-56.

Waite, A. M., O. Gustafsson, P. Lindhal and P. Tiselius. 2005. Linking ecosystem dynamics and biogeochemistry, Sinking fractionation of organic carbon in a Swedish fjord. Limnol. Oceanogr., $\underline{50,658-671 .}$.

Waite, A. and S. D. Nodder. 2001. The effect of in situ iron addition on the sinking rates and export flux of Southern Ocean diatoms. Deep-Sea Res. I, 48(11-12), 2635-2654.

Wakeham, S. G. and C. Lee. 1989. Organic geochemistry of particulate matter in the ocean, The role of particles in oceanic sedimentary cycles. Organic Geochem., 14, 83-96.

Waniek, J. J., D. E. Schulz-Bull, T. Blanz, R. D. Prien, A. Oschlies and T. J. Müller. 2005. Interannual variability of deep water particle flux in relation to production and lateral sources in the northeast Atlantic. Deep-Sea Res. I, 52, 33-50.

Wei, C.-L. and J. W. Murray. 1992. Temporal variations of ${ }^{234} \mathrm{Th}$ activity in the water column of Dabob Bay: Particle scavenging. Limnol. Oceanogr., 37, 296-314.

Wiebe, P. H., S. H. Boyd and C. Winget. 1976. Particulate matter sinking to the deep-sea floor at $2000 \mathrm{~m}$ in the Tongue of the Ocean, Bahamas. J. Mar. Res., 34, 341-354.

Yu, E.-F., R. Francois, M. P. Bacon, S. Honjo, A. P. Fleer, S. J. Manganini, M. M. Rutgers van der Loeff and V. Ittekkot. 2001. Trapping efficiency of bottom-tethered sediment traps estimated from the intercepted fluxes of ${ }^{230} \mathrm{Th}$ and ${ }^{231} \mathrm{~Pa}$. Deep-Sea Res. I, 48, 865-889.

Received: 17 March, 2006; revised: 27 February, 2007. 